

\section{NOTICE}

This report was prepared as an account of work sponsored by an agency of the United States Government. Neither the United States nor any agency thercof, nor any of their a mployees, makes any warranty, expressed or implied, or assumes dny legal liability of responsibility for any third party's use or the results of such use of any information, apparatus, product or process disclosed in this report, or represents that its use by such third party would not infringe privately owned rights

Printed in the United States of America Available from

National Technical Information Service

U.S. Department of Commerce 2528 Port Royal Road Springfield, Virginia 22161

Price: Printed Copy A07; Microfiche A01 


\section{DISCLAIMER}

This report was prepared as an account of work sponsored by an agency of the United States Government. Neither the United States Government nor any agency Thereof, nor any of their employees, makes any warranty, express or implied, or assumes any legal liability or responsibility for the accuracy, completeness, or usefulness of any information, apparatus, product, or process disclosed, or represents that its use would not infringe privately owned rights. Reference herein to any specific commercial product, process, or service by trade name, trademark, manufacturer, or otherwise does not necessarily constitute or imply its endorsement, recommendation, or favoring by the United States Government or any agency thereof. The views and opinions of authors expressed herein do not necessarily state or reflect those of the United States Government or any agency thereof. 


\section{DISCLAIMER}

Portions of this document may be illegible in electronic image products. Images are produced from the best available original document. 
GA-A15605

UC-77

\title{
NUMERICAL ACCURACY OF LINEAR TRIANGULAR FINITE ELEMENTS IN MODELING MULTI-HOLED STRUCTURES
}

\author{
by \\ R. M. SULLIVAN and J. E. GRIFFEN
}

\begin{abstract}
Prepared under
Contract DE-AT03-76ET35300

for the San Francisco Operations Office

Department of Energy

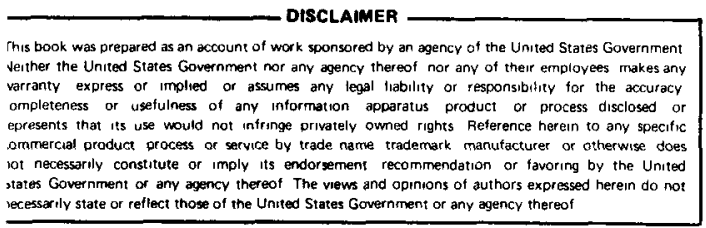

GENERAL ATOMIC PROJECT 640J

DATE PUBLISHED: JUNE 1980
\end{abstract}

\section{GENERAL ATOMIC COMPANY}


•

$\bullet$ 


\begin{abstract}
A study has been performed to quantify the accuracy of linear triangular finite elements for modeling temperature and stress fields in structures with multiple holes. The purpose of the study was to evaluate the use of these elements for the analysis of HTGR fuel blocks, which may contain up to 325 holes. Since an accurate full scale analysis was not feasible with existing methods, a representative small scale benchmark problem containing only seven holes was selected. The finite element codes used in this study were TEPC-2D for thermal analysis and SAFIRE for stress analysis. It was concluded that linear triangular finite elements are too inefficient for this application. An accurate analysis of stresses in HTGR fuel blocks will require the use of higher order elements, such as the 8-node quadrilaterals in the new TWOD code.
\end{abstract}


1. SUMMARY AND CONCLUSIONS .................. 1-1

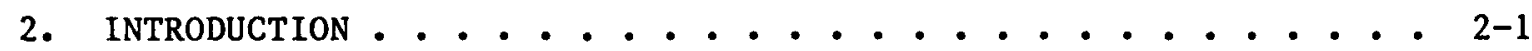

3. ANALYSIS AND RESULTS .................... 3-1

4. REFERENCES ......................... 4-

APPENDIX A: FINITE ELEMENT MESHES .............. A-1

APPENDIX B: ONE-TWELFTH SECTOR THERMAL ANALYSIS ........ B-1

APPENDIX C: STRESS ANALYSIS OF ONE-TWELFTH AND ONE-HALF SECTORS.$\quad$ C-1

TABLES

1. One-twelfth sector analysis accuracy results. . . . . . 3-51

2. One-half element analysis accuracy results. . . . . . . 3-52

B.1. TEPC sample problem input data . . . . . . . . . . . B-6

B.2. TEPC output model Bl . . . . . . . . . . . . . B-7

C.1. SAFIRE sample problem input data ............. . C-2

C.2. SAFIRE output for one-twelfth sector sample problem thermal

stress analysis .................... C-3

C.3. SAFIRE sample problem input data one half element analysis . . C-23

C.4. SAFIRE ouptut for one-half sector sample problem mechanical

load analysis . . . . . . . . . . . . . . C-26

\section{FIGURES}

1. Seven hole element (mesh Al) .............. 2-2

2. One-twelfth sector of seven hole element (mesh C1). . . . . 3-2

3. Temperature field $\left({ }^{\circ} \mathrm{F}\right)(1 / 12$ th sector - mesh B4) . . . . 3-4

4. Maximum temperature differences (1/12th sector) . . . . . 3-5

5. Coolant hole circumference temperature profiles $(1 / 12$ th sector) .................... 3-6

6. Fuel hole circumference temperature profiles (1/12th sector). - 3-7

7. X-axis temperature profiles (1/12th sector) . . . . . . 3-8

8. Thirty degree line of symmetry temperature profiles (1/12th sector) ...................... 3-9

9. Finite element grid (1/12th sector - mesh B4) ........ 3-11 
FIGURES (continued)

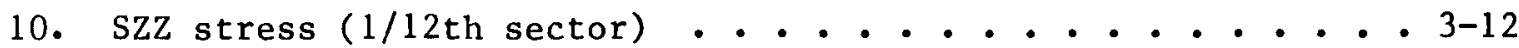

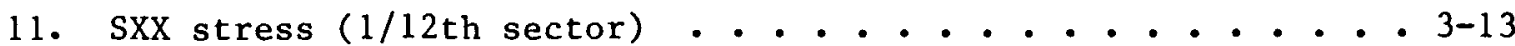

12. SYY stress (1/12th sector) . . . . . . . . . 3-14

13. SXY stress (1/12th sector) . . . . . . . . . . 3-15

14. Peak stress values $(1 / 12$ th sector) . . . . . . . . . 3-17

15. Peak stress and maximum temperature difference errors ( $1 / 12$ th

sector)....................... 3-18

16. Peak stress vs maximum temperature difference (1/12th

sector).................. 3-19

17. Percent error - peak stress vs max temperature difference

(1/12th sector)................ 3-20

18. Displacement (in.) along $X$-axis in $X$ direction (1/12th

sector)....................... 3-22

19. Radial displacement (in.) along thirty degree line of symmetry (1/12th sector) . . . . ......... 3-23

20. SYY stress (psi) along X-axis (1/12th sector) ....... 3-24

21. Detailed blowup of SYY stress (1/12th sector) . . . . . 3-25

22. SxX stress along X-axis (1/12th sector) ....... 3-26

23. SzZ stress along $\mathrm{X}$-axis (1/12th sector) ........ 3-27

24. SXY stress along $\mathrm{X}$-axis (1/12th sector) . . . . . . 3-28

25. Therma1 stress along X-axis (1/12th sector - mesh B4) • . . 3-30

26. SRR stress along thirty degree line of symmetry $(1 / 12$ th sector)...................... . 3-31

27. STT stress along thirty degree line of symmetry (1/12th sector).................... . . 3-32

28. SZZ stress along thirty degree line of symmetry $(1 / 12 \mathrm{th}$ sector).................... 3-33

29. Thermal stress along thirty degree line of symmetry (1/12th sector - mesh B4) ................ 3-34

30. One half seven hole element (mesh HCl). . ...... 3-36

31. Finite element grid (1/2 element - mesh HC3) . . . . . 3-37

32. Deformation field ( $100 \mathrm{x}$ true size) of one-half element under 100 psi load (mesh HC3) . . . . . . . . . . . 3-38

33. SXX stress (1/2 element) . . . . . . . . . . . 3-39

34. SYY stress $(1 / 2$ element $)$. . . . . . . . . . . . 3-40

35. SXY stress $(1 / 2$ element $)$. . . . . . . . . . . 3-41 
FIGURES (continued)

36. Stresses along $X$-axis for 100 psi load ( $1 / 2$ element) . . . 3-42

37. Displacement along $X$-axis for $100 \mathrm{psi} 1$ load ( $1 / 2$ element) . . 3-43

38. SYY stress along $X$-axis for $100 \mathrm{psi}$ load ( $1 / 2$ element) . . 3-44

39. STT (hoop) stress around center hole for $100 \mathrm{ps} 1$ load ( $1 / 2$

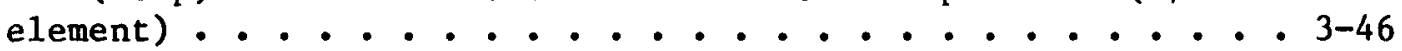

40. Percent error in peak stress and displacements for 100 psi

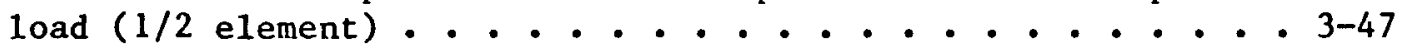

41. Percent error - peak stress vs $\mathrm{Y}$ displacement for 100 psi

load $(1 / 2$ element) . . . . . . . . . . . . 3-48

42. Peak stress for 100 psi load for all one half element meshes . . . . . . . . . . . . . . . . 3449

Al. One-twelfth sector of seven hole element (mesh B1) ..... A-2

A2. One-twelfth sector of seven hole element (mesh C1) . . . . A-3

A3. One-twelfth sector of seven hole element (mesh B2) . . . . A-4

A4. One-twelfth sector of seven hole element (mesh C2) . . . . A-5

A5. One-twelfth sector of seven hole element (mesh B3) . . . . A-6

A6. One-twelfth sector - seven hole element (mesh C3) . . . . A-7

A7. One-twelfth sector - seven hole element (mesh B4) . . . . A-8

A8. One-half seven hole element (mesh HBl) . . . . . . . A-9

A9. One-half seven hole element (mesh $\mathrm{HCl}$ ) . . . . . . . A-10

A10. One-half seven hole element (mesh HB2) . . . . . . . . A-11

Al1. One-half seven hole element (mesh HC2) . . . . . . . A-12

A12. One-half seven hole element (mesh HB3) .......... A-13

A13. One-half seven hole element (mesh HC3) . . . . . . . A-14

A14. One-half seven hole element (mesh HBlEMB1) . . . . . . A-15

Al5 One-half seven hole element (mesh HBlEMB2) . . . . . . A-16

A16. One-half seven hole element (mesh HB1EMB3) . . . . . . . A-17

A17. One-half seven hole element (mesh HB2EMB1) . . . . . . A-18

A18. One-half seven hole element (mesh HB2EMB2) . . . . . . . A-19

A19. Ist refine. of extract. from mesh HBl, mesh HBlEXT1. . . . . A-20

A20. 2nd refine. of extract. from mesh HBl, meshes HBlEXT2

and HB2EXT1 ....................... . $^{\mathrm{A}-21}$

A21. 3rd refine. of extract. from mesh HB1, mesh HB2EXT2. •. • . A-22 


\section{SUMMARY AND CONCLUSION}

This report quantifies the numerical accuracy of linear triangular finite elements used for two-dimensional thermal and stress analyses of graphite components. Accuracies were examined for thermal and mechanical loadings for a hole geometry similar to those found in HTGR fuel elements. A simplified model (the seven hole element shown in Figure 1) was used so that existing linear finite element computer codes could assure a converged solution with adequate mesh fineness. An accurate analysis of the full HTGR fuel element is more expensive and is currently beyond the capability of these codes.

A thermal stress problem with two lines of thermal and structural symmetry (a one-twelfth sector) was examined using seven different meshes. The coarsest mesh employed only four elements to model the web of symmetry between fuel and coolant holes. The most refined mesh had 64 times that number of elements. The differential temperature across the sector predicted by the coarse mesh was ten percent less than that found by the most refined mesh. The resulting peak in-plane tensile and compressive thermal stresses were twenty-one and sixty-two percent less, respectively, than those for the converged solution.

A uniform static load problem with only one line of structural symmetry (a one-half sector) was also examined using several different meshes. Both uniformly and partially refined (embedded) meshes were used in order to test the effectiveness of local refinement techniques. The finest uniformly refined half element mesh had sixteen times as many elements as the coarsest mesh (four elements in the web of symmetry). In addition, segments of this model were extracted, refined, and analyzed using nodal displacements determined from a complete coarse mesh analysis as displacement boundary conditions for the extracted regions. The coarsest half sector mesh predicted only sixty-one percent of the 
displacement at the peak stress location and only thirty-five percent of the peak stress, respectively, of those from the most uniformly refined mesh. The extraction and refinement procedure, using the coarse mesh displacement boundary conditions, did not predict any increase in peak stress even for two successive refinements (a factor of 16 on the number of elements) of the extracted region.

The failure of the extraction procedure is attributed to the fact that errors in the coarse mesh displacement field (caused by incorrect stiffness) preclude convergence of the local stress field to the correct solution. The fact that local mesh refinement caused no change in the peak stress may be regarded as incidental, since other less stressed areas showed some increase in stress with refinement. The embedded meshes, on the other hand, produced more accurate results than the extracted and refined meshes. The degree of accuracy depended on the level of refinement in both the local area and the surrounding coarser mesh.

The conclusions that may be drawn from this study are:

1. For applied mechanical loads with few lines of loading and/ or structural symmetry, the extraction technique will predict stresses with an error directly proportional to the error in the coarse mesh displacement boundary conditions. In the case of a coarse mesh having four elements in the web of symmetry (a finer mesh than has been used in prior fuel element stress analyses) the calculated peak stress was only 35 percent of that found by the most refined mesh analysis.*

*

* This does not imply that actual stresses will be three times higher than calculated using existing fuel element meshes. This is simply the numerical error in an elastic solution. Actual stresses resulting from the time-dependent nonlinear material behavior can not be determined until such errors are eliminated. Improved material models (the discussion of which is beyond the scope of this report) will also be required for accurate fuel element stress analysis. 
2. The error in the temperature, displacement, and stress fields calculated using the extraction procedure was found to be insensitive to the level of local mesh refinement. That is, local refinement with the resultant increased model flexibility did not offset the error introduced through the displacement boundary conditions as caused by a too stiff or coarse mesh representation of the entire model. The extraction technique as currently formulated is not reliable and should be discontinued.

3. An embedded mesh with the same level of refinement is more accurate than an extracted mesh. The error depends upon the ratio of the refined to coarse mesh areas and upon the level of overall mesh fineness. In the mechanical load analysis an embedded mesh having only twenty-three percent as many elements as the most uniformly refined mesh found over ninety percent of the peak stress.

4. For multiholed structures such as fuel elements, linear finite element codes are too inefficient for accurate stress calculations. To obtain an accuracy of within ten percent, a fuel element mesh would require nearly 100,000 linear triangular elements. A higher ordered quadrilateral element, currently being programmed in the new TWOD code, should dramatically reduce this. 


\section{INTRODUCTION}

HTGR fuel elements are graphite hexagonal right prisms with arrays of fuel, coolant, and burnable poison holes. The major structural loads are those due to differential thermal and irradiation strains and those from seismic excitations of the core. The resulting temperature and stress fields arising from these loads are typically analyzed using two dimensional triangular finite element codes with linear temperature and displacement fields. Since strains are combinations of displacement derivatives, these are constant strain elements. For a linear constitutive (stress-strain) law, these are a1so constant stress elements.

In the past, owing to limited computer capability, rather coarse finite element meshes have been used for temperature and structural evaluations of fuel elements. Detailed analysis has been performed using a coarse mesh model to determine displacement boundary conditions for a locally refined analysis of a critical area (the so called extraction technique). The accuracy of this technique, which depends upon the accuracy of the coarse mesh displacement field, had never been quantified. The primary purpose of this study is to assess how the accuracy of the temperature and stress fields varies with mesh fineness and to quantify the errors of the extraction technique.

The seven hole element illustrated in Fig. 1 provides a relatively simple geometry for evaluating the numerical accuracy of these codes while retaining the essential features of the HTGR fuel element such as local and overall temperature fields and complicated load paths. This element has the same fuel/coolant hole pitch and hole sizes as the 10-row FSV fuel element and approximately similar thermal loadings between the fuel and coolant holes. 


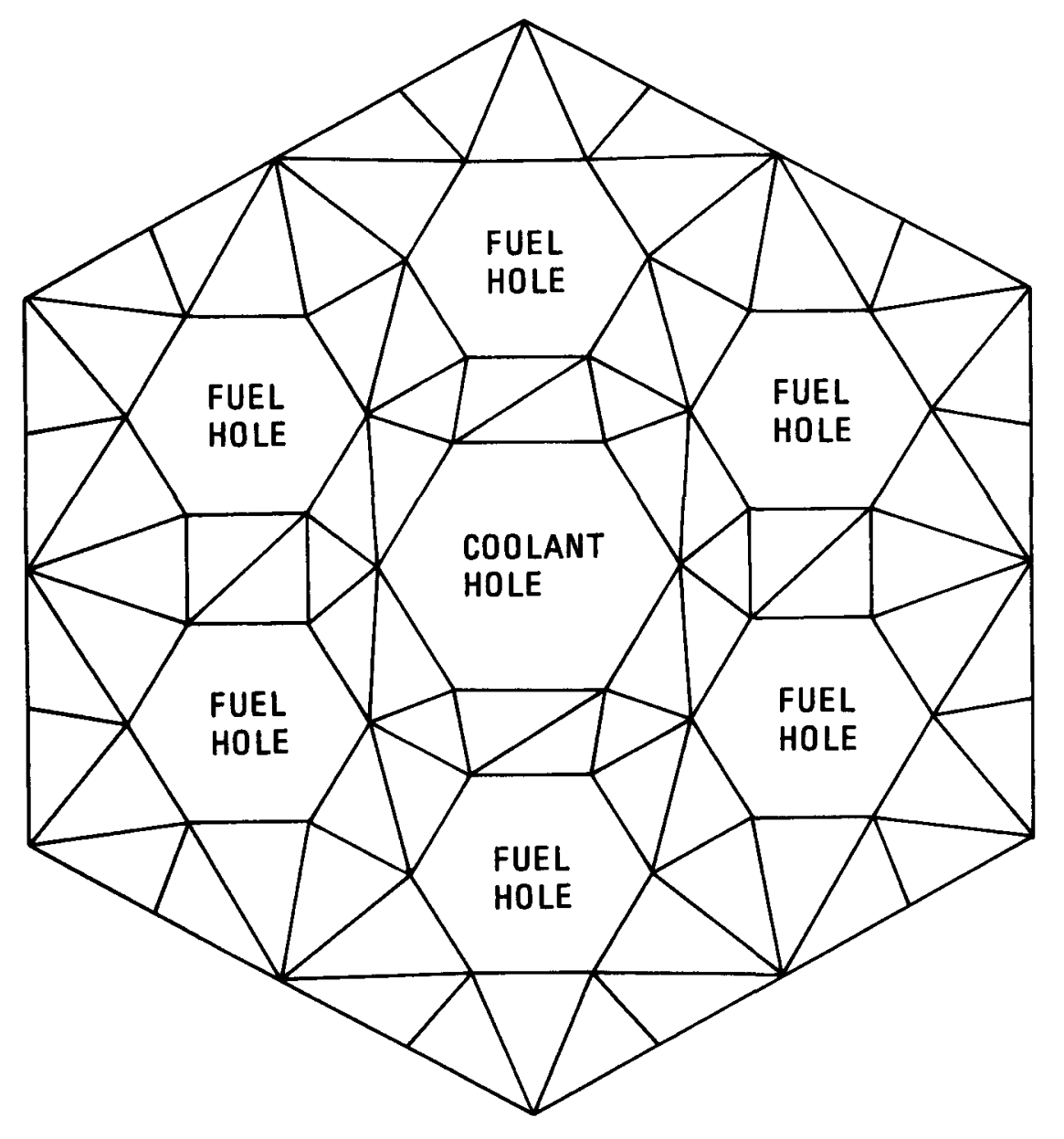

Fig. 1. Seven hole element (Mesh A1) 
The mesh shown in Figure 1 is constructed with the same level of mesh refinement, hence numerical accuracy, as that used in some recent fuel element stress analyses. The Figure 1 mesh is coarser than those used in the present study, in which the coarsest mesh has finite element boundaries at all lines of geometric symmetry and contains about twice the number of finite elements as in Figure 1 . Three additional levels of mesh refinement were required to achieve a converged solution. 


\section{ANALYSIS AND RESULTS}

The numerical accuracy study was performed for both thermal and mechanical loads using symmetrical sectors of the seven hole element. The thermal load arises from the spatially varying temperature field between the center coolant hole and the six surrounding fuel holes. A one-twelfth symmetrical sector of the seven hole element was used for the thermal problem as this allowed extremely detailed mesh fineness. A one-half sector was used to examine the more asymmetrical mechanical load.

\subsection{ONE-TWELFTH SECTOR THERMAL ANALYSIS}

A one-twelfth sector of the element was analyzed for temperatures via the TEPC-2D linear finite element code (Reference 1). The thermal boundary conditions consisted of a uniform heat flux on the surface of the fuel hole, convective cooling on the coolant hole surface, and adiabatic boundaries on the geometrical lines of symmetry and the outer surface, as illustrated in Figure 2.

The seven finite element meshes used in the analysis are shown in Appendix A (figures Al through A7). They consist of two series of mesh refinements created with the REFINE code (Reference 2). Each series starts from coarse meshes referred to respectively as $\mathrm{Bl}$ and $\mathrm{Cl}$. Each refinement quadruples the number of elements, and since mesh $\mathrm{C} 1$ has about twice the number of elements as $B 1$, the two initial meshes yield a series ( $\mathrm{B} 1, \mathrm{C} 1, \mathrm{~B} 2, \mathrm{C} 2$, etc.) with approximately twice the number of elements in each successive mesh in the series. Mesh B1 has only boundary nodes, while mesh $\mathrm{Cl}$ has interior nodes at places of interest and, consequently, has a different element pattern. The series terminates with mesh B4 which has 64 times the number of elements as mesh B1. For structural comparisons, the polygonal holes were sized to preserve the cross sectional area. The heat flux on the fuel hole surface and the heat transfer coefficient on the coolant hole surface were modified 


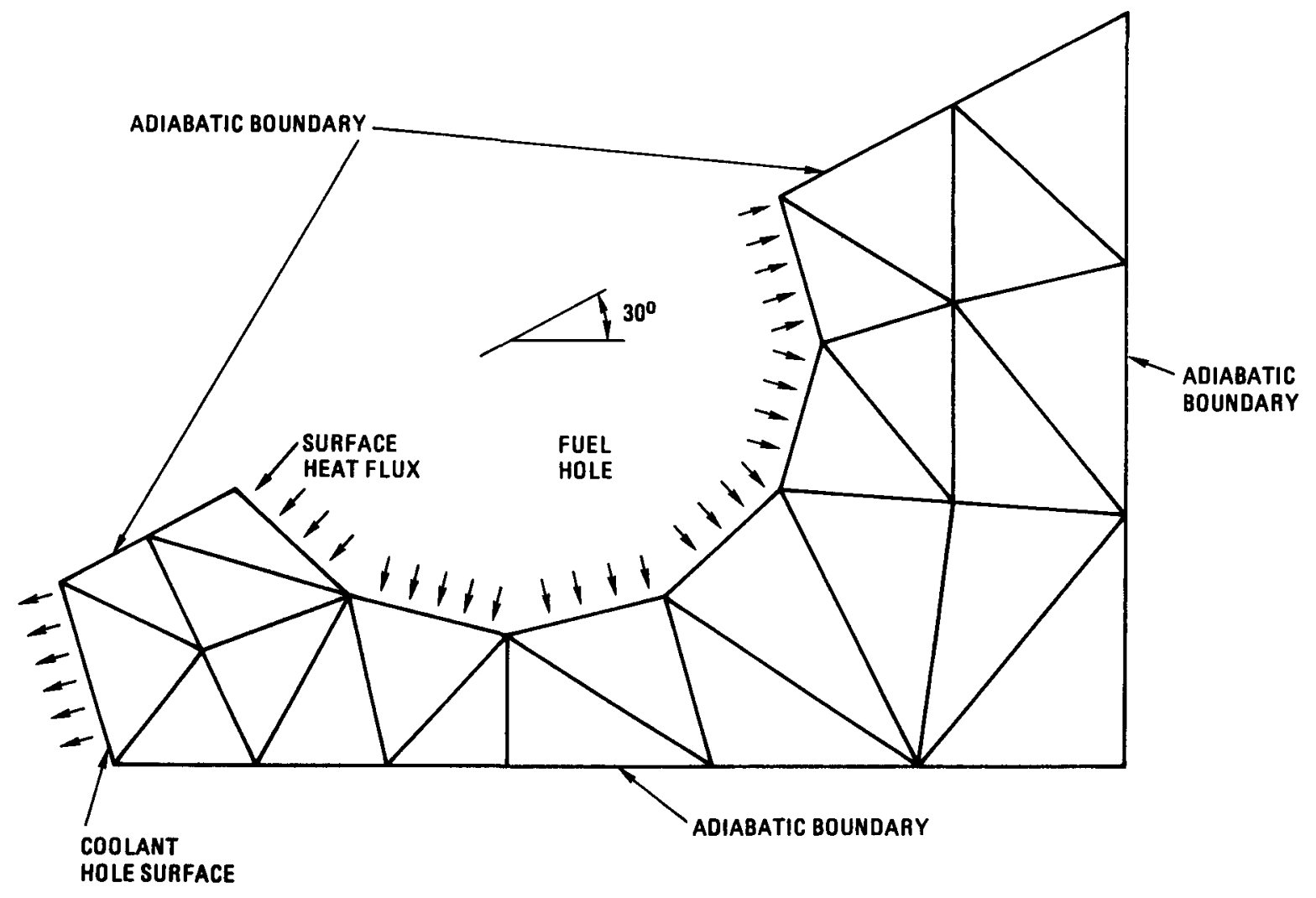

Fig. 2. One-twelfth sector of seven hole element (Mesh C1) 
appropriately as their perimeters varied. The details of the thermal analyses are given in Appendix $B$.

A contour plot of the resultant temperature field is shown in Figure 3 for the finest mesh (B4). The maximum temperature difference across the sector as predicted by all seven meshes is shown in Figure 4. As depicted in this figure, mesh $B 3$ predicts the maximum temperature different within one percent of mesh B4, while mesh BI underpredicts it by ten percent. This underprediction leads to lower estimates of the thermal stress.

The temperatures on the exterior boundaries of the one-twelfth sector are shown in Figures 5 through 8 for all meshes. The temperature profiles along the coolant and fuel hole surfaces are shown in Figures 5 and 6 , respectively while the profiles along the $x$ axis and the 30 degree line of symmetry are depicted in Figures 7 and 8 . Convergence of the temperature field is indicated at mesh fineness level B3.

The effect of using the linear interpolation/extrapolation part of the extraction technique in finding the nodal temperatures for a uniform refinement of the entire one-twelfth model was also examined. The nodal temperatures from mesh B2 were used to find those for mesh B3 via linear interpolation and compared to those calculated via TEPC for mesh B3 directly.

The maximum temperature difference across the sector was found to increase by only $1.5^{\circ} \mathrm{F}$ via linear interpolation/extrapolation while the direct calculation yielded an increase of $17.1^{\circ} \mathrm{F}$. Most of the error occurred in underpredicting the hottest temperature which lies on the surface of the fuel hole furthest from the center coolant hole and on the 30 degree line of symmetry. For this analysis, the total area was preserved during mesh refinement. This caused the nodes along the 
CONTOUR VALUes $\left({ }^{\circ} \mathrm{F}\right)$
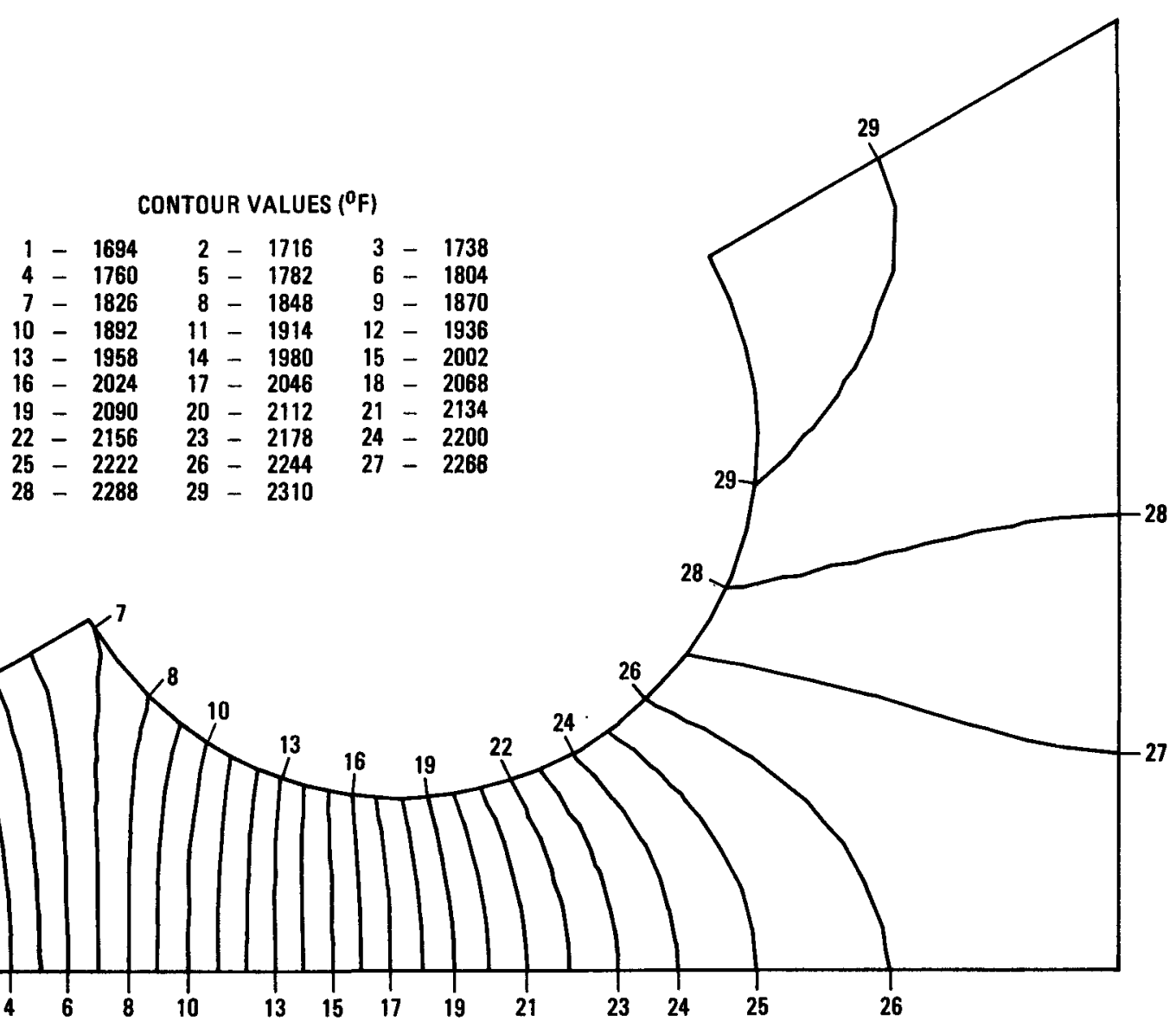

Fig. 3. Temperature field $\left({ }^{\circ} \mathrm{F}\right)$ (1/12th sector - Mesh B4) 


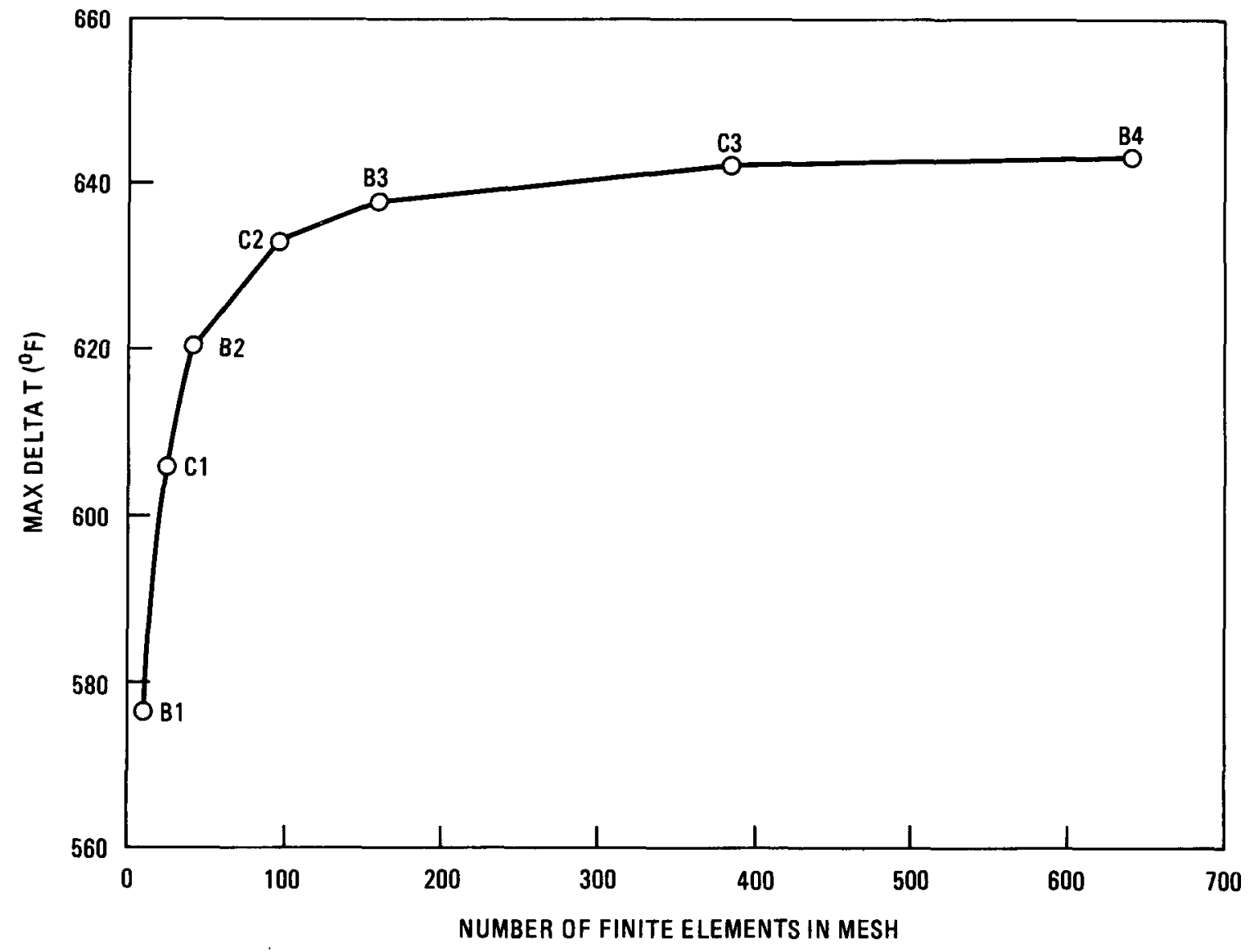

Fig. 4. Maximum temperature differences (1/12th sector) 


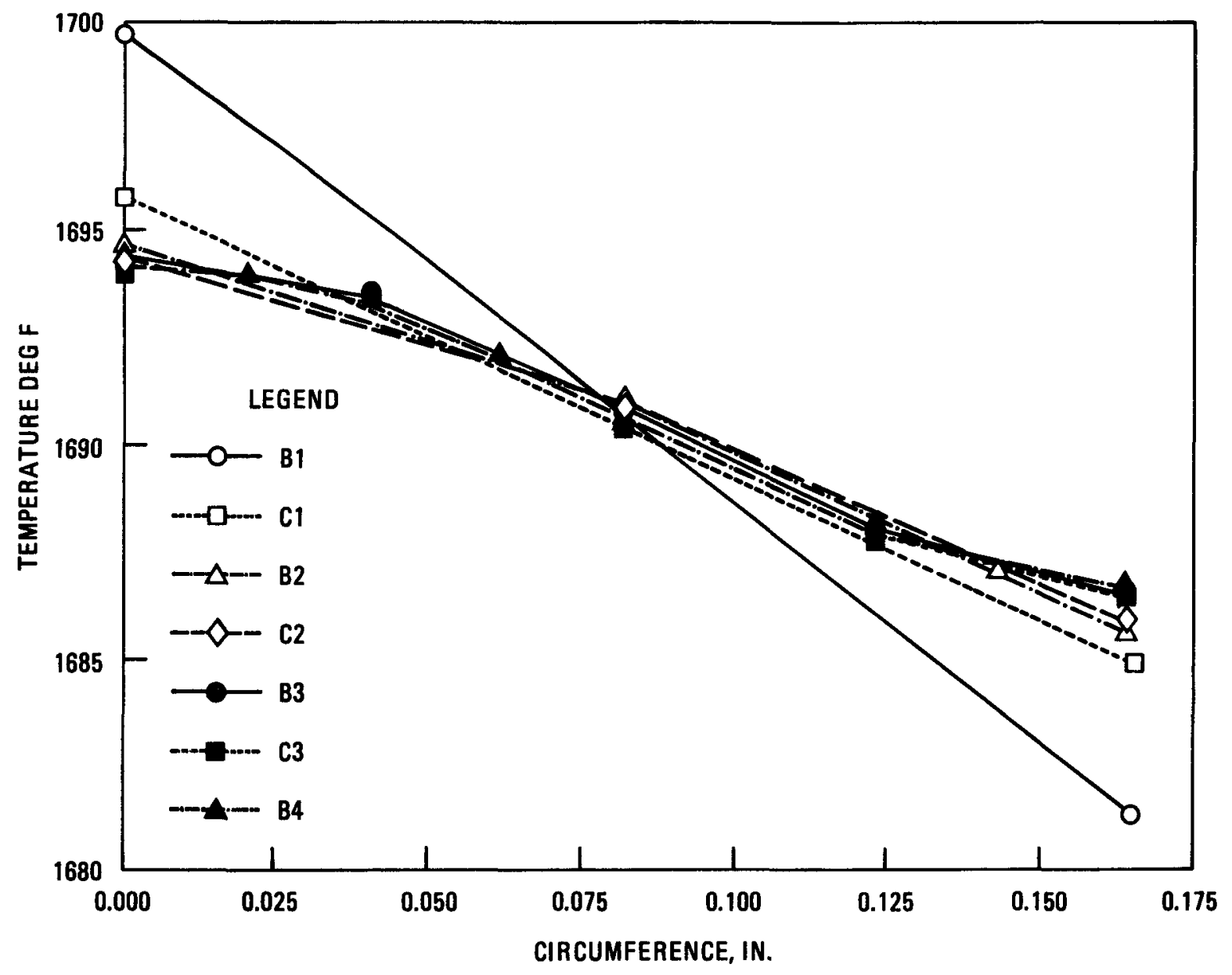

Fig. 5. Coolant hole circumference temperature profiles (1/12th sector) 


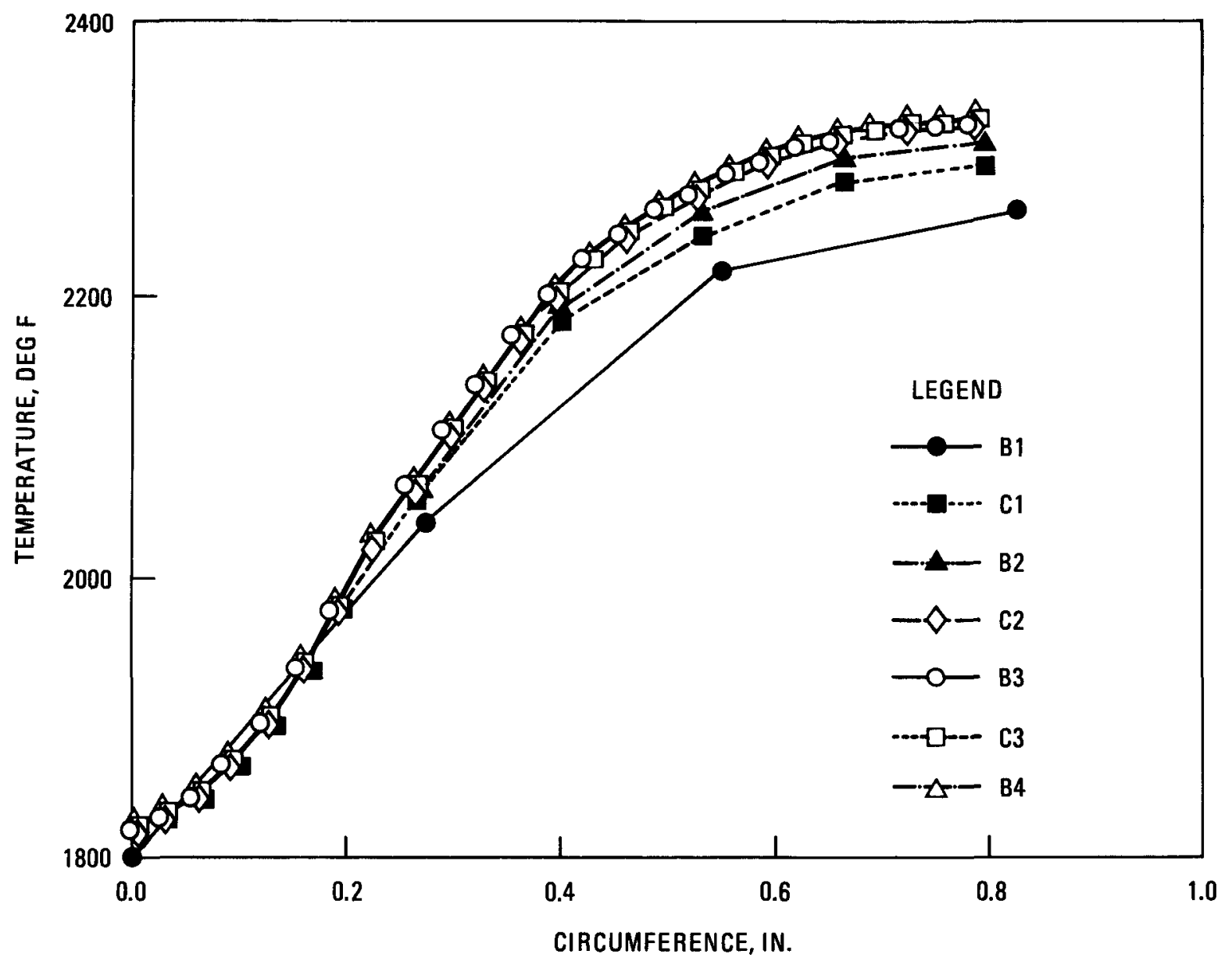

Fig. 6. Fuel hole circumference temperature profiles (1/12th sector) 


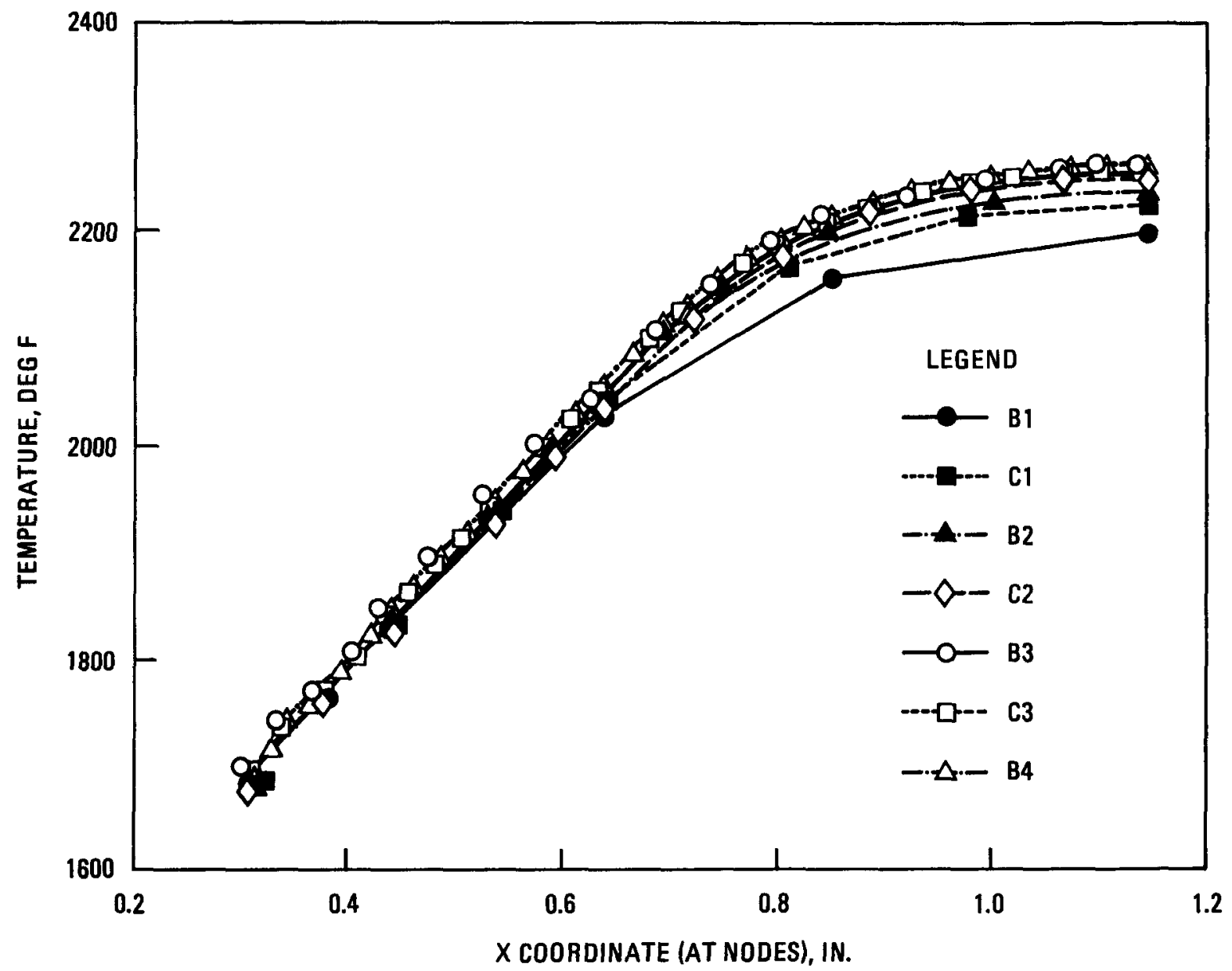

Fig. 7. X-Axis temperature profiles (1/12th sector) 


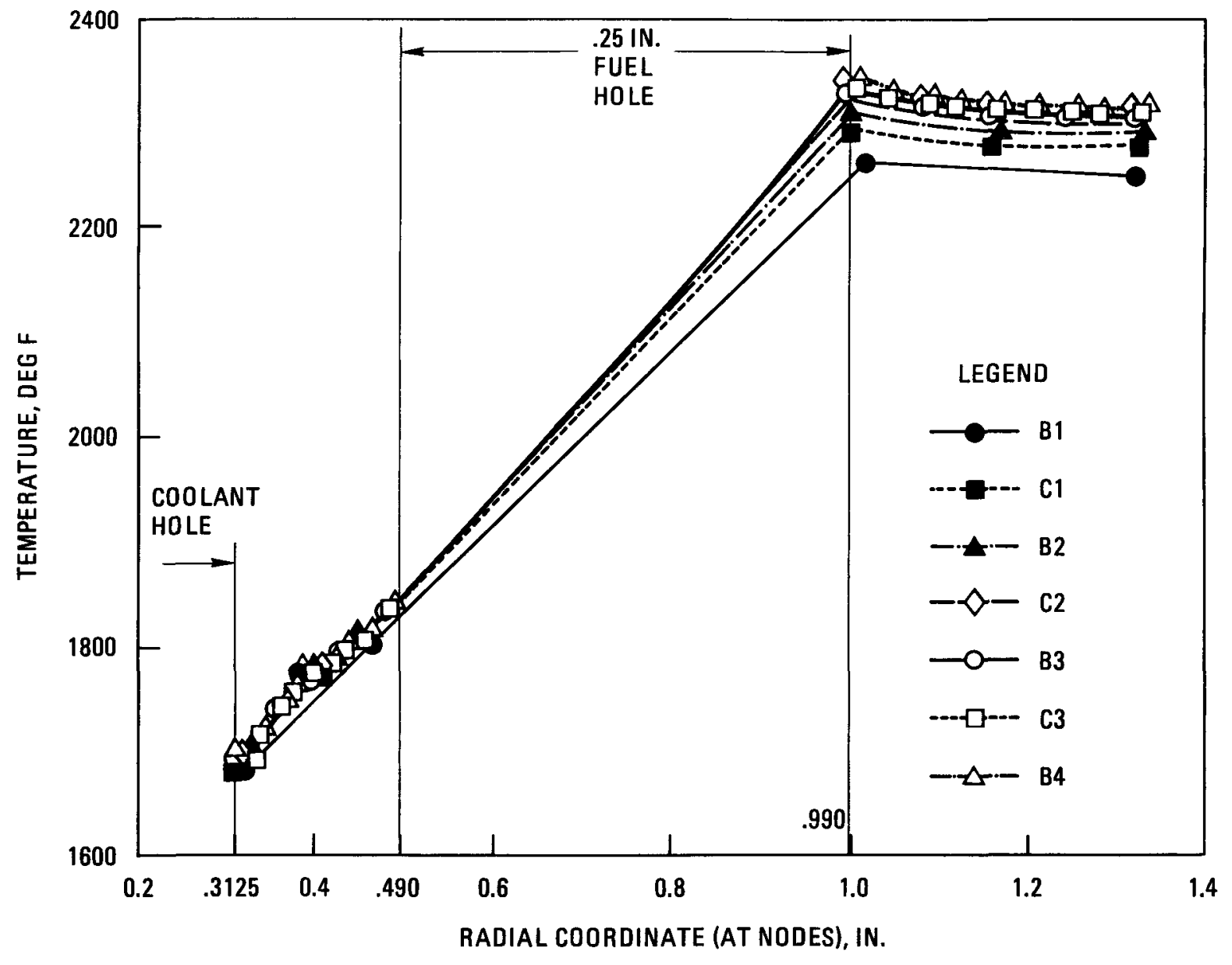

Fig. 8. Thirty degree line of symmetry temperature profiles (1/12th sector) 
fuel hole surface to move towards the hole center so a linear extrapolation was actually employed. The error in the maximum temperature difference, however, is most likely not due to any error in this extrapolation process but rather results from the use of the inaccurate coarse mesh temperature field.

\subsection{ONE-TWELTH SECTOR THERMAL STRESS ANALYSIS}

The SAFIRE code (Reference 3) was used to find the resultant thermal stress arising in the one-twelth sector due to the nonuniform temperature field between the fuel and coolant holes. Generalized plane strain analyses were performed for all seven meshes using the nodal temperatures found via the TEPC-2D analyses. The $H-451$ graphite material property module built into the SAFIRE code was utilized. For this elastic analysis, only the temperature dependent elastic moduli, linear coefficients of thermal expansion, and Poisson's ratios for both axial and in-plane directions were required.

The adiabatic boundaries along the $x$-axis and the $30^{\circ}$ line of symmetry were treated as lines of structural symmetry (zero shear stress, zero net transverse force, and zero rotation of the line) as shown in Figure 9 for mesh B4. The details of the SAFIRE analyses including sample data input listings are given in Appendix C.

Contour plots for the axial (SZZ) stress and the three plane (SXX, SYY, SXY) stress components for mesh B4 are shown in Figures 10 through 13. The maximum tensile stresses for both the axial and in-plane (radial) directions occur at the coolant hole surface on the $30^{\circ}$ line of symmetry: the coolest point in the sector. This maximum in-plane stress is the hoop stress around the coolant hole. The maximum compressive stresses for both the axial and in-plane directions occur at the hottest point in the sector: at the outer edge of the fuel hole on the $30^{\circ}$ line of symmetry. This maximum in-plane stress is the hoop stress around the fuel hole. The locations of these peak stress values are indicated in Figure 9. 


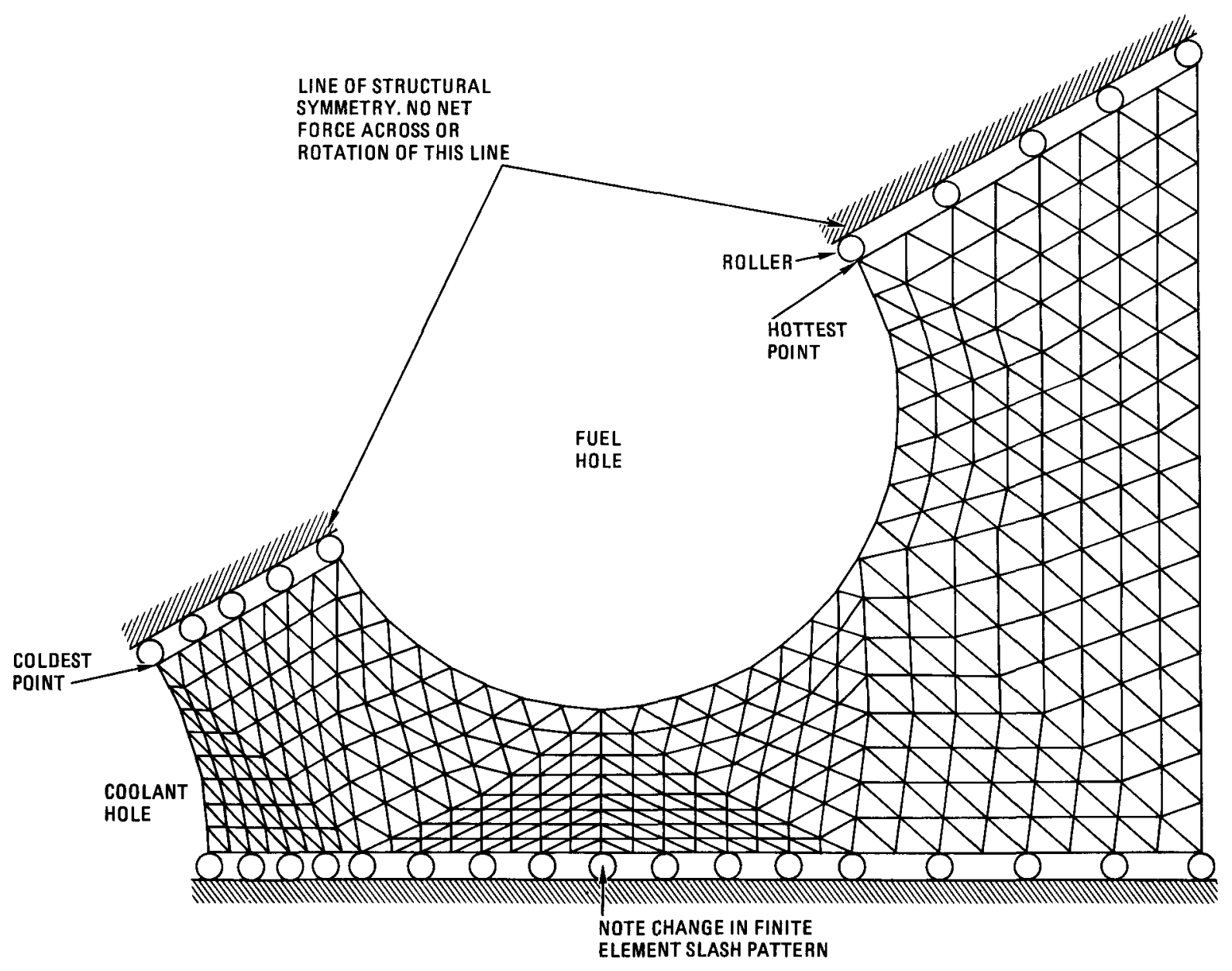

Fig. 9. Finite element grid (1/12th sector - Mesh B4) 


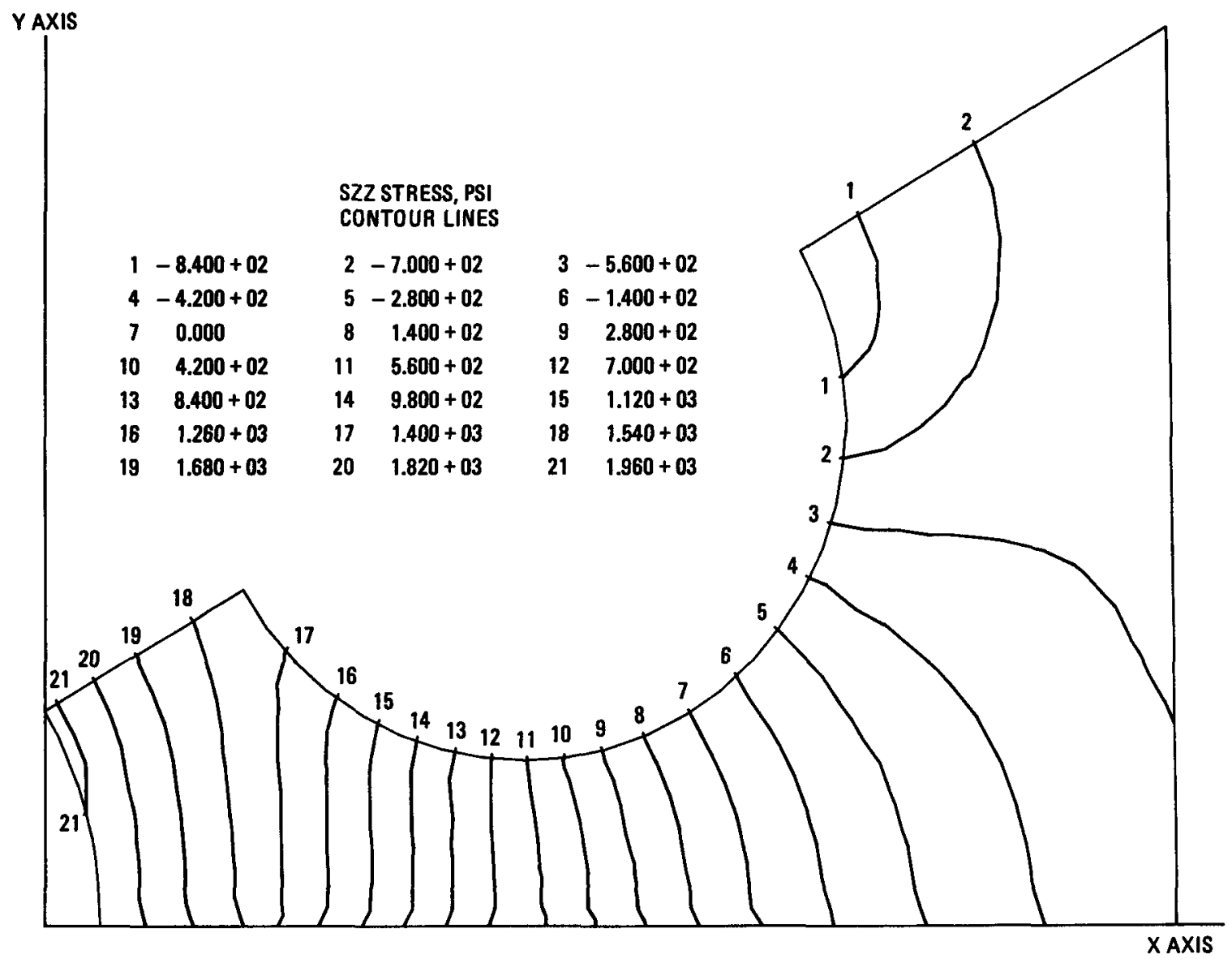

Fig. 10. SZZ stress (1/12th sector) 


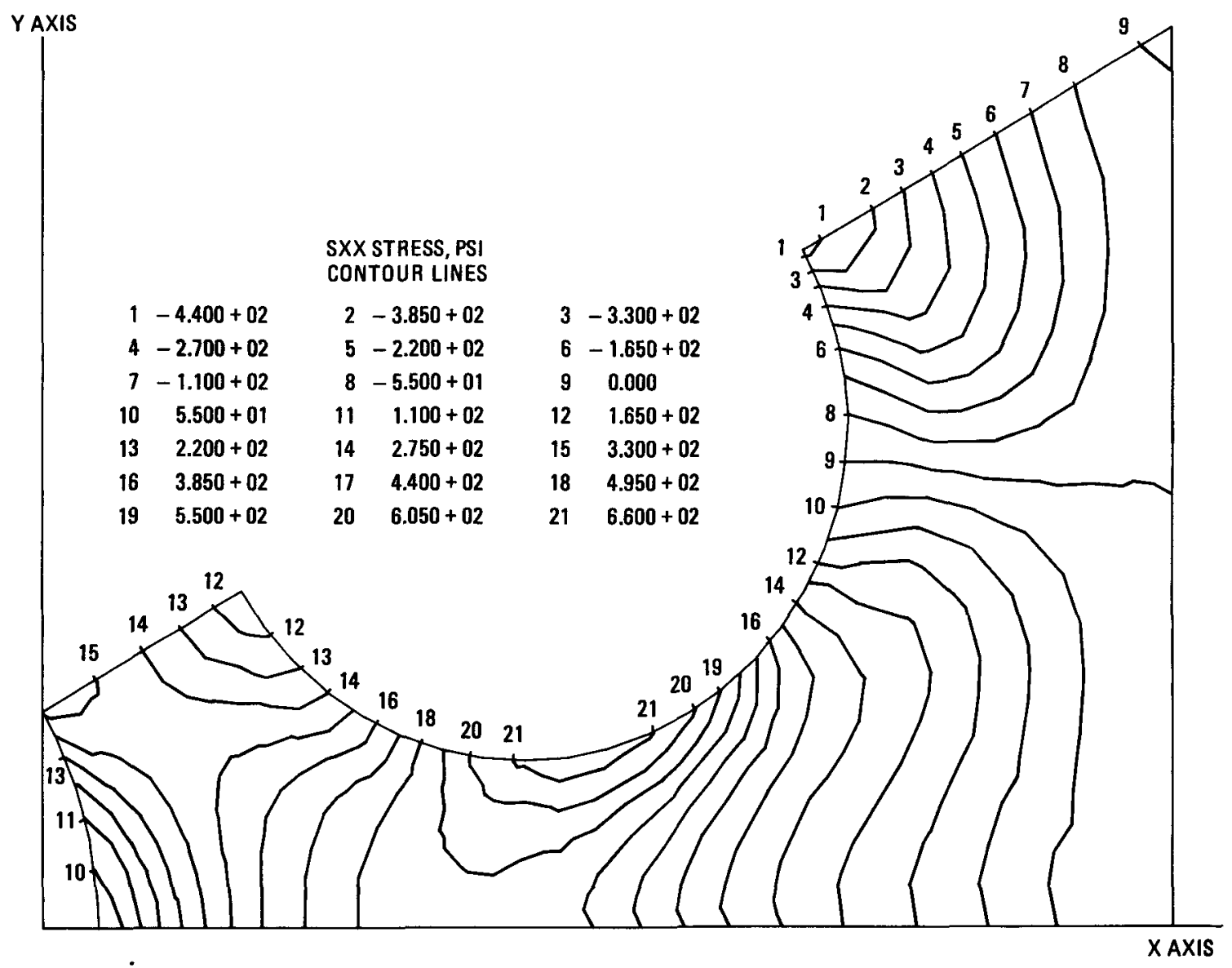

Fig. 11. SXX stress (1/12th sector) 


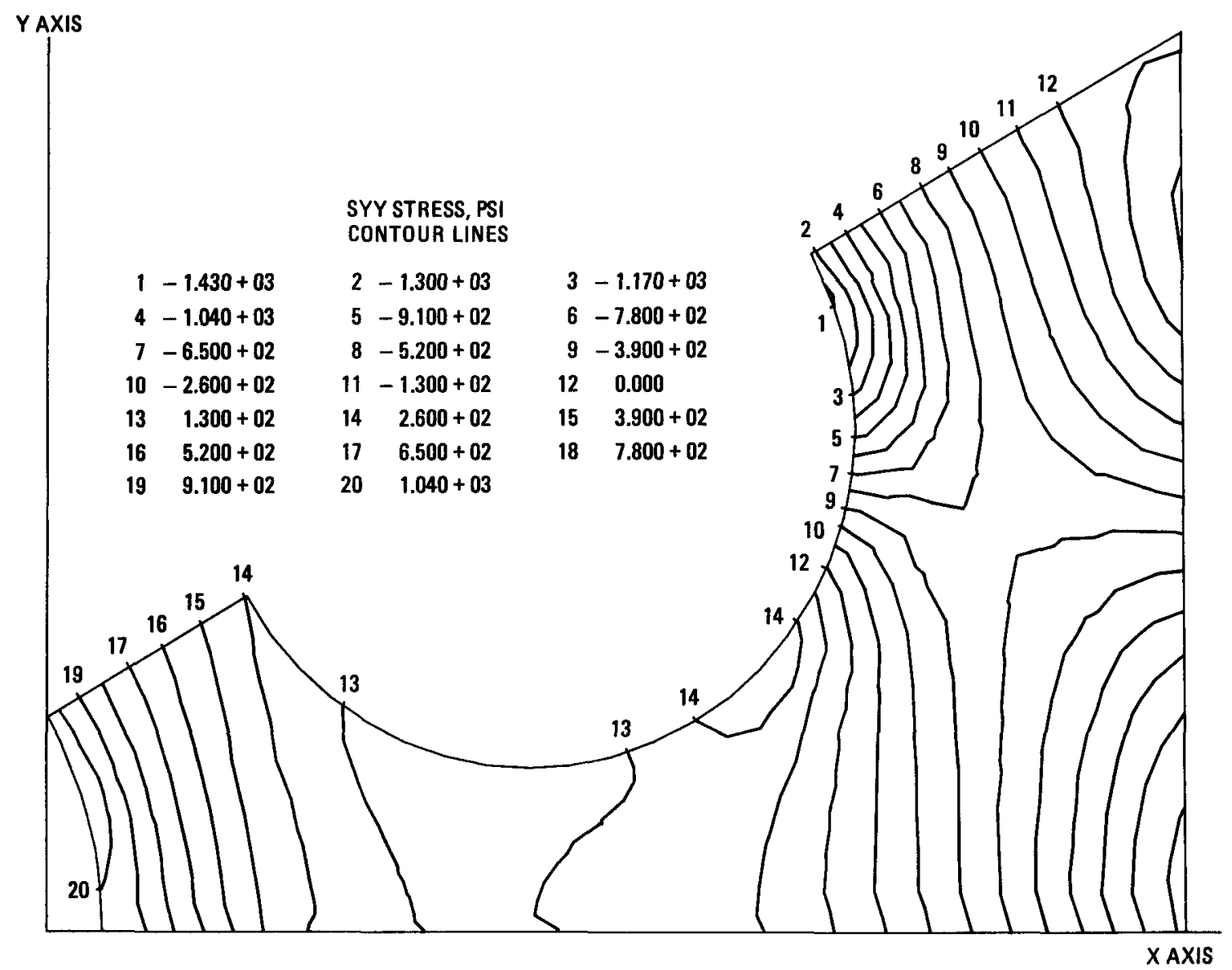

Fig. 12. SYY stress (1/12th sector) 


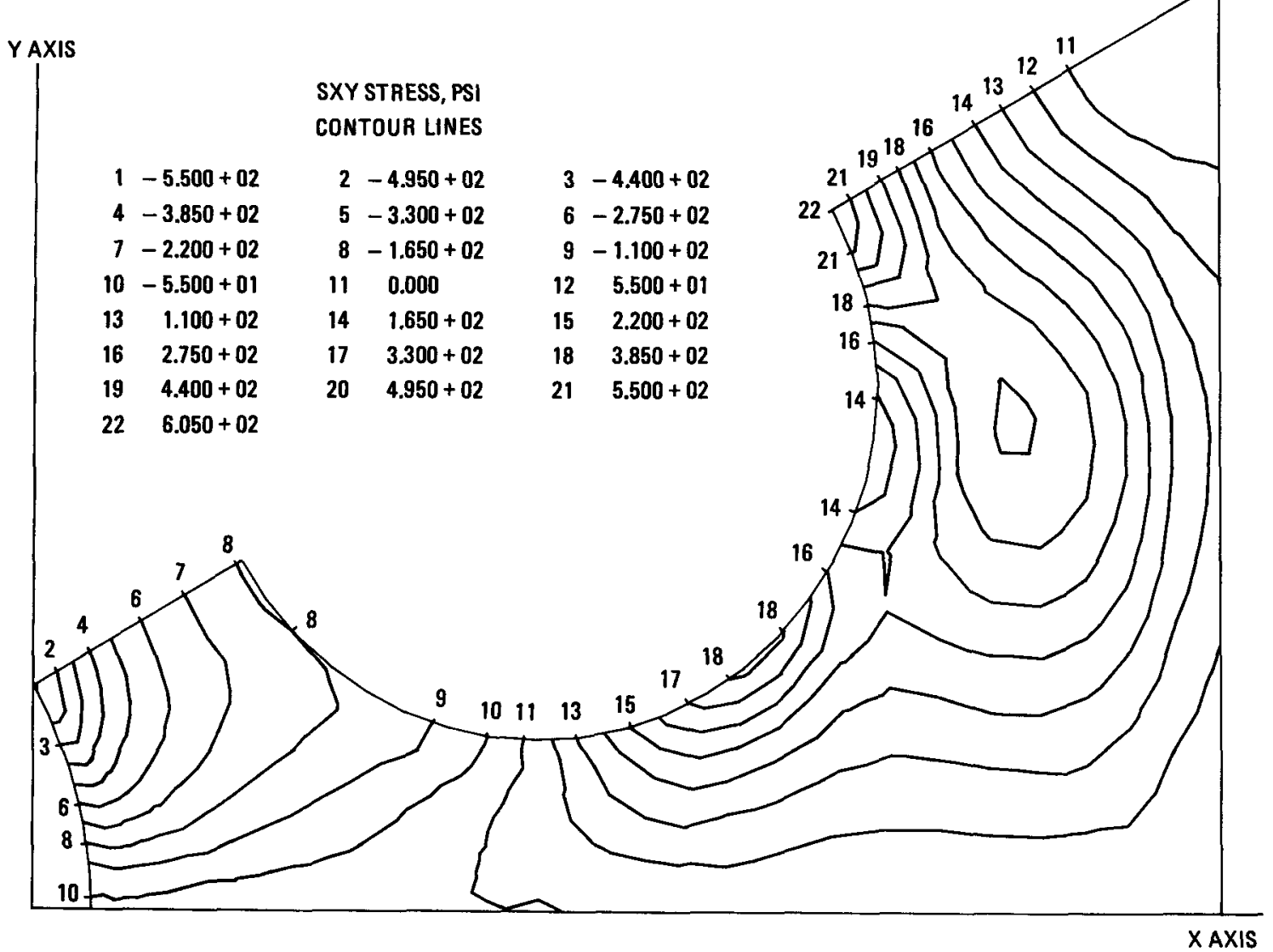

Fig. 13. SXY stress (1/12th sector) 
Figure 14 shows the peak stress values in both tension and compression as calculated with the seven meshes. The percent error in the maximum temperature difference and in the peak tensile and compressive stresses for all meshes compared to those predicted by mesh $\mathrm{B} 4$ is given in Figure 15. As seen in this figure, the peak stress values are predicted to within about ten percent of the mesh B4 values at mesh fineness level B3, while the coarsest mesh $B 1$ has a sixty-two percent error in predicting the compressive stress near the fuel hole and a twenty-one percent error in predicting the tensile stress near the coolant hole.

The peak stresses are plotted versus the maximum temperature difference for all meshes in Figure 16. The axial stress is seen to be nearly linear with increasing temperature difference. In actuality, the axial stress is directly proportional to the difference between the element mean temperature and the temperature at the point of interest which for this problem is approximately one-half of the maximum temperature difference; therefore, the linearity of the stress-temperature difference relation is nearly maintained. (The in-plane stress is also proportional to the temperature difference but the shape of the temperature field affects the relation.) Finally, in Figure 17, the percent error in peak stress values is plotted versus the percent error in the maximum temperature difference where the error is again defined relative to the mesh $B 4$ values.

Figures 16 and 17 together illustrate the resulting error in stress prediction due to the combined errors in temperature prediction and in mesh fineness. In order to separate the effect of the temperature error from the structural stiffness error, it is noted that if the structural mesh were fully refined, yet the coarse mesh temperature field were used in the stress analysis, the percent error in the stresses would be nearly equal to the percent error in the temperature differences. Thus, it is approximately correct to assume that any percent error in excess of the temperature error is due solely to the structural modeling. Thus, the error in the fuel hole hoop stress of eleven percent for mesh B3 is primarlly due to mesh coarseness and not due to the associated one per- 


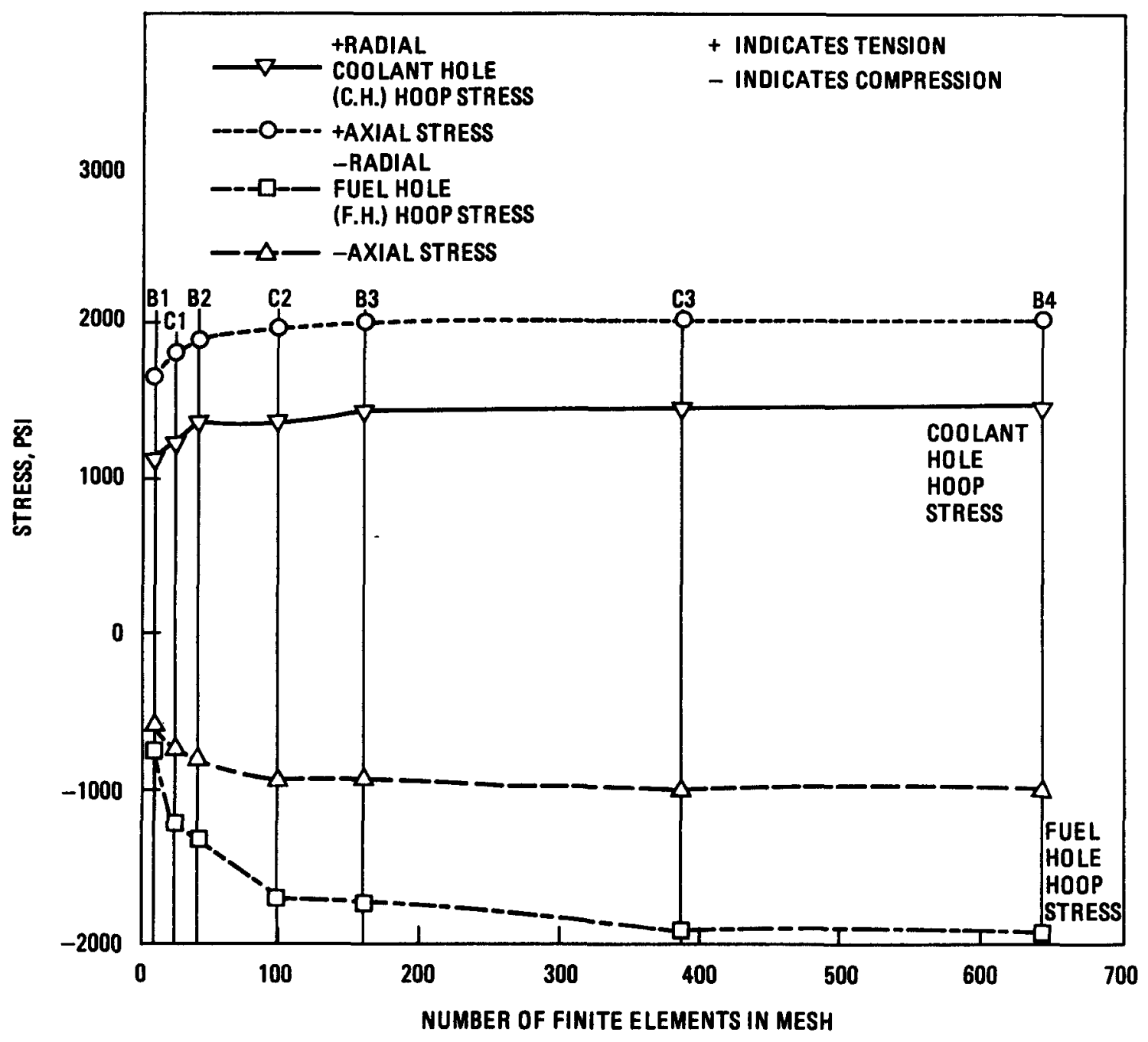

Fig. 14. Peak stress values (1/12th sector) 


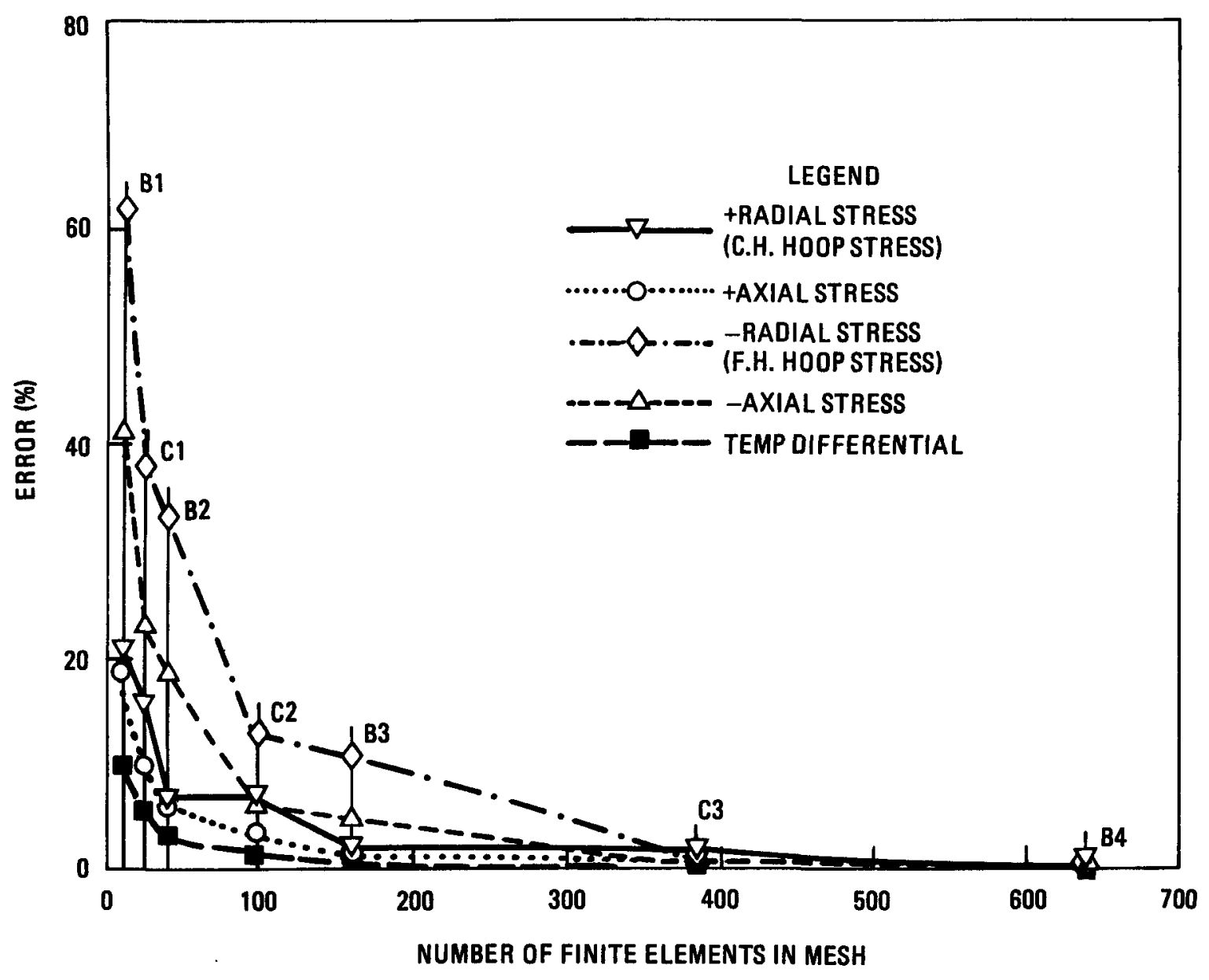

Fig. 15. Peak stress and maximum temperature difference errors (1/12th sector) 


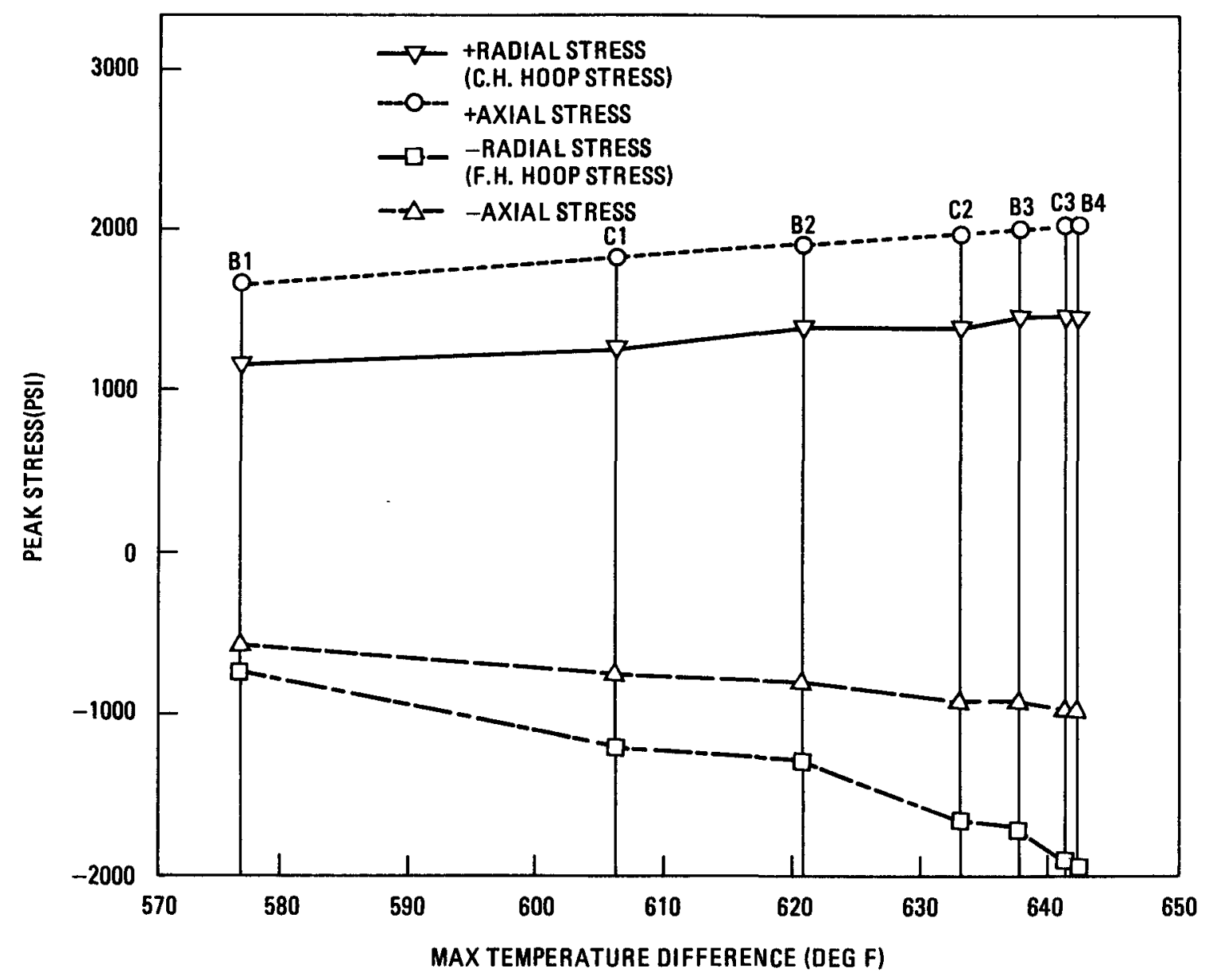

Fig. 16. Peak stress vs maximum temperature difference (1/12th sector) 


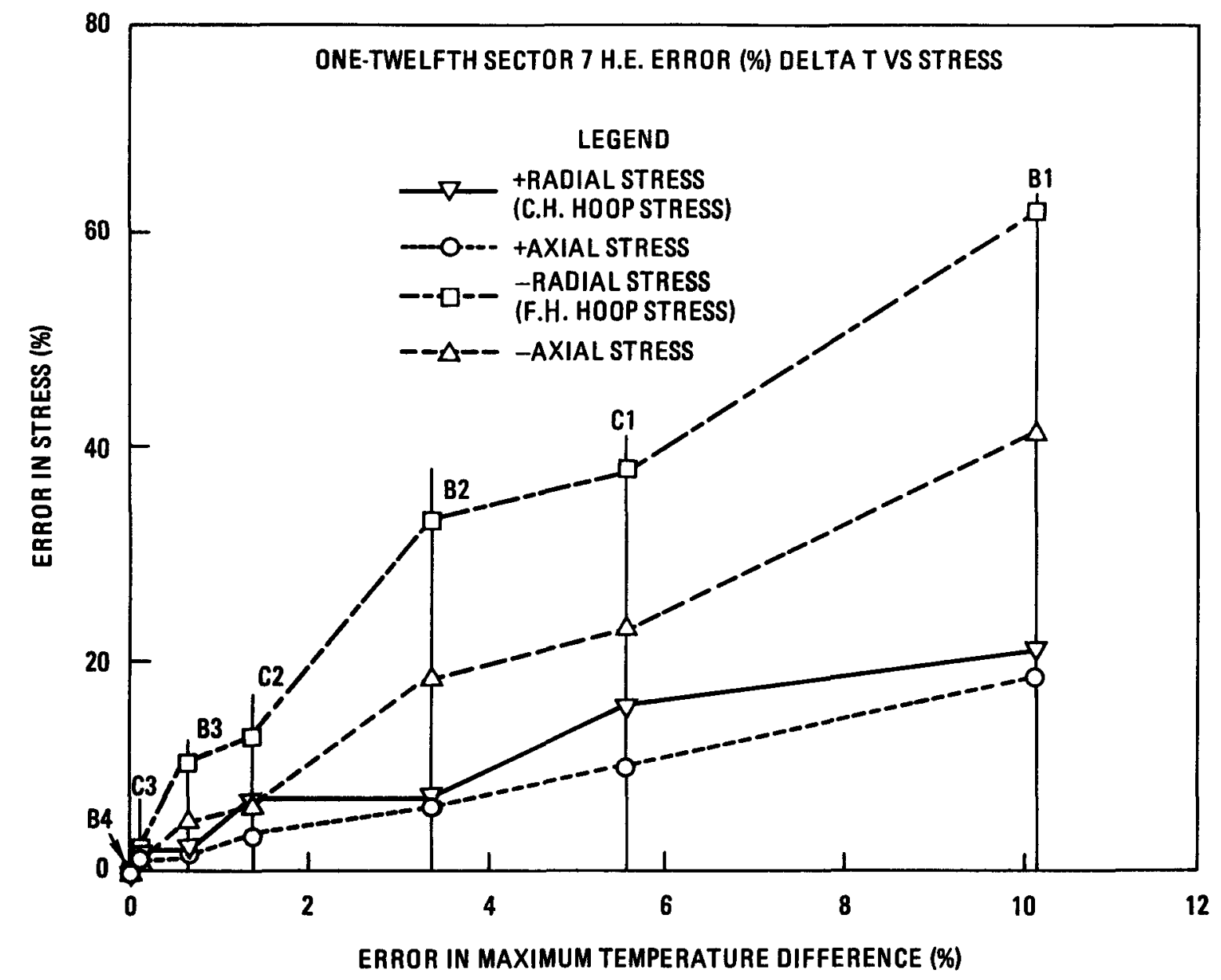

Fig. 17. Percent error - peak stress vs $\max$ temperature difference (1/12th sector) 
cent error in temperature difference (see Figure 17). Table 1 (page 3-51) gives a summary of the error for the maximum temperature differential and peak stress values for a11 meshes.

The test for convergence for the stress field (a tensor variable) is more complex than that for temperature (a scalar variable) and requires an examination of the entire field rather than just the peak values. A1though the values of the resolved scalar displacements, DELX, along the $x$-axis (Figure 18) and DELR, along the $30^{\circ}$ line of symmetry (Figure 19) reveal no anomalies for all meshes, plots of the scalar components of the stress tensor along the $x$-axis do. Figure 20 shows the value of SYY (the stress component on the face of a stress cube with constant $Y$ coordinate value and acting in the $\mathrm{Y}$ direction) along the $\mathrm{x}$-axis. (This stress component becomes the hoop stress around the center coolant hole.) The discontinuity in this variable that occurs at the $x$ coordinate value of 0.64 inches (as shown in Figure 20 and in more detail in the blow up of this region in Figure 21) is related to the change in the finite element pattern or orientation at this location (see Figure 9). It results primarily from the difference in mechanical and free thermal strains (in the $y$ direction) between adjacent elements; the mechanical strain is controlled by the $y$ displacement of the common node off the $x$-axis (the common node on the $x$-axis has zero $y$ displacement), but the free thermal strain has a variation between elements. One way to avoid this is to maintain a consistent element slash pattern.

The magnitude of any such discontinuity decreases with increasing mesh fineness and is only 70 psi or five percent of the peak SYY value at mesh level B4. The value of the SXX stress component along the $\mathrm{x}$-axis also reveals this discontinuity as well as smaller ones for $x$ values of 0.44 inches and 0.85 inches as shown in Figure 22. The axial stress component, $\mathrm{SZZ}$, along the $\mathrm{x}$-axis varies smoothly with no jumps and appears we11 predicted for meshes finer than $\mathrm{B} 2$ as shown in Figure 23. The in-plane shear stress component, SXY, which should be zero along the $\mathrm{x}$-axis since it is a line of structural symmetry, is shown in Figure 24 for all meshes. 


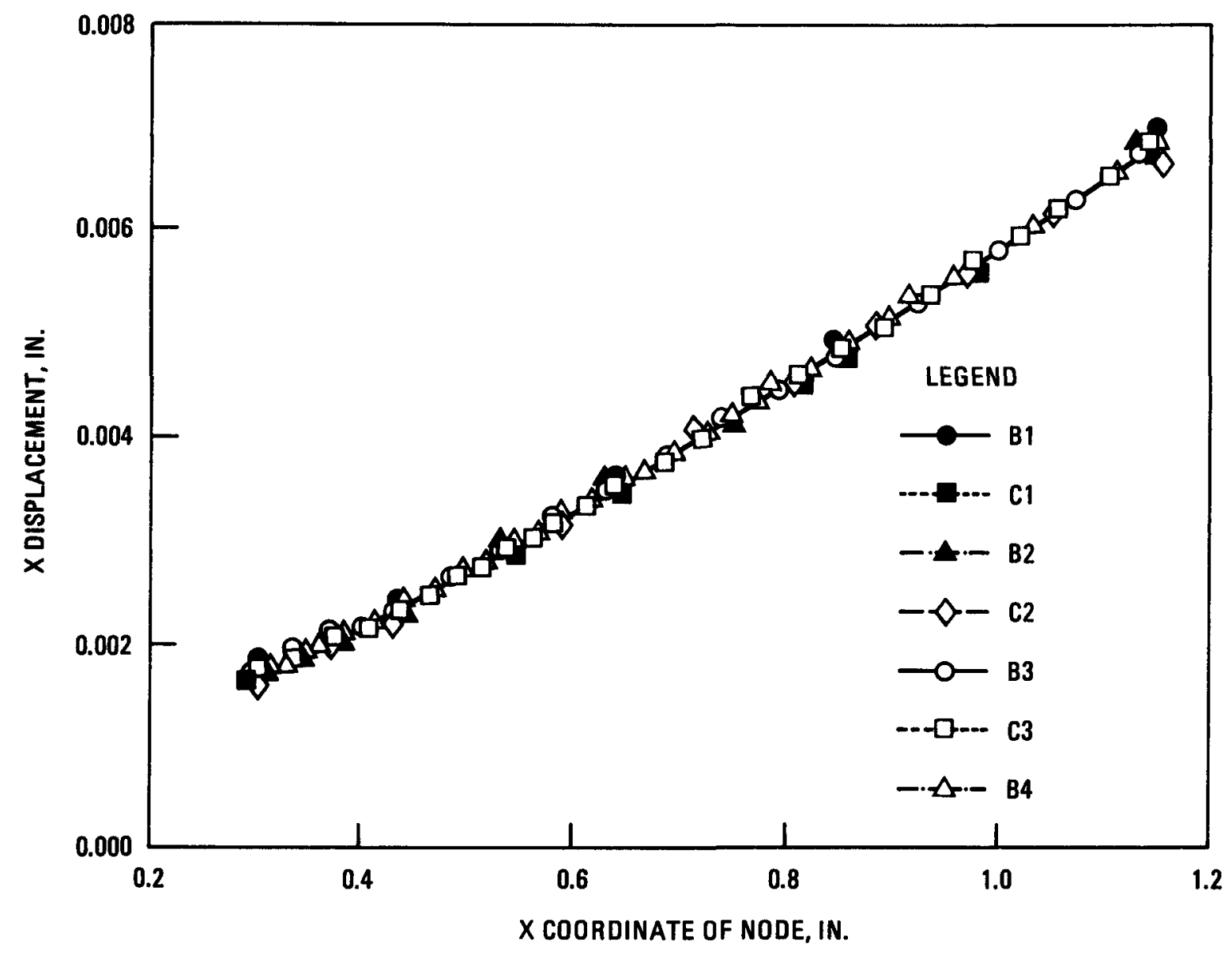

Fig. 18. Displacement (in.) along $\mathrm{X}$-Axis in $\mathrm{X}$ direction (1/12th sector) 


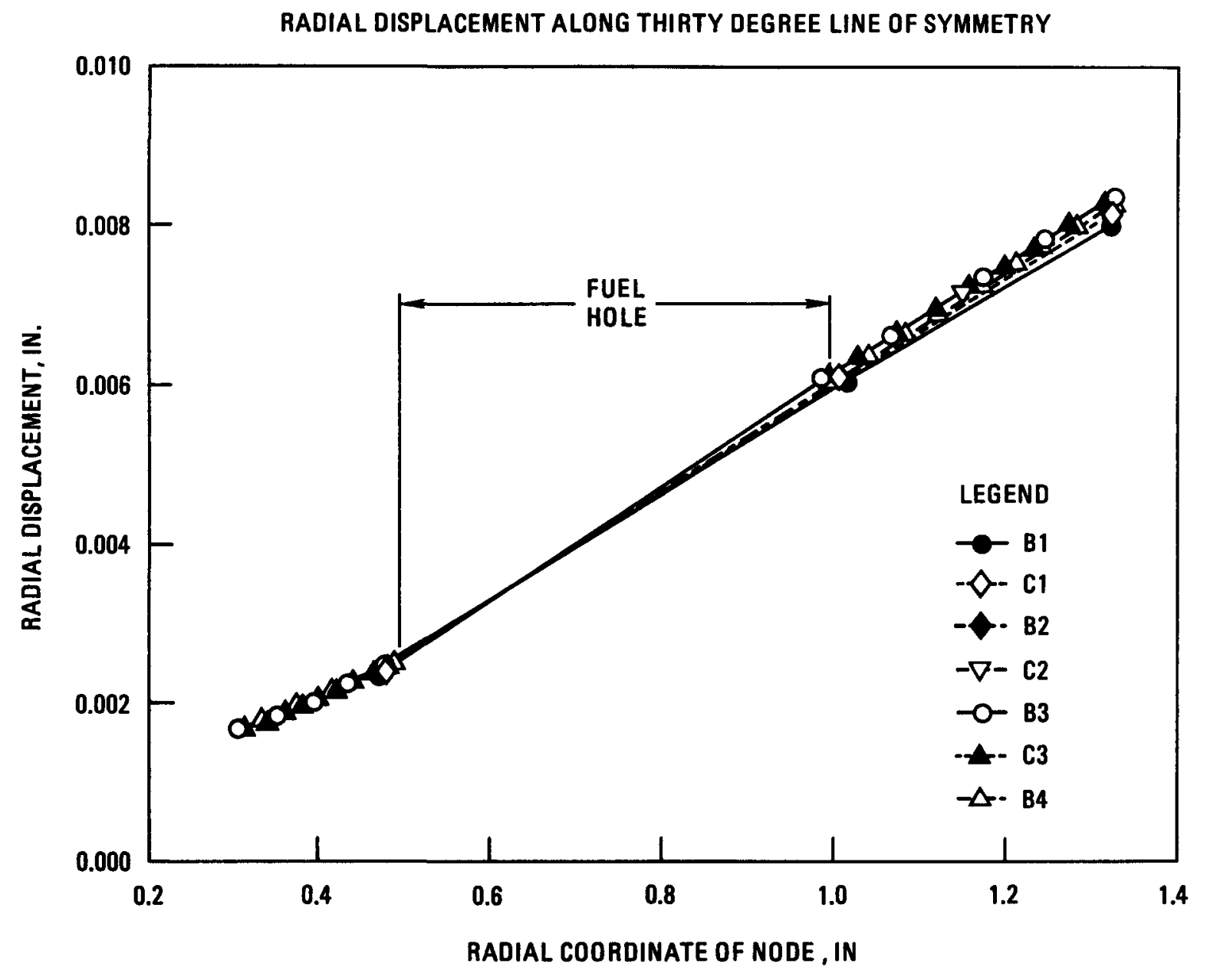

Fig. 19. Radial displacement (in.) along thirty degree line of symmetry ( $1 / 12$ th sector) 


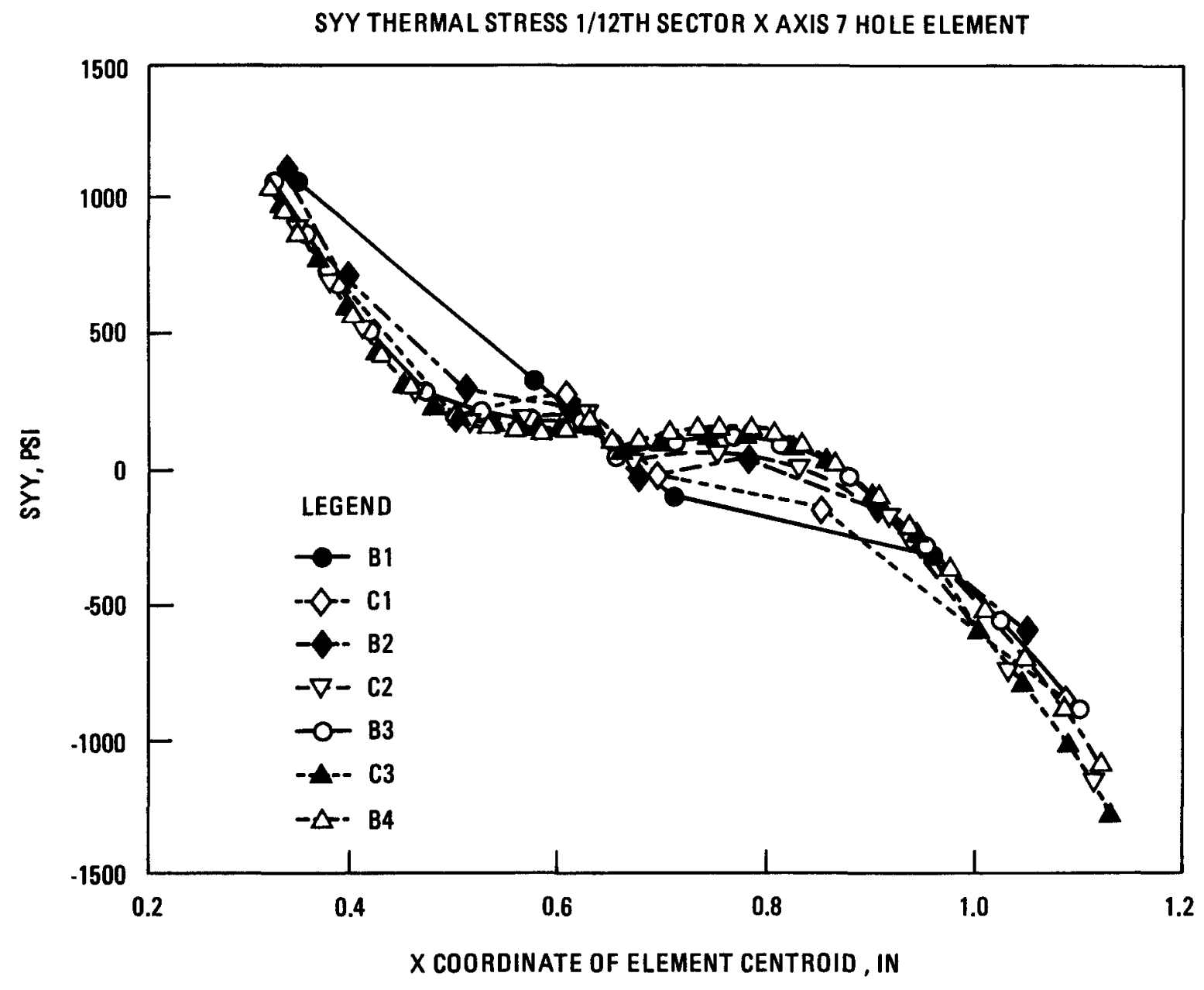

Fig. 20. SYY stress (PSI) along X-Axis (1/12th sector) 


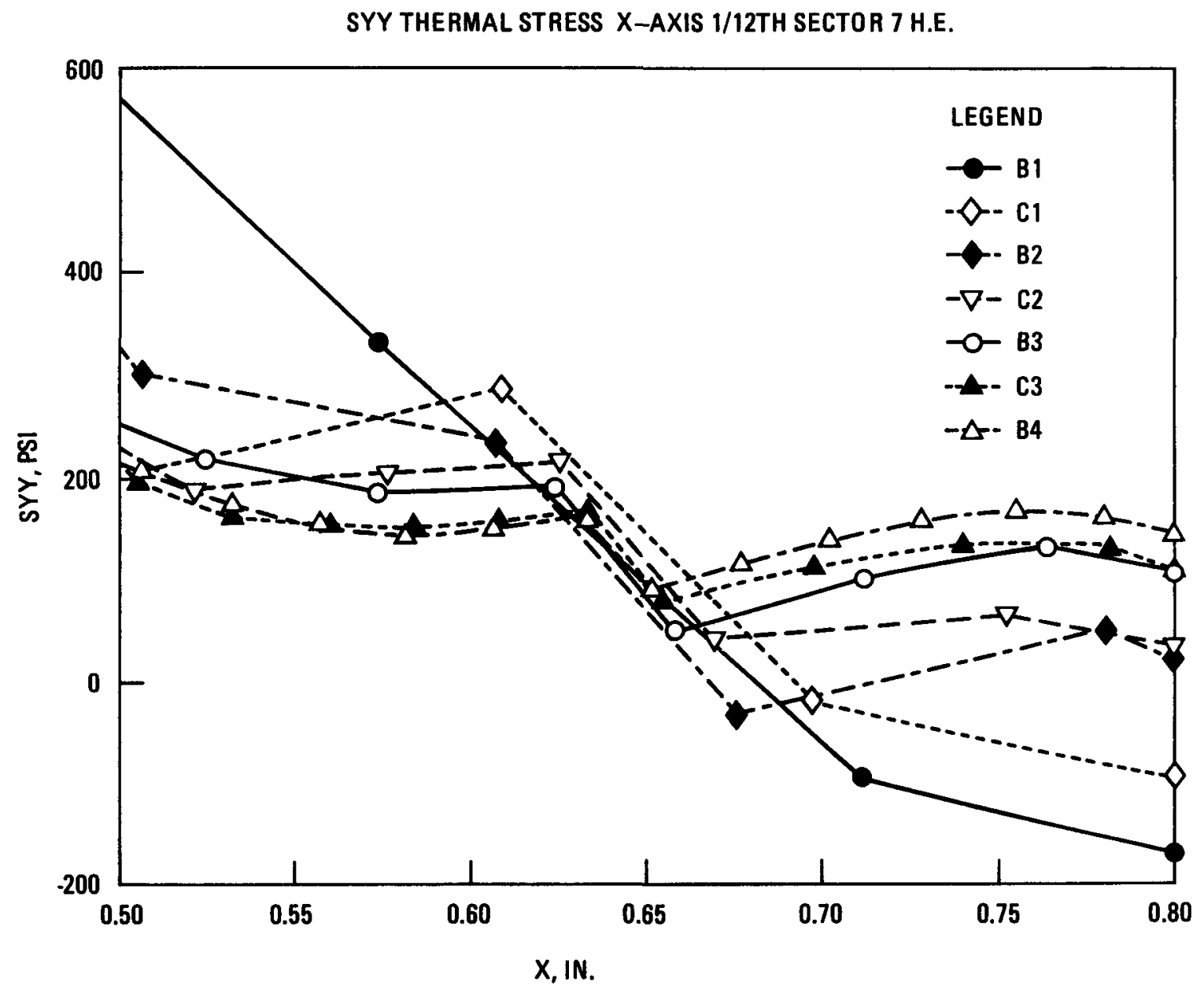

Fig. 21. Detailed blowup of SYY stress (1/12th sector) 


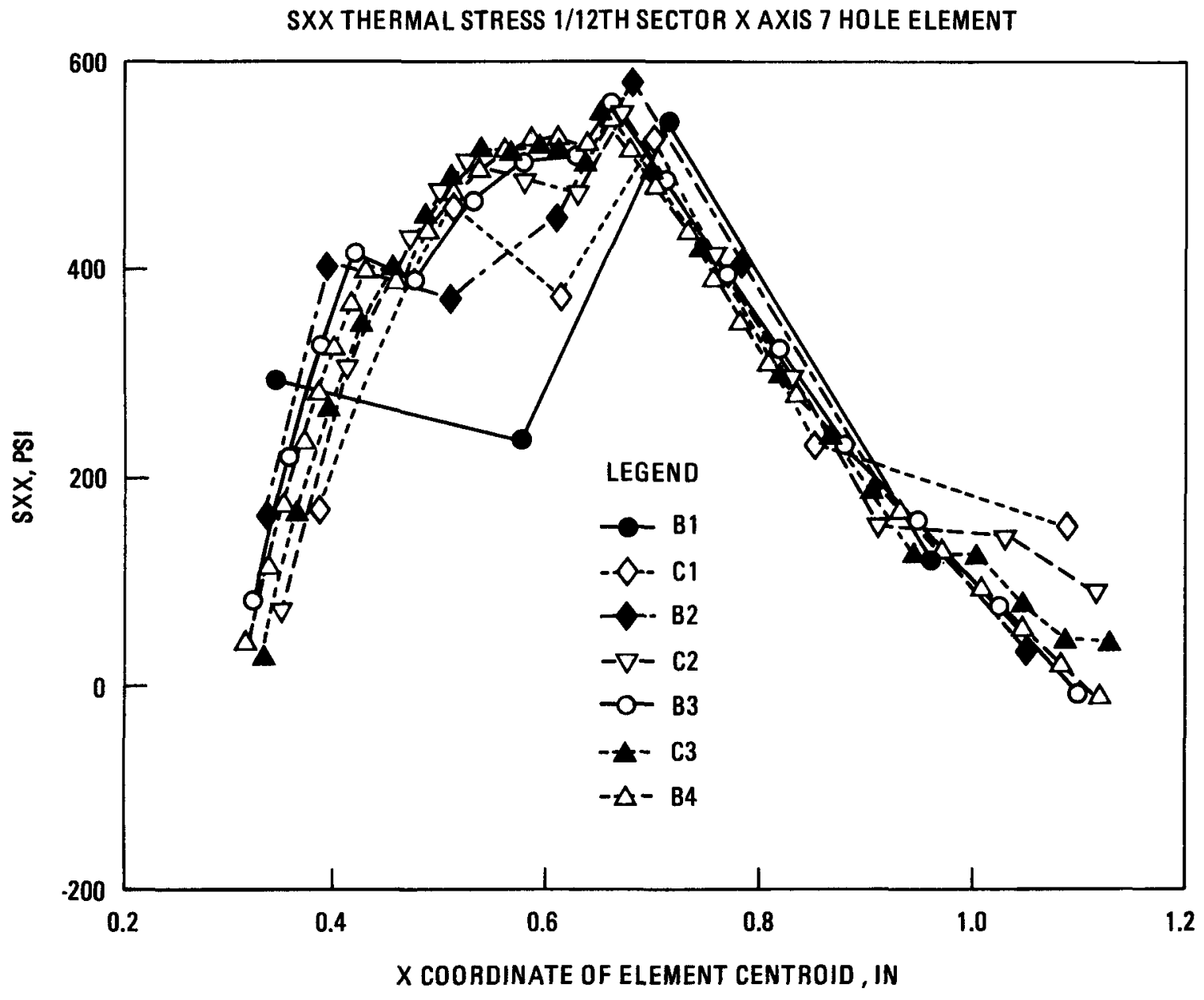

Fig. 22. SXX stress along X-Axis (1/12th sector) 


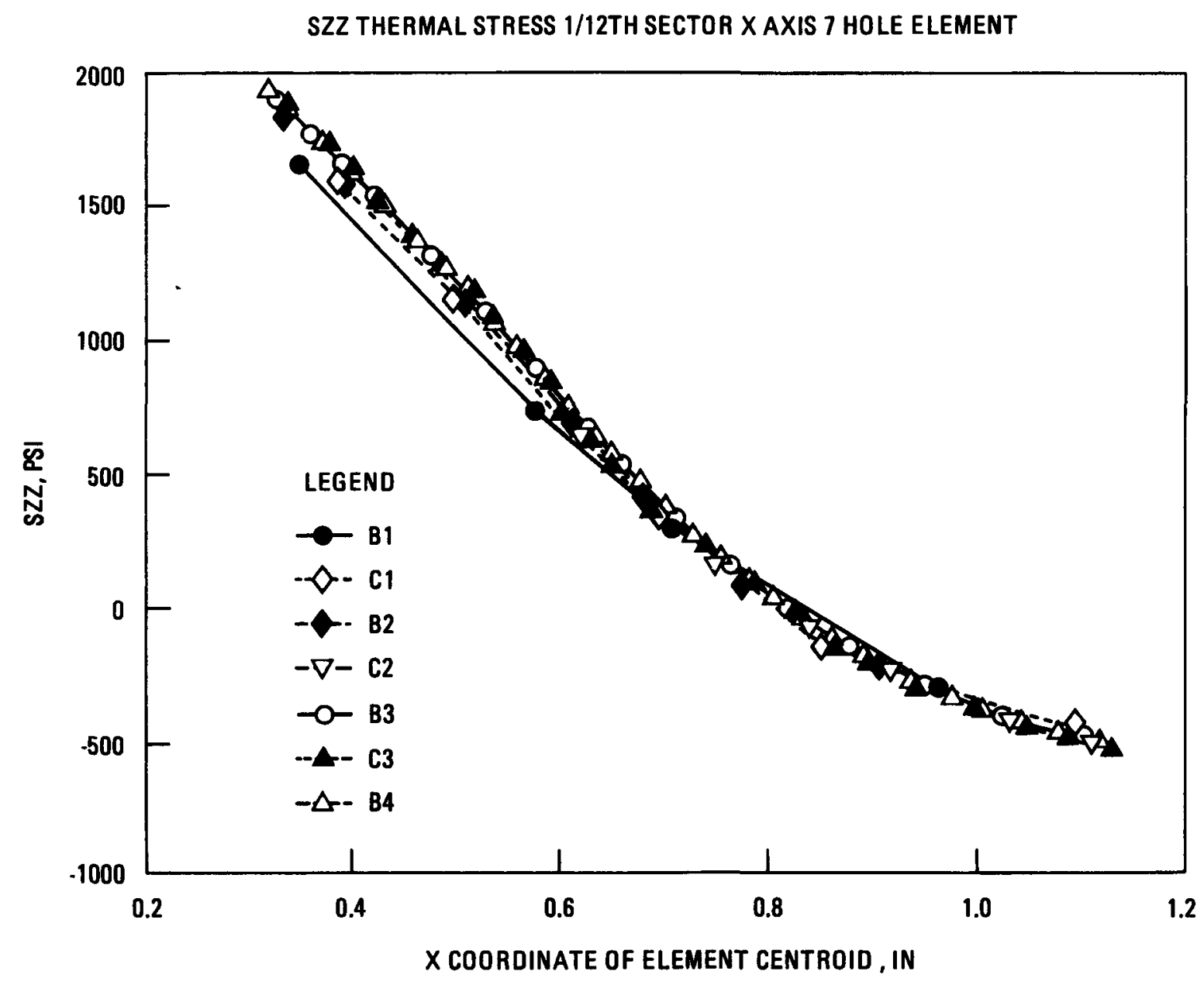

Fig. 23. SZZ stress along X-Axis (1/12th sector) 


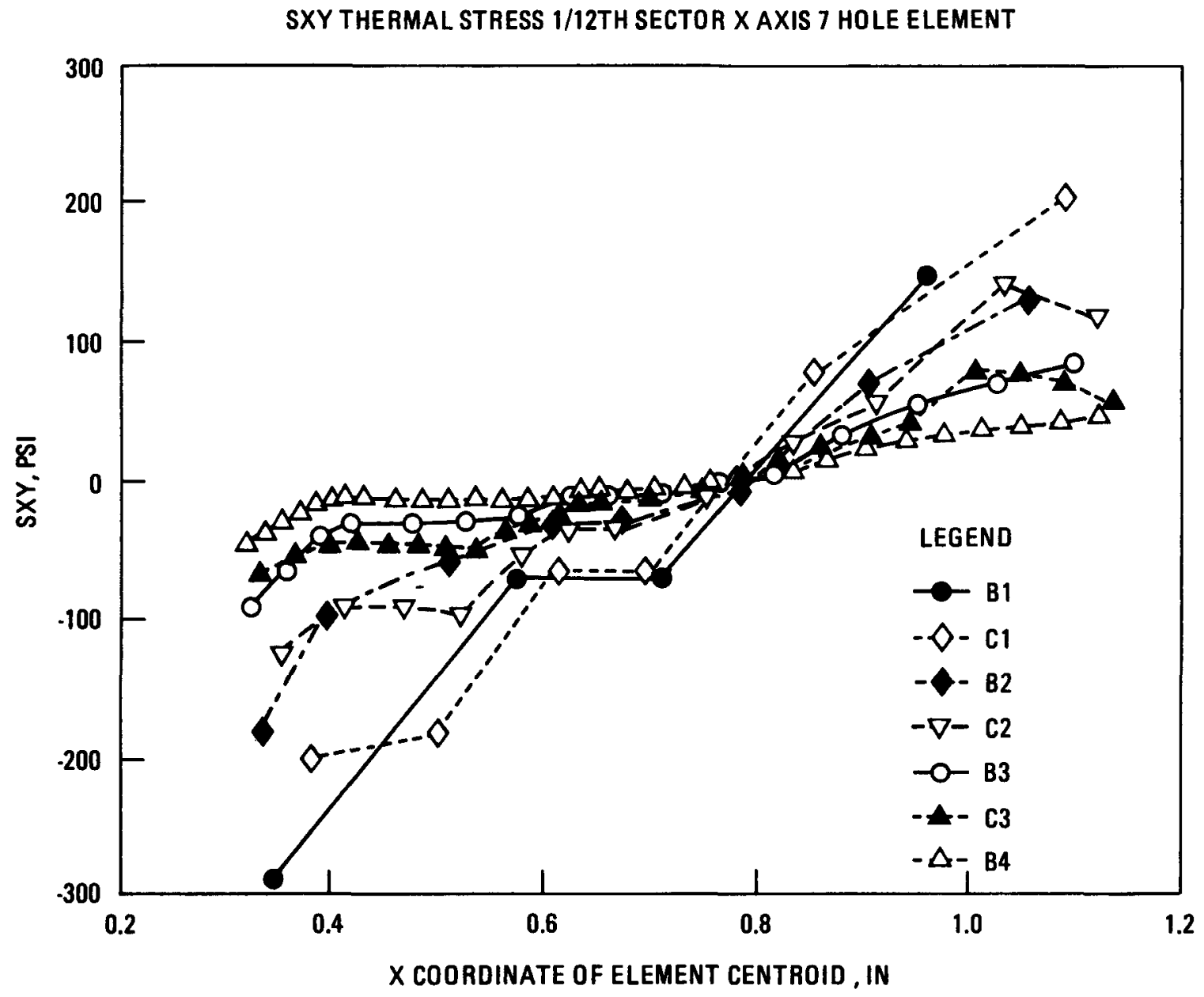

Fig. 24. SXY stress along $X$-Axis (1/12th sector) 
Finally, to provide perspective, all four stress components are plotted along the $\mathrm{x}$-axis for mesh level B4 in Figure 25.

To provide more insight to the stress field along the $30^{\circ}$ line of symmetry, the in-plane cartesian stress components SXX, SYY, and SXY may be transformed to the in-plane polar coordinate stress components SRR, STT, and SRT via the stress transformation laws (Reference 4). The radial stress component, SRR, should vanish at the hole boundaries and the STT stress component becomes the peak tensile hoop stress for the coolant hole and the peak compressive hoop stress for the fuel hole at radii of 0.31 inches and 0.99 inches, respectively, These components are shown in Figures 26 and 27 for all meshes and are seen to be strong functions of the radius. These figures illustrate the difficulty in accurate stress calculations without extremely fine meshes. Figure 28 shows the axial stress component, SZZ, for all meshes along this line of symmetry. Finally, for additional perspective, all four stress components are shown in Figure 29 along the upper boundary of the onetwelfth sector $\left(30^{\circ}\right.$ line plus fuel hole boundary) for mesh B4.

\subsection{ONE-HALF SECTOR MECHANICAL LOAD}

To assess the accuracy in predicting displacements and stresses under mechanical loading, a one-half sector of the seven hole element was used as the model. Two series of uniformly refined meshes were created by first successively flipping the one-twelfth sector meshes $B 1$ and $\mathrm{Cl}$ about their lines of symmetry (referred to as $\mathrm{HB} 1$ and $\mathrm{HCl}$, respectively) and then refining these two meshes. The most refined mesh, HC3, has 16 times the number of elements (2304) as mesh $\mathrm{HC1}$ (144) and about 38 times as many elements as mesh HB1 (60). In addition, local refinement of the center regions of $\mathrm{HBl}$ and $\mathrm{HCl}$ was used to create two series of embedded fine meshes. The center region of HB1 was also extracted and

thrice refined to obtain a series of extracted meshes. All these meshes are shown in Appendix A. 


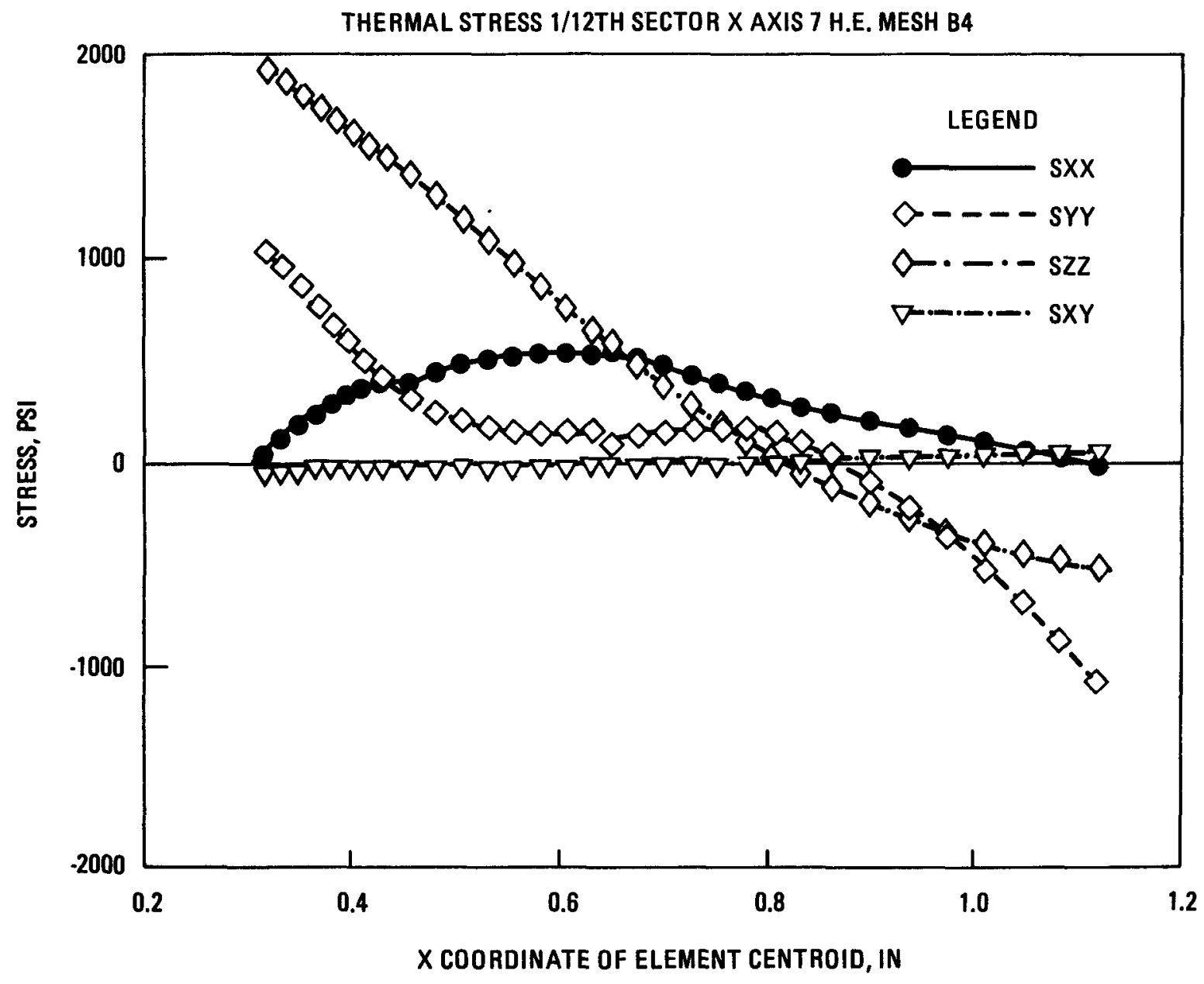

Fig. 25. Thermal stress along X-Axis (1/12th Sector - Mesh B4) 


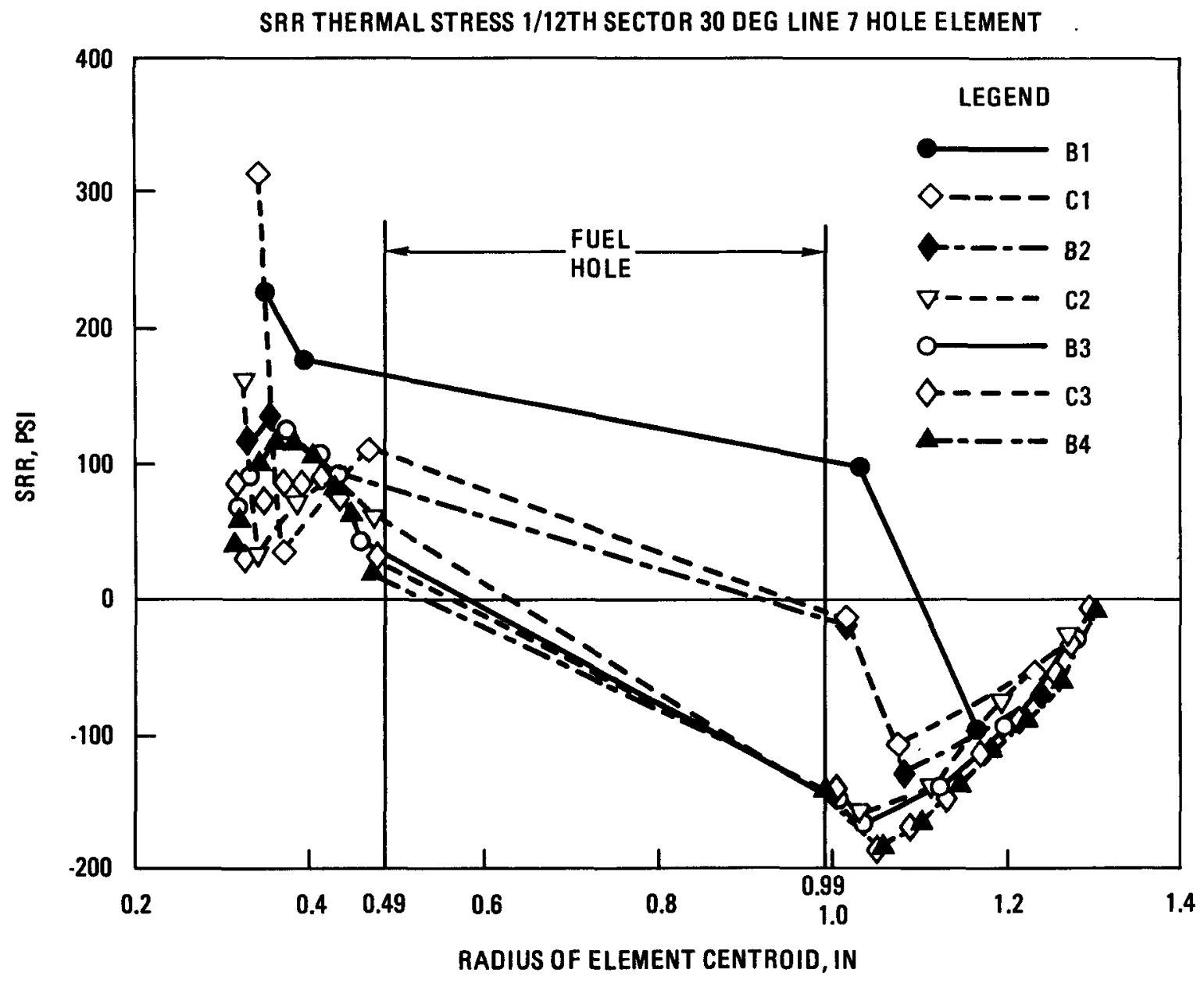

Fig. 26. SRR stress along thirty degree line of symmetry (1/12th sector) 


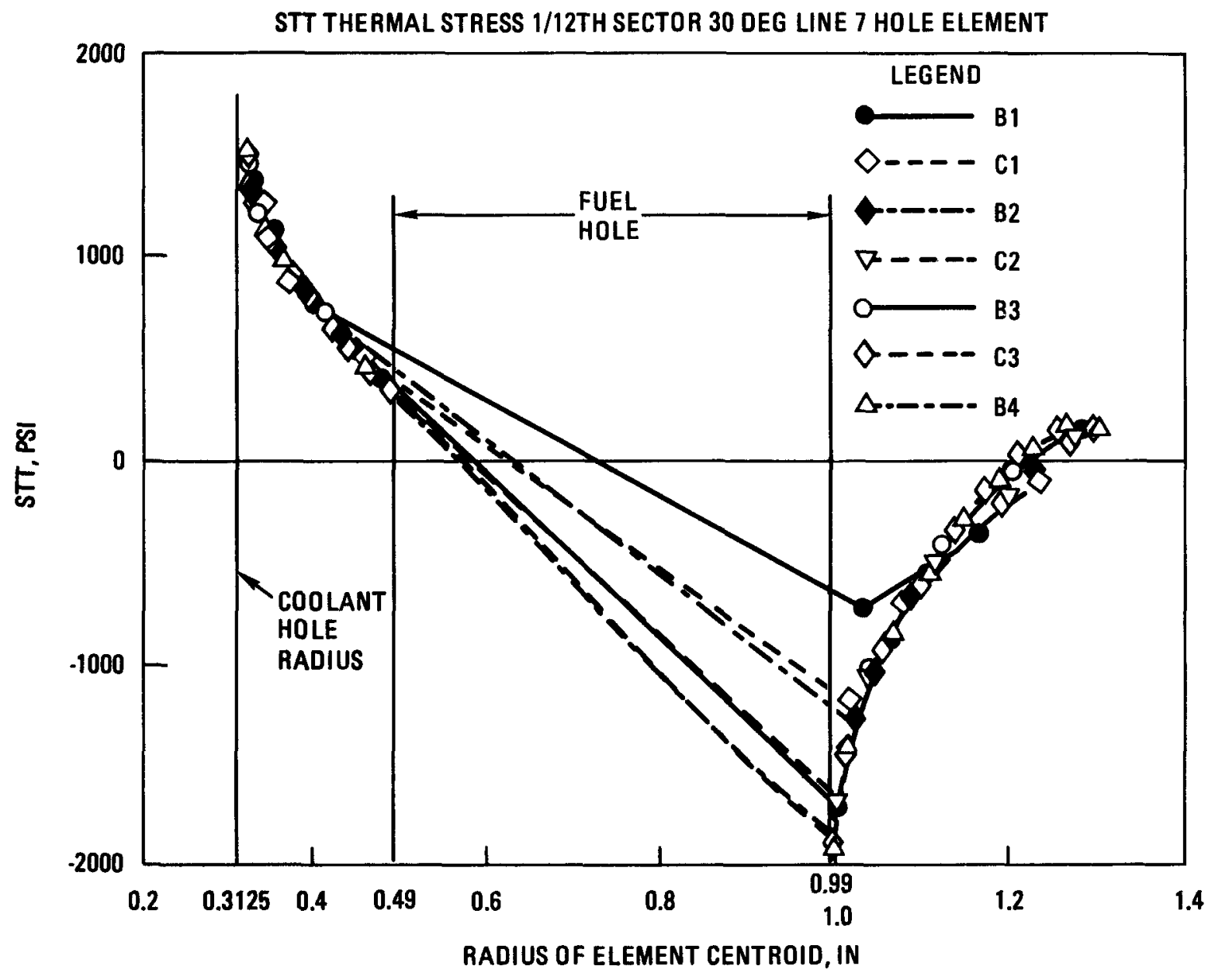

Fig. 27. STT stress along thirty degree line of symmetry (1/12th sector) 


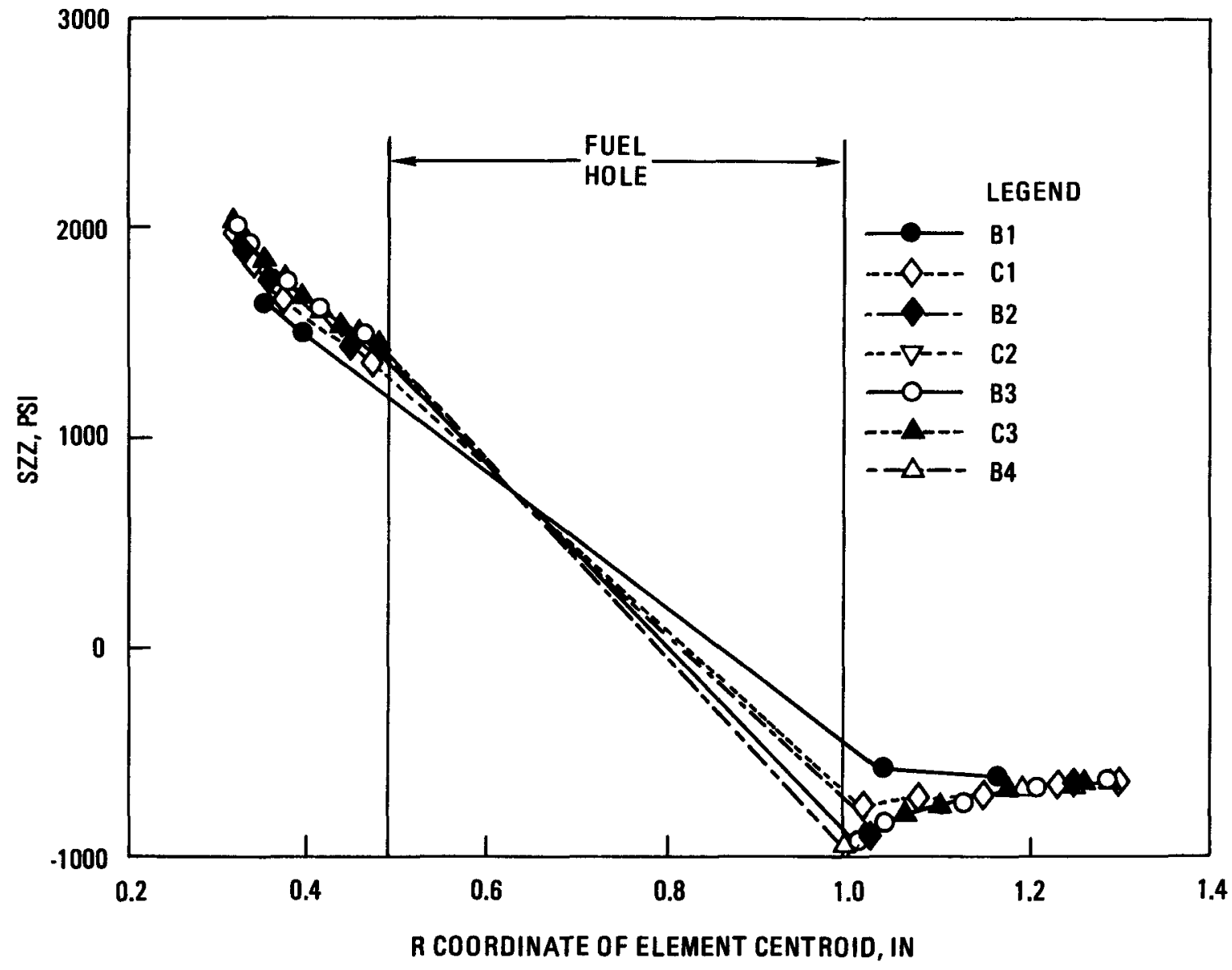

Fig. 28. SZZ stress along thirty degree line of symmetry (1/12th sector) 


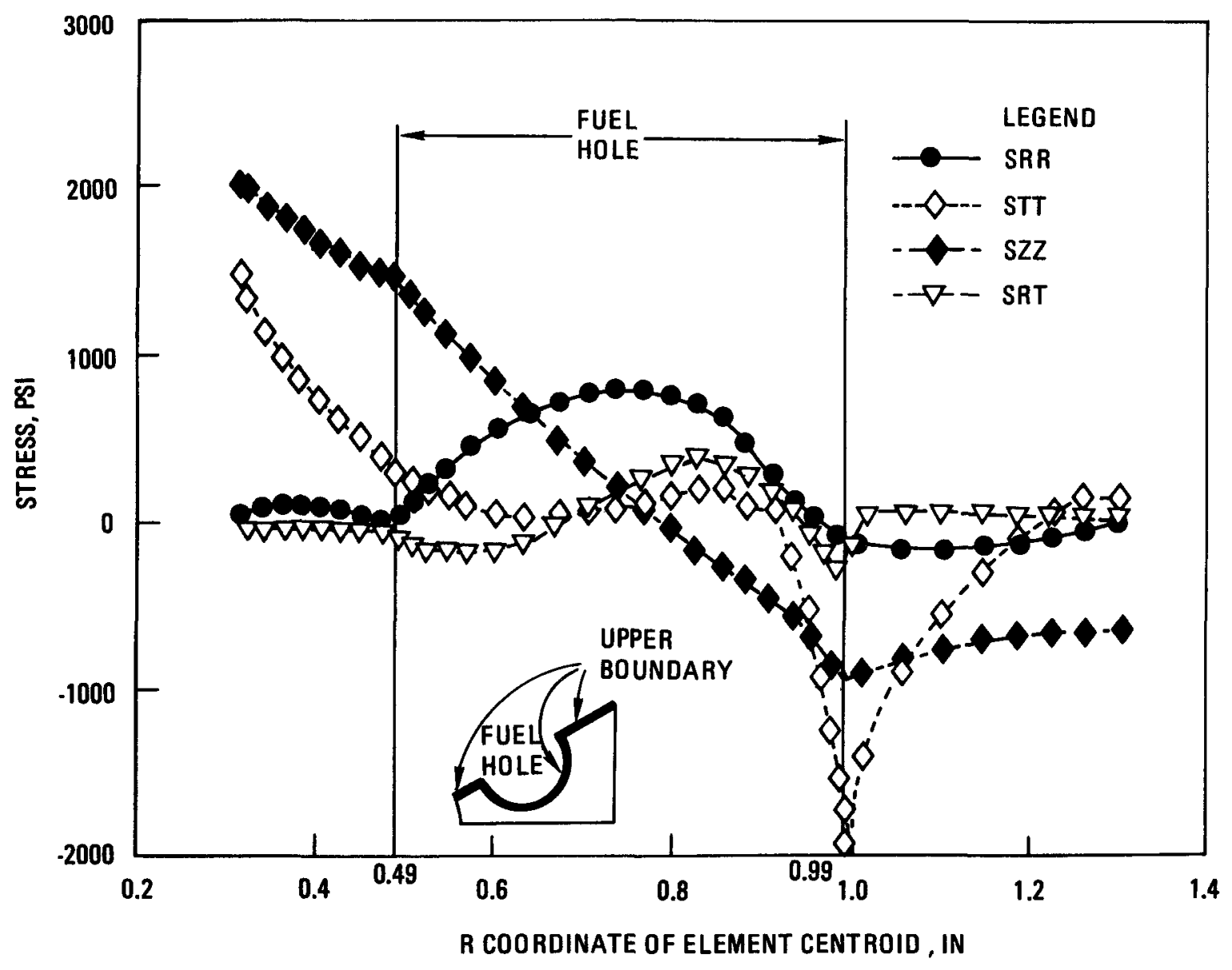

Fig. 29. Thermal stress along thirty degree line of symmetry (1/12th sector - Mesh B4) 
The loading, restraint, and symmetry conditions applicable to the half element analyses are shown in Figure 30 for mesh HCl. The load consisted of a uniform pressure of 100 psi on one face which is restrained on the opposite side by a rigid frictionless surface. In retrospect, a one-quarter element model with symmetrical loading would probably have sufficed for this study and allowed a finer mesh pattern. The SAFIRE code was used to find the resultant displacement and stress fields for all cases. The details of the analysis along with sample 1istings of data input and code output are presented in Appendix D.

The undeformed and deformed meshes for mesh HC3 under the 100 psi static pressure load are presented for comparison in Figures 31 and 32, respectively. The deformations in Figure 32 are 100 times true size. Contour plots of the in-plane stress components, SXX, SYY, and SXY are shown in Figures 33, 34, and 35, respectively. The peak in-plane tensile stress is the SYY (hoop) stress that occurs at the surface of the center coolant hole on the $x$-axis as shown in Figure 34. Peak values for the inplane compressive stresses are also hoop stresses that occur on both coolant and fuel holes. These are also shown in Figure 34. For additional insight to the stress field, the values of the three in-plane stress components for mesh HC3 along the positive x-axis are shown in Figure 36 .

This displacement in the $\mathrm{x}$ direction, DELX, along the $\mathrm{x}$-axis is shown in Figure 37 for the six uniformly refined meshes (URM) HB1, HC1, etc. The displacement along this axis in the $\mathrm{Y}$ direction is, of course, zero since this is a line of structural symmetry. The stress component, SYY, along the $x$-axis for these same six meshes is shown in Figure 38 . This stress becomes the hoop stress at the edge of the center hole, and Figure 38 illustrates its highly peaked nature and consequent poor evaluation with coarse mesh analyses. The hoop stress around the center hole may be found via the stress transformation laws from cartesian to polar coordinates. The STT or hoop stress component versus 


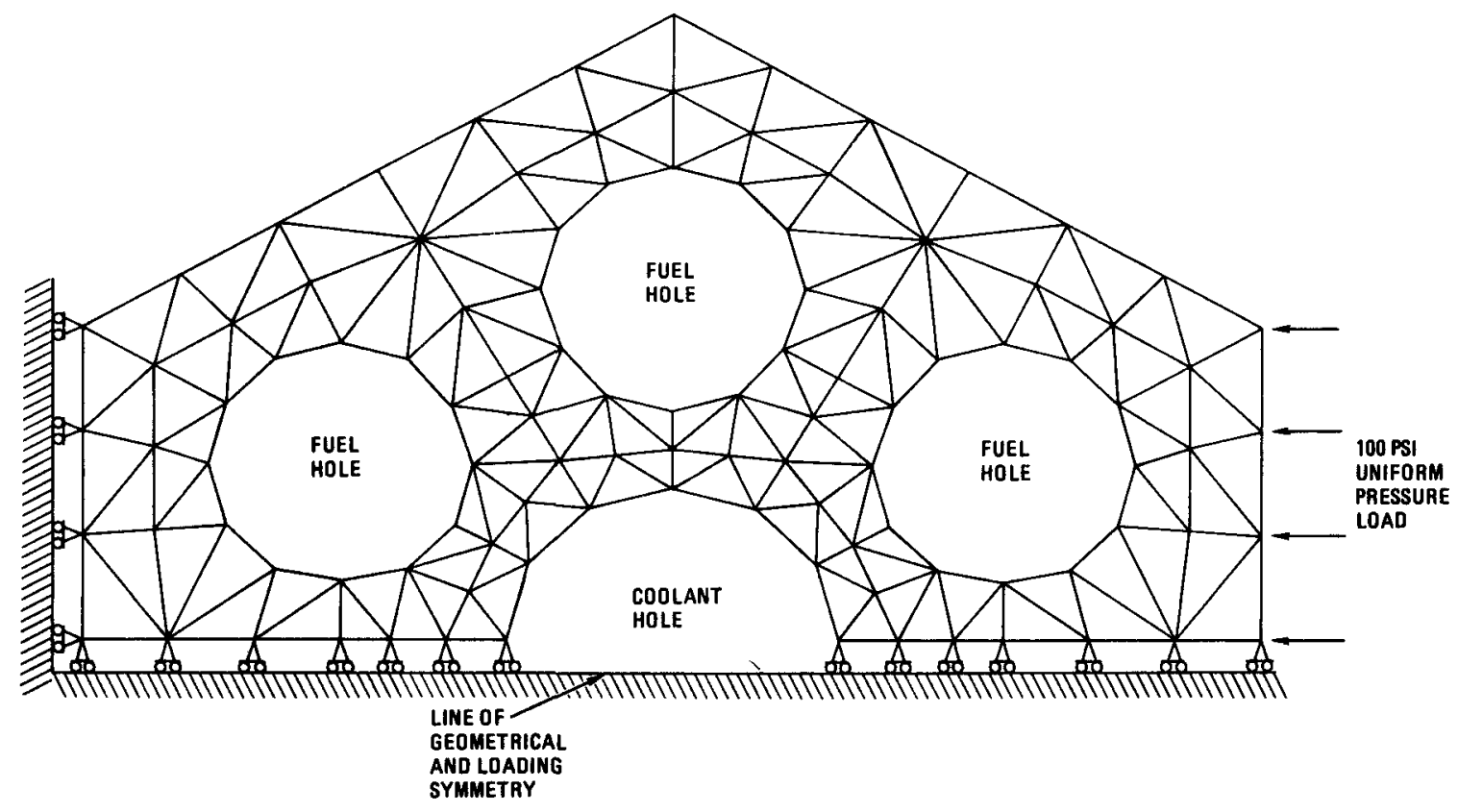

Fig. 30. One half seven hole element (Mesh HCl) 


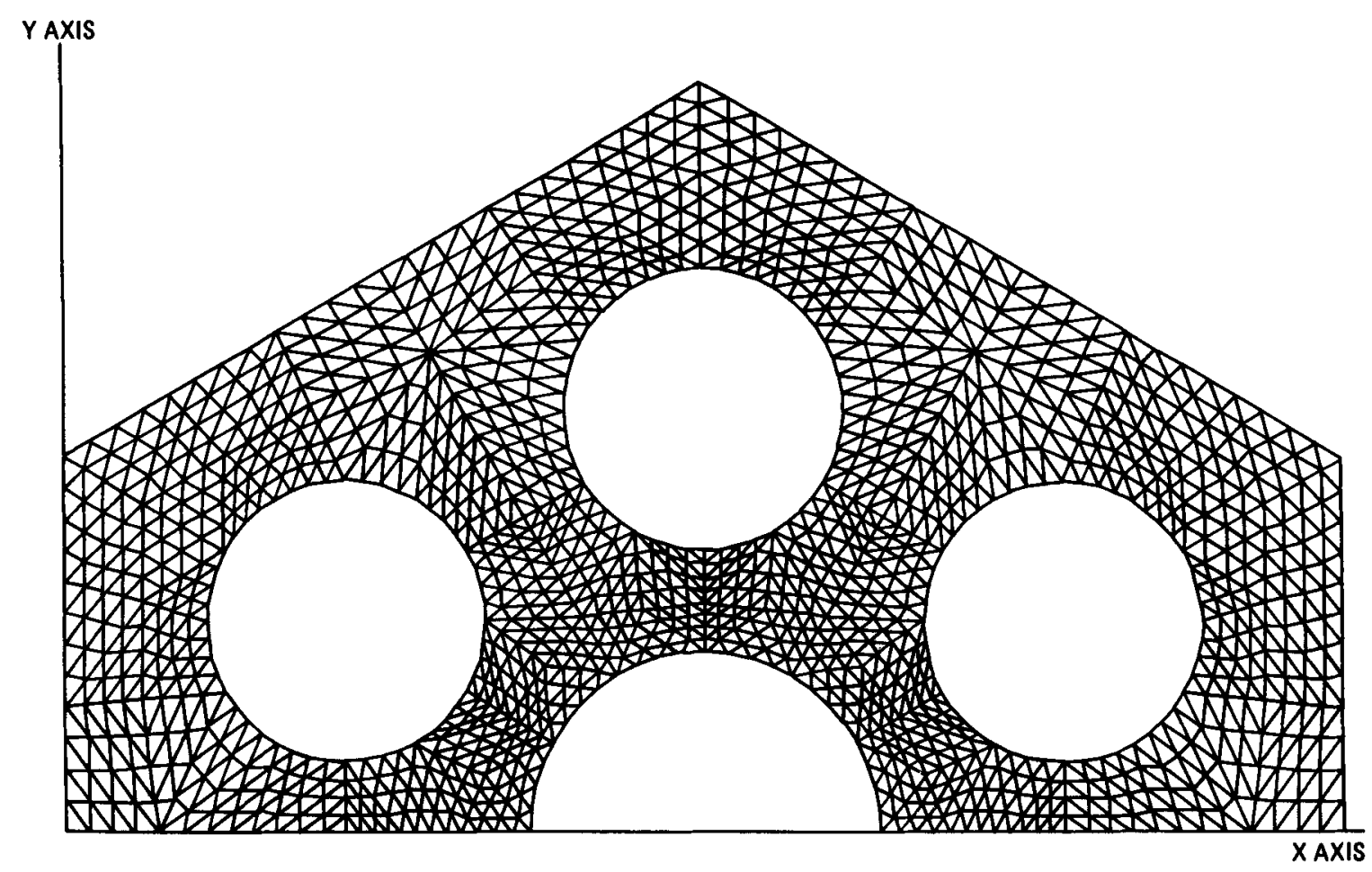

Fig. 31. Finite element grid (1/2 element - Mesh HC3) 


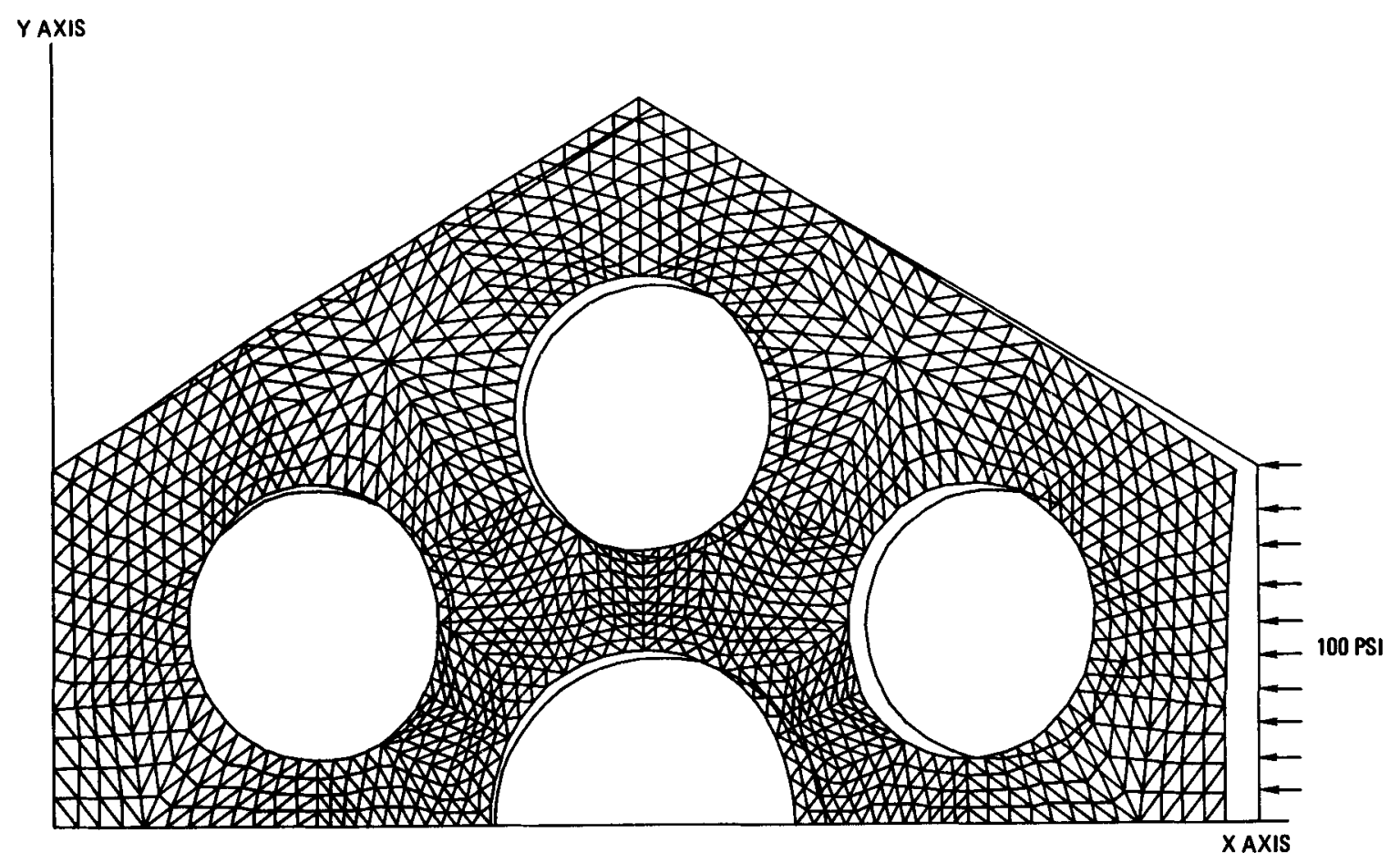

Fig. 32. Deformation field ( $100 \times$ true size) of one-half element under 100 PSI load (Mesh HC3) 


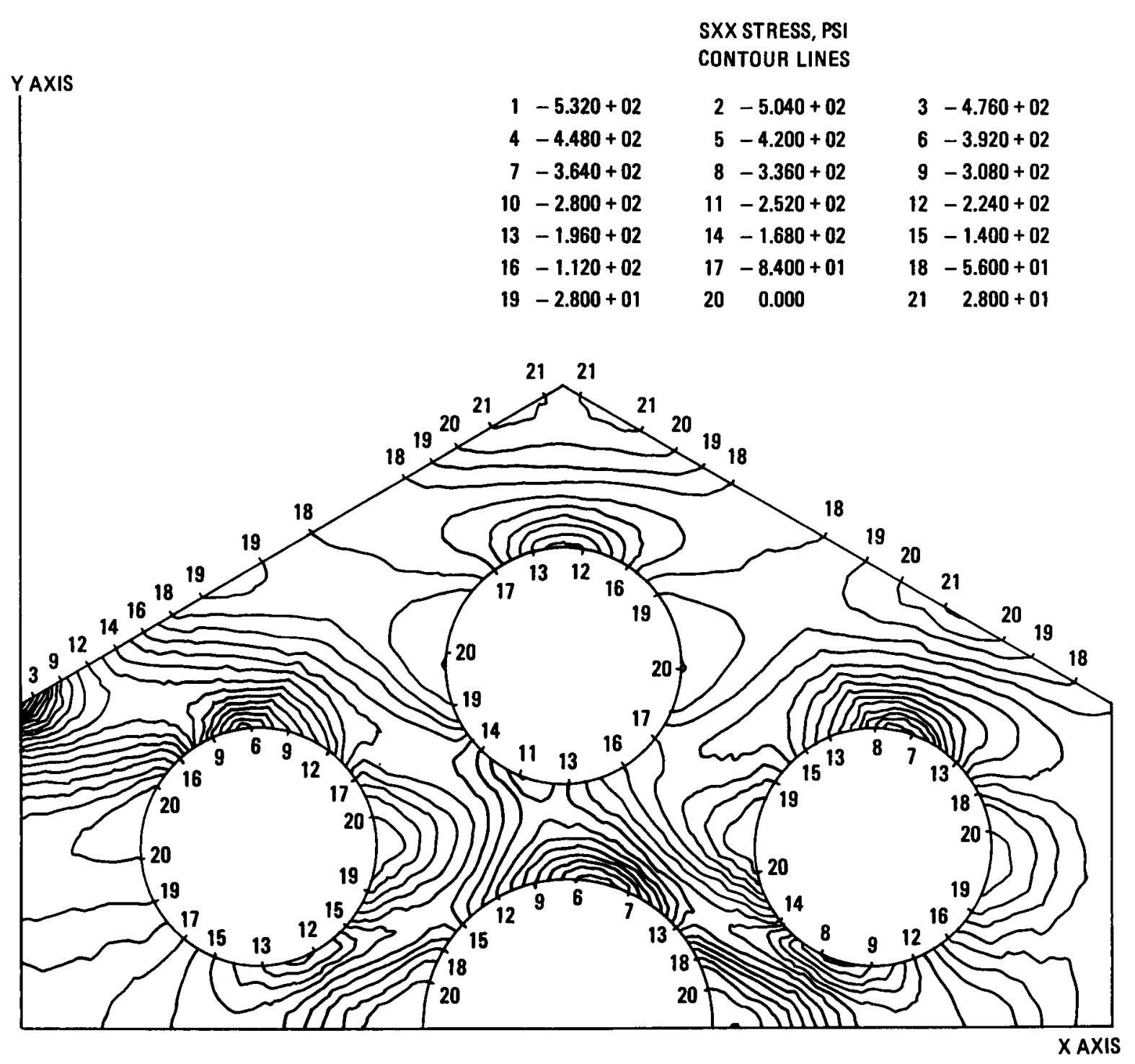

Fig. 33. SXX stress ( $1 / 2$ element) 


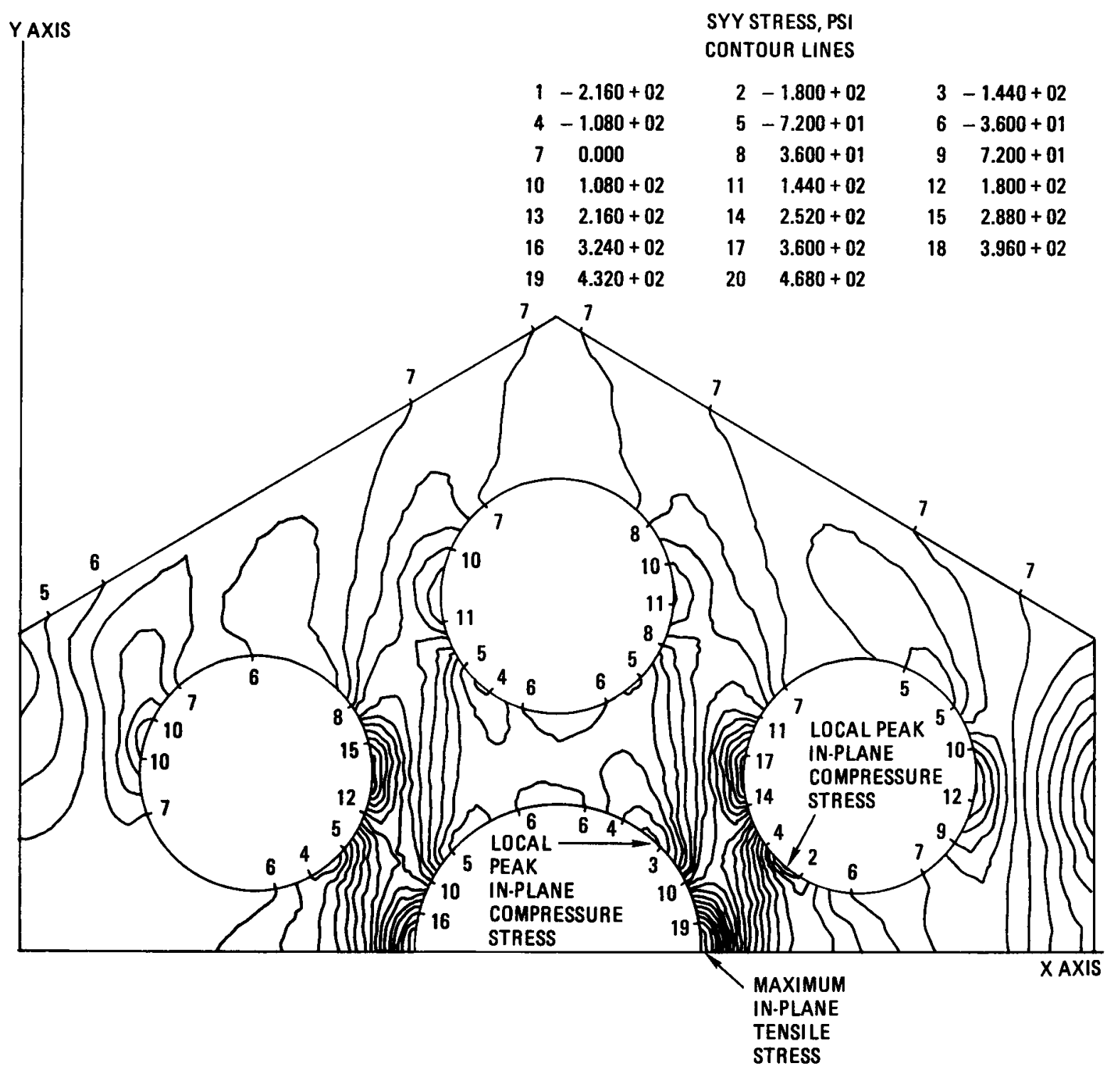

Fig. 34. SYY stress ( $1 / 2$ element) 


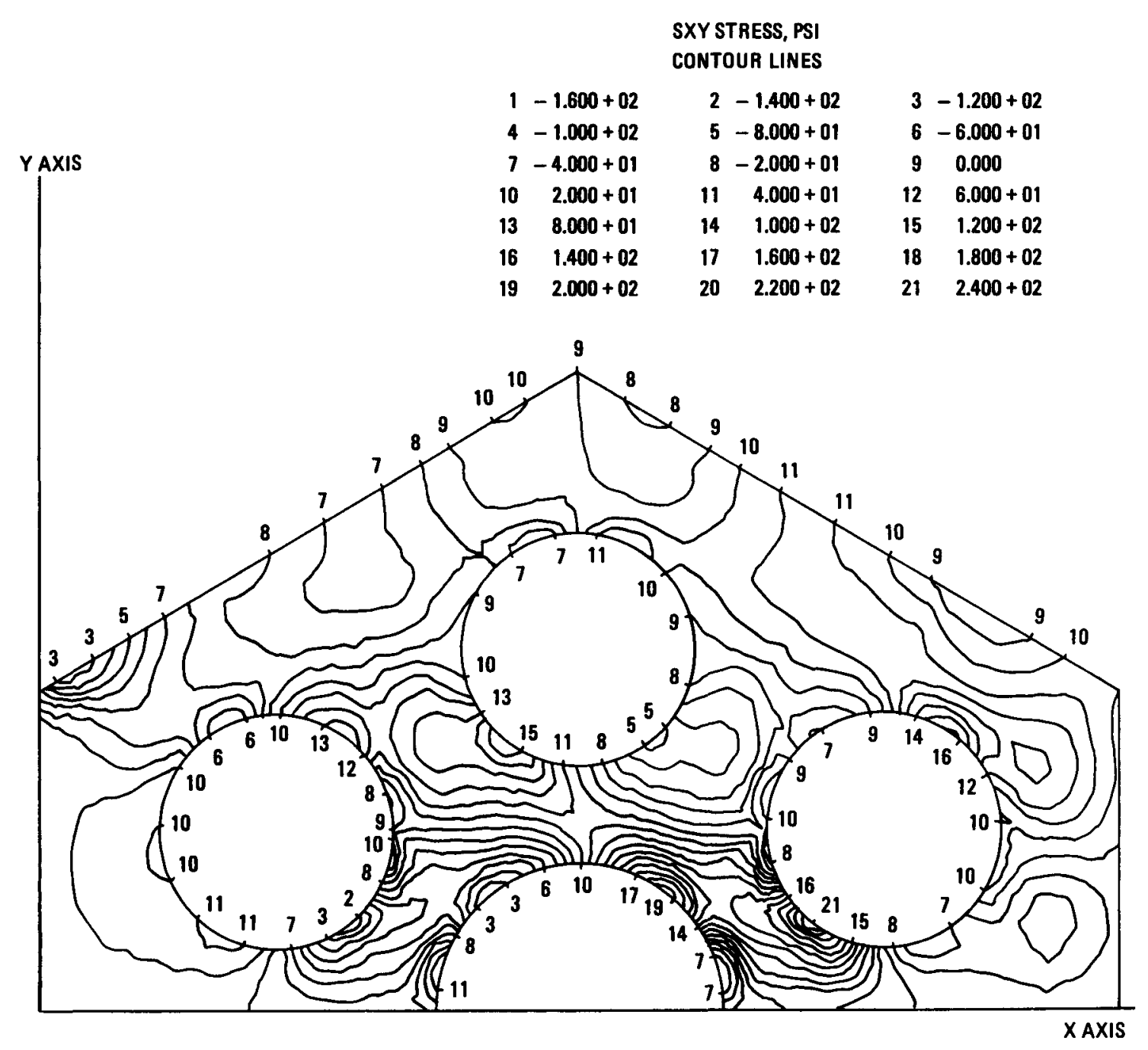

Fig. 35. SXY stress (1/2 element) 


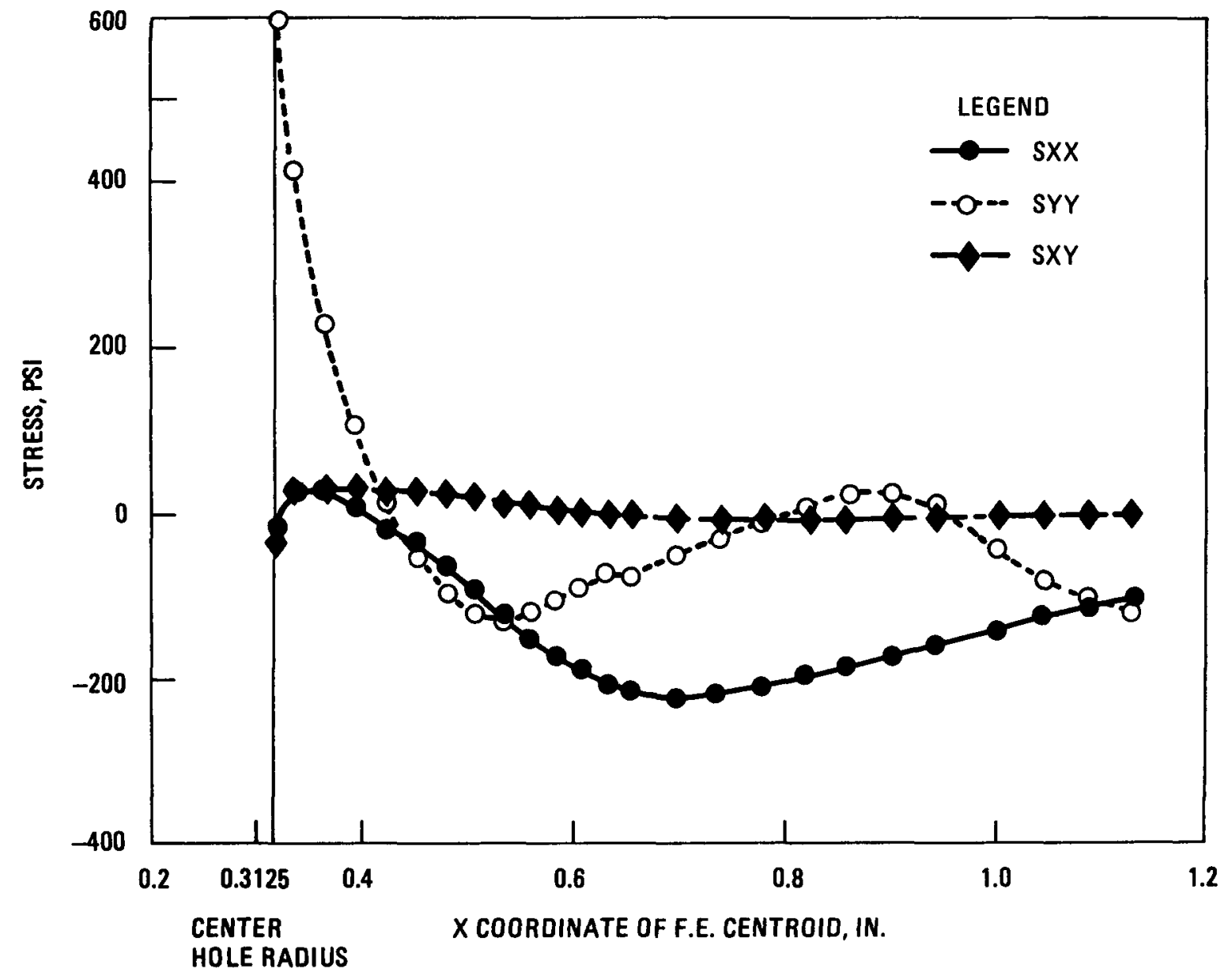

Fig. 36. Stresses along X-Axis for 100 PSI load ( $1 / 2$ element) 


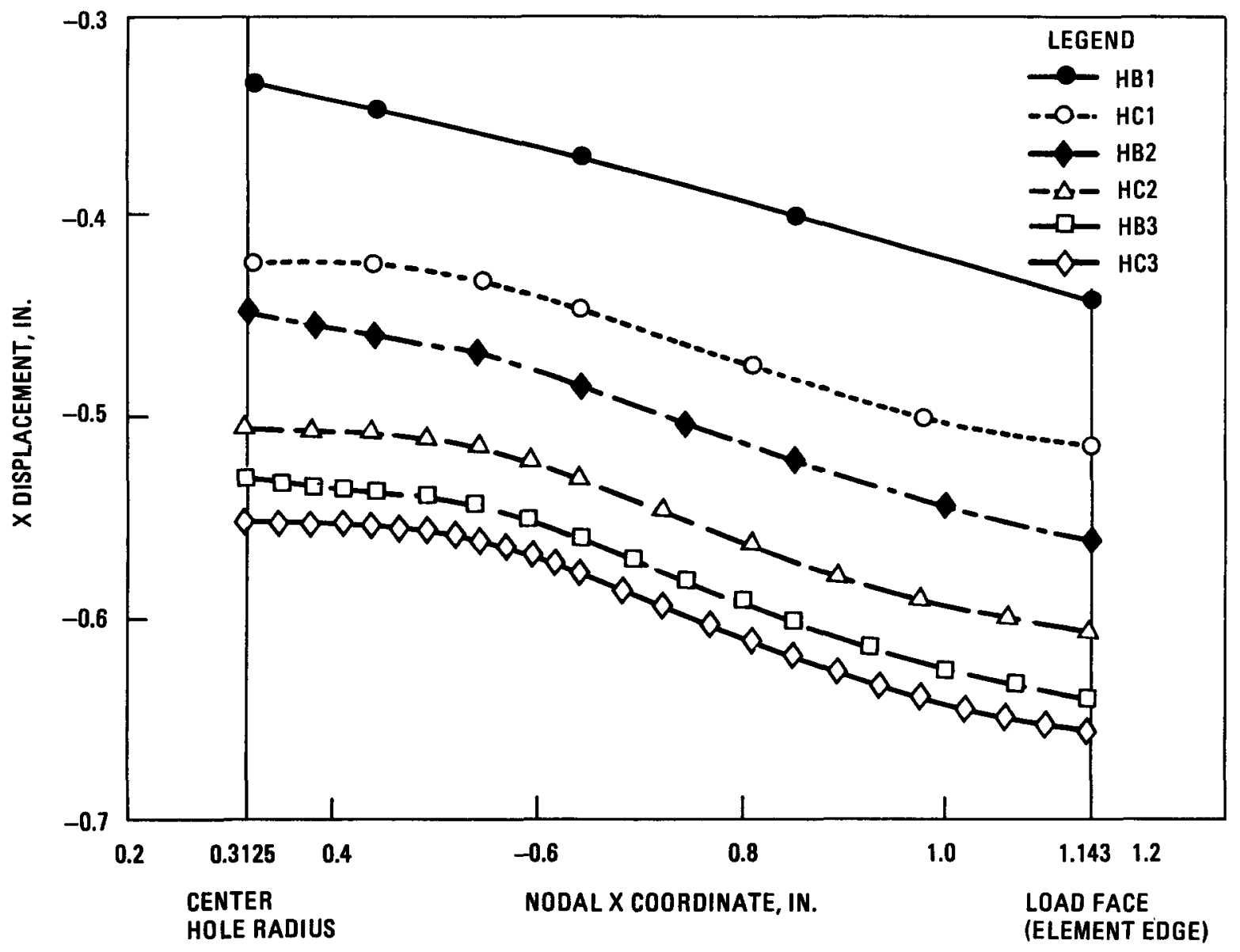

Fig. 37. Displacement along X-Axis for 100 PSI load ( $1 / 2$ element) 


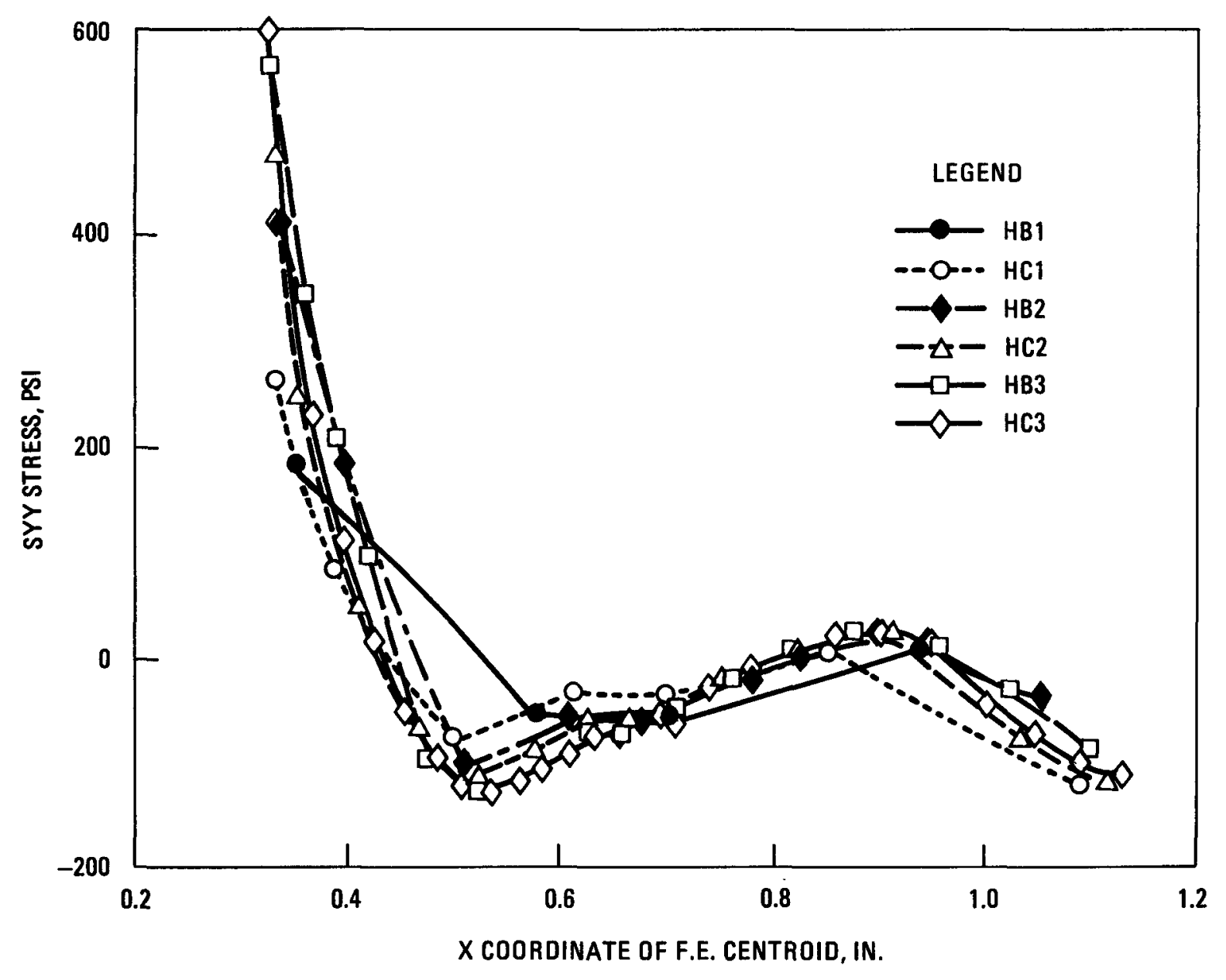

Fig. 38. SYY stress along X-Axis for 100 PSI load ( $1 / 2$ element) 
angular coordinate, $\theta$, for the positive $\mathrm{X}, \mathrm{Y}$ quadrant is shown in Figure 39 as calculated using the six meshes.

The percent error in the peak tensile hoop stress and in the $x$ displacements for the points on the $x$-axis at the load face (LF) and at the coolant hole $(\mathrm{CH})$ edge, relative to the HC3 values, are shown in Figure 40 for all six meshes. As this figure 1llustrates, the coarsest mesh, $\mathrm{HB} 1$, underpredicts the peak tensile stress by about sixty-six percent while underpredicting the $x$ displacement at the same location by about thirty-nine percent. In Figure 41, the ratio of the peak stress predicted by each mesh relative to that by HC3 is plotted versus the ratio of the $x$ displacement prediction relative to that from HC3. When allowance is taken for the differences between the HB and HC mesh patterns, two straight lines result. The cause of this linearity is not obvious but may relate in a general way to the load/deflection relation for a linear elastic spring.

The peak in-plane tensile stress predicted by the series of uniformly refined meshes (URM) HB1, HC1, etc., is shown in Figure 42. As indicated in this figure, the solution probably has not converged but for purposes of this study, mesh HC3 was taken as the reference case. Also indicated in this figure is the peak tensile stress as calculated using the so-called embedded meshes which have local refinement of the center regions of the $\mathrm{HB}$ series of meshes (HB1EMB1, HB2EMB2, etc.) and the peak stress as calculated using the extracted and refined meshes (HB1EXT1, HB2EXT2, etc).

As Figure 42 illustrates, the embedded mesh concept can provide a means of obtaining relatively accurate results with far fewer elements and less expense, e.g. the embedded mesh HB2EMB2 calculates over ninety percent of the peak stress predicted by mesh HC3 but has only twenty-three 


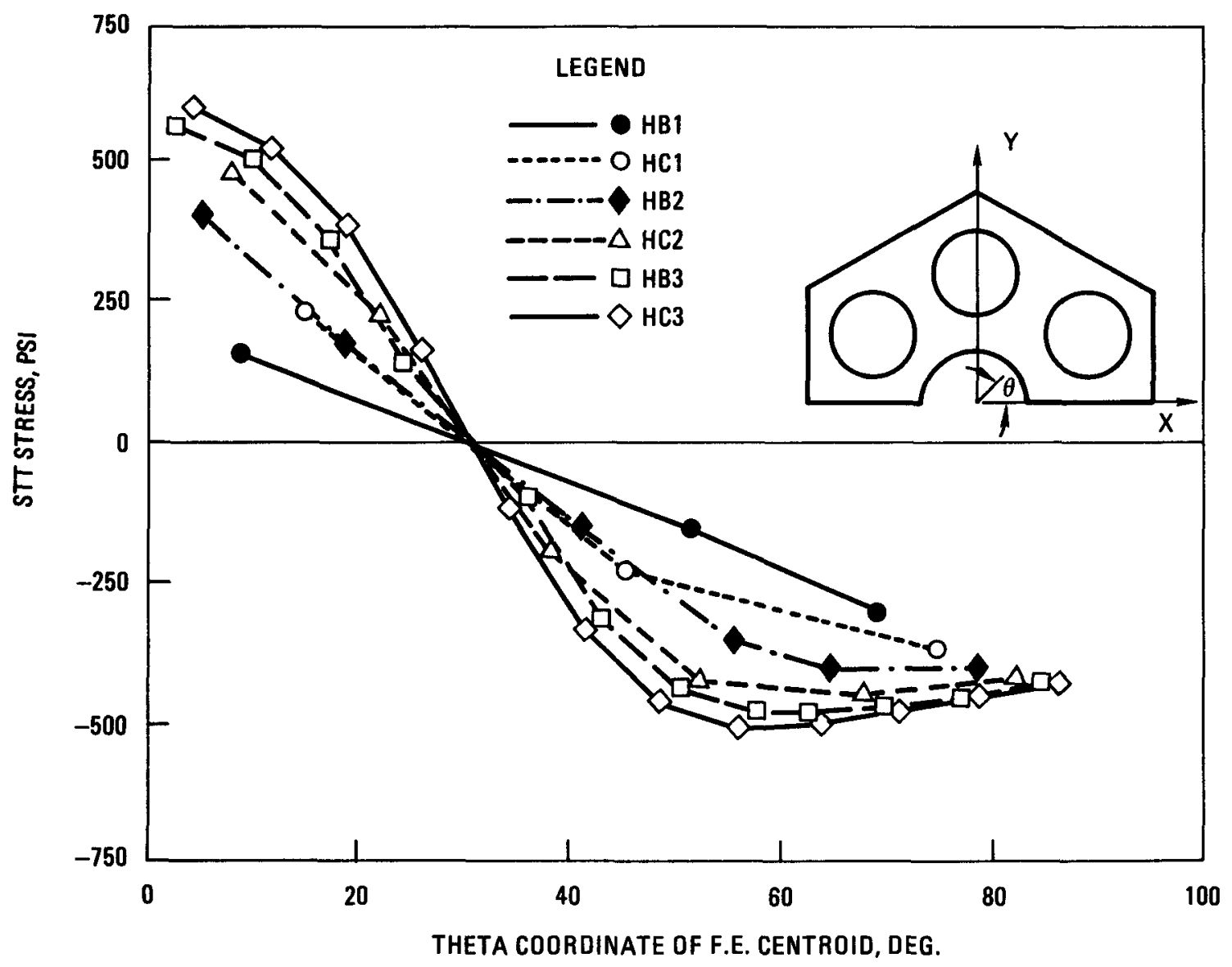

Fig. 39. STT (Hoop) stress around center hole for 100 PSI load ( $1 / 2$ element) 


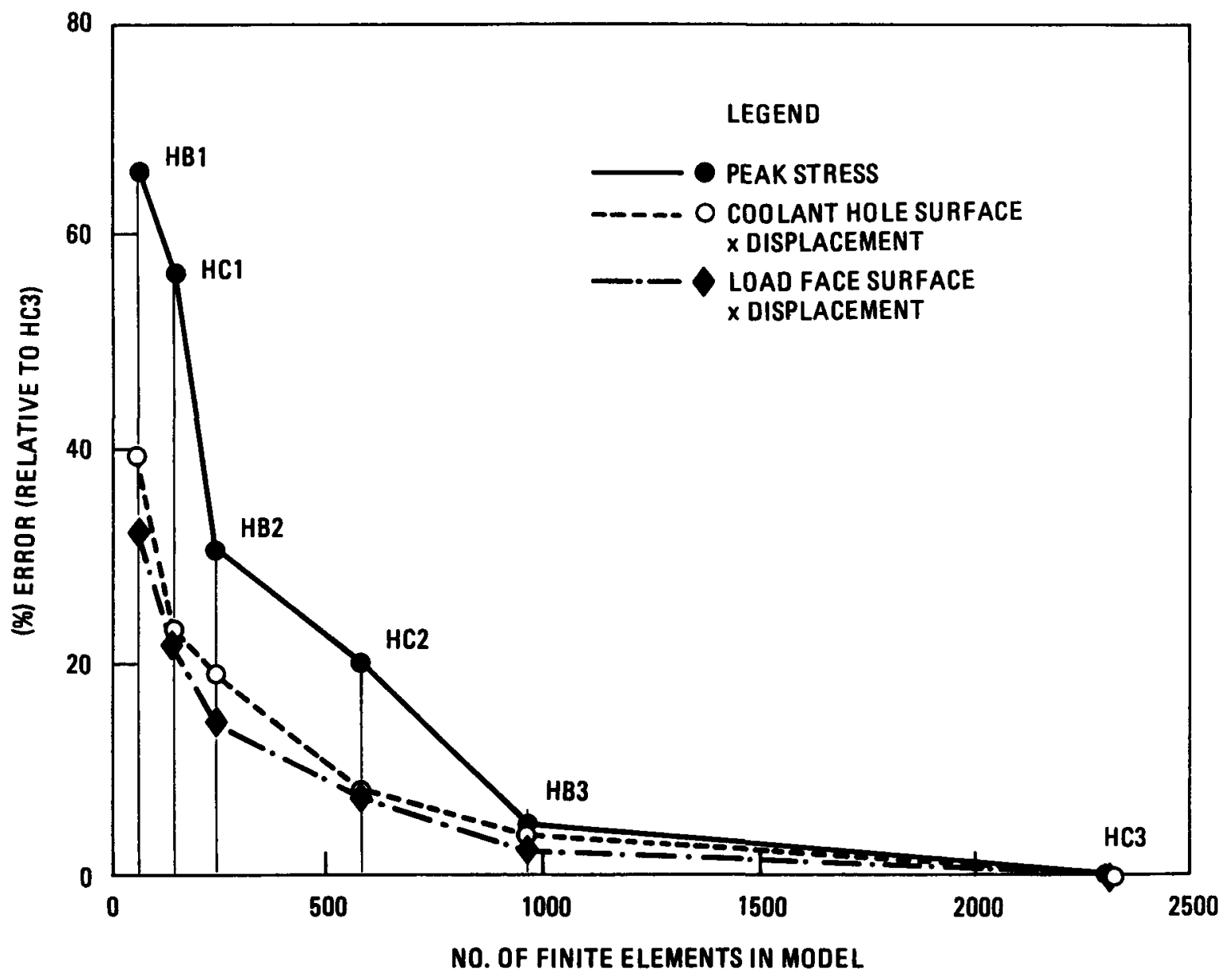

Fig. 40. Percent error in peak stress and displacements for 100 PSI load $(1 / 2$ element) 


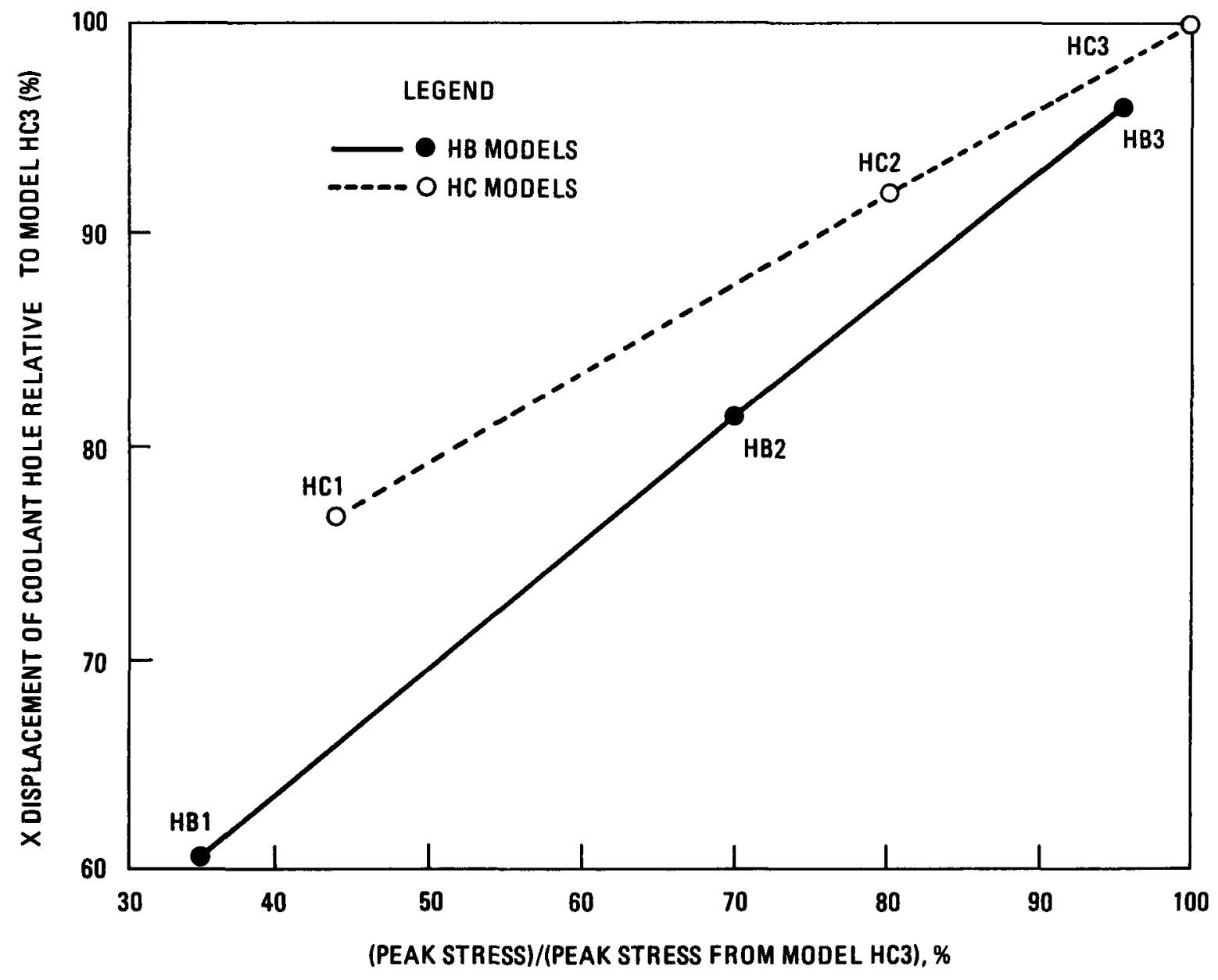

Fig. 41. Percent error - peak stress vs Y displacement for 100 PSI load ( $1 / 2$ element) 


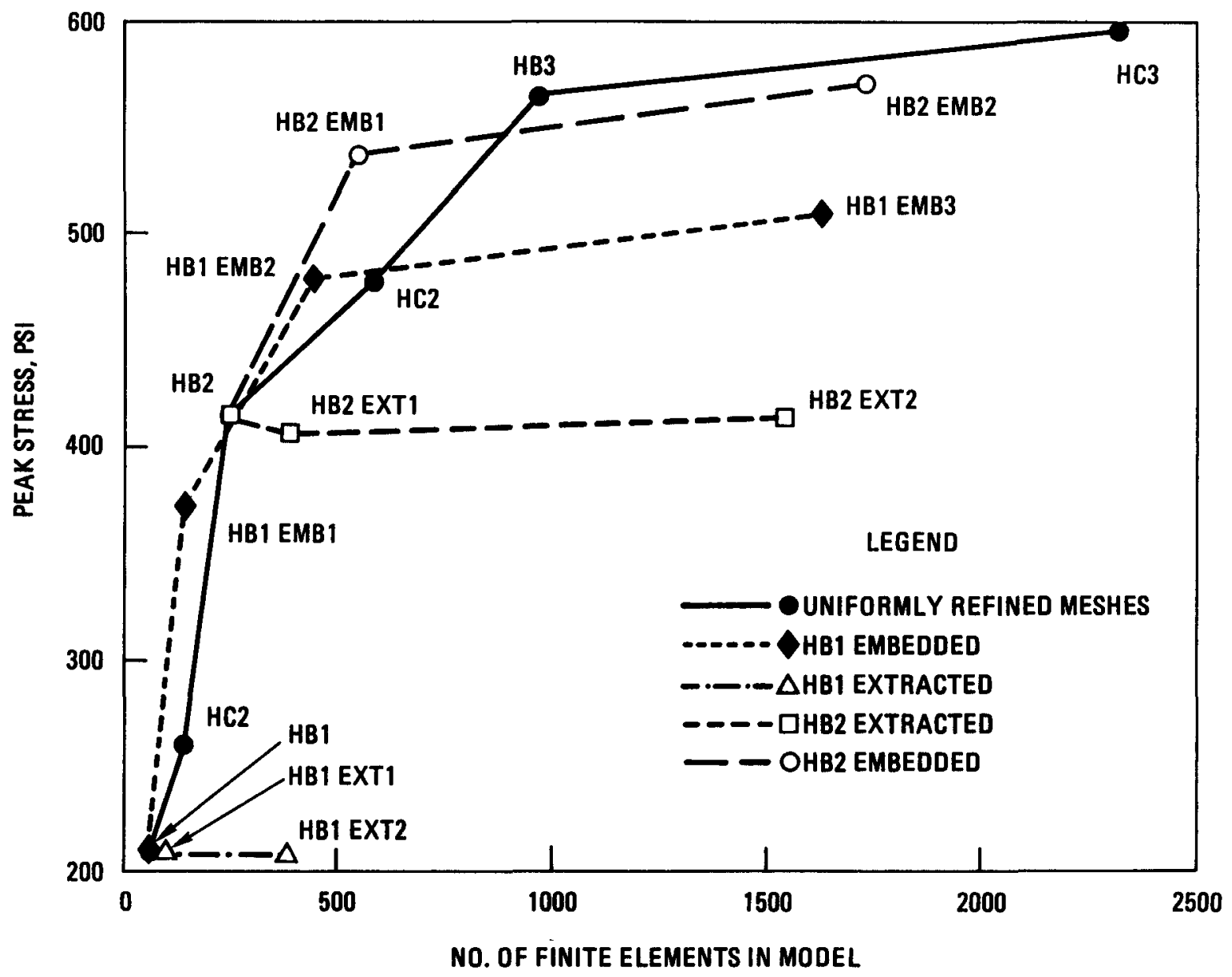

Fig. 42. Peak stress for 100 PSI load for all one half element meshes 
percent as many finite elements. The difficulty in using the method occurs in assessing its accuracy which depends both upon the ratio of embedded to total area and upon the fineness of mesh outside and inside the embedded region. The latter effect is indicated by the curves for $\mathrm{HB} 1 \mathrm{EMB}$ and $\mathrm{HB} 2 \mathrm{EMB}$. The embedded to total area ratio in this study was about 0.23 for all cases. Accuracy would improve as this ratio approaches unity.

Finally, the curves for HBLEXT and HB2EXT indicate that the solutions using the extraction technique as currently formulated depend greatly upon the accuracy of the overall coarse mesh displacement field from which the displacement boundary conditions for the extracted mesh analyses are derived. 
TABLE 1

ONE-TWELTH SECTOR ANALYSIS ACCURACY RESULTS

\begin{tabular}{lccrcccc} 
& & \multicolumn{7}{c}{$\begin{array}{c}\text { Error (\%) } \\
\text { Mode1 }\end{array}$} & $\begin{array}{c}\text { No. of } \\
\text { Elements }\end{array}$ & $\begin{array}{l}\text { No. of } \\
\text { Nodes }\end{array}$ & $\begin{array}{r}\Delta \mathbf{T}_{\max } \\
\text { Peak In-P1ane Stress }\end{array}$ & \multicolumn{2}{c}{ Peak Axial Stress } \\
B1 & 10 & 12 & -10.6 & -21.1 & -62.0 & -18.5 & -41.5 \\
C1 & 24 & 23 & -5.6 & -15.9 & -37.9 & -10.3 & -22.9 \\
B2 & 40 & 33 & -3.4 & -7.1 & -33.2 & -6.3 & -18.5 \\
C2 & 96 & 69 & -1.4 & -6.9 & -13.1 & -3.6 & -6.4 \\
B3 & 160 & 105 & -0.7 & -2.1 & -10.9 & -1.6 & -4.9 \\
C3 & 384 & 233 & -0.1 & -2.0 & -1.0 & -0.9 & -0.3 \\
B4 & 640 & 369 & 0 & 0 & 0 & 0 & 0
\end{tabular}

Notes: (1) Minus (-) sign Indicates under prediction. 
TABLE 2

ONE HALF ELEMENT ANALYSIS ACCURACY RESULTS 100 PSI LOAD

$\begin{array}{lcccc}\text { Mode1 } & \begin{array}{c}\text { Number } \\ \text { of } \\ \text { Elements }\end{array} & \begin{array}{c}\text { Number } \\ \text { of } \\ \text { Nodes }\end{array} & \begin{array}{c}\text { Error (\%) (1)(2) } \\ \text { Disp1acement } \\ \text { Along X Axis } \\ \text { At Center Hole }\end{array} & \begin{array}{c}\text { Peak } \\ \text { Stress }\end{array} \\ \text { HB1 } & 60 & 50 & 39.3 & 64.9 \\ \text { HB1 EXT1 } & 96 & 71 & 39.4 & 64.9 \\ \text { HB1EMB1 } & 138 & 97 & 25.6 & 37.5 \\ \text { HC1 } & 144 & 106 & 23.4 & 56.2 \\ \text { HB2 } & 240 & 162 & 18.8 & 30.4 \\ \text { HB1EXT2 } & 384 & 237 & 39.5 & 65.1 \\ \text { HB2EXT1 } & 384 & 237 & 18.9 & 31.9 \\ \text { HB1 EMB2 } & 438 & 263 & 17.0 & 19.6 \\ \text { HB2EMB1 } & 540 & 328 & 9.1 & 9.7 \\ \text { HC2 } & 576 & 358 & 8.3 & 20.0 \\ \text { HB3 } & 960 & 556 & 4.1 & 5.0 \\ \text { HB2EXT2 } & 1536 & 857 & 19.0 & 30.6 \\ \text { HB1 EMB3 } & 1614 & 883 & 14.2 & 14.7 \\ \text { HB2EMB2 } & 1716 & 948 & 5.9 & 4.2 \\ \text { HC3 } & 2304 & 1294 & 0 & 0\end{array}$

Notes: (1) Percent error is relative to HC3 values.

(2) All values are under predictions. 


\section{REFERENCES}

1. Tzung, F., and C. Charman, "TEPC-2D A User's Manual for the Two Dimensional Finite Element Computer Program for Therma1Elastic-Plastic-Creep Analysis," Gulf- GA-A-A12753, November 7, 1973 .

2. Plaehn, M.H., D. Pelessone, and P.D. Smith, "REFINE, A Computer Program to Locally Refine Triangular Finite Element Meshes," Doc. No. 904423/1, November, 1979.

3. Tang, P.Y., and P.D. Smith, "SAFIRE A Two Dimensional Computer Program for the Viscoelastic/Cracking Analysis of Graphite Structures: Part 1 - User's Manual," GA-Al4652, September, 1977.

4. Huges, W.F., and E.W. Gaylord, Basic Equations of Engineering Science, Schaum's Outline Series, McGraw-Hill Co., New York, 1964, pp 87-88.

5. Zienkiewicz, O.C., The Finite Element Method in Engineering Science, McGraw-Hill Co., London, 1971. 
APPENDIX A

FINITE ELEMENT MESHES

Figs. A1 through A7 show the finite element meshes used for the onetwelfth sector thermal and stress analyses. Figs. A8 through A21 show the meshes used for the one-half element mechanical load analysis. The total area is preserved in all refinements for both the one-twelfth sector and the one-half element meshes. 


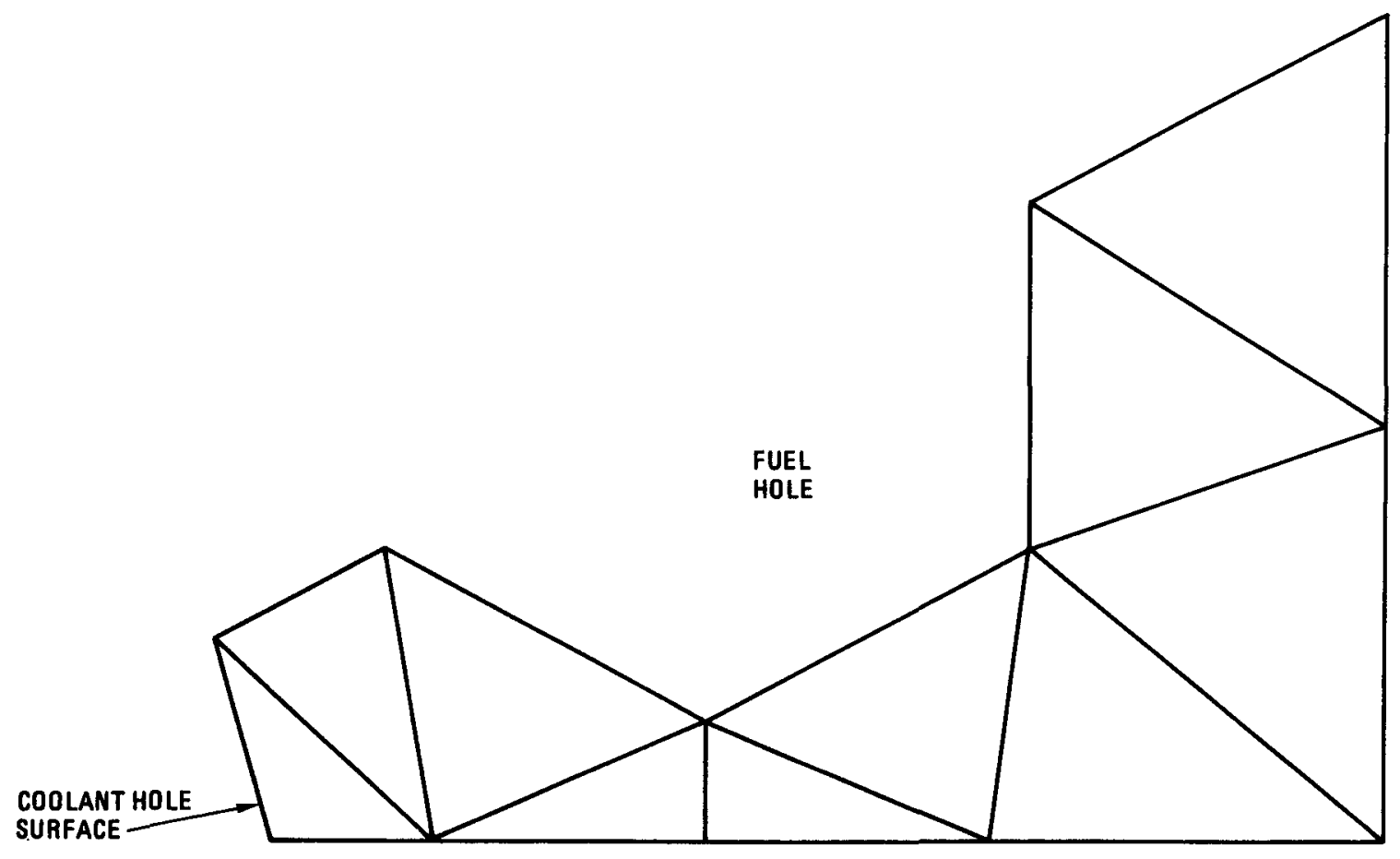

Fig. Al. One twelfth sector of seven hole element (Mesh B1) 


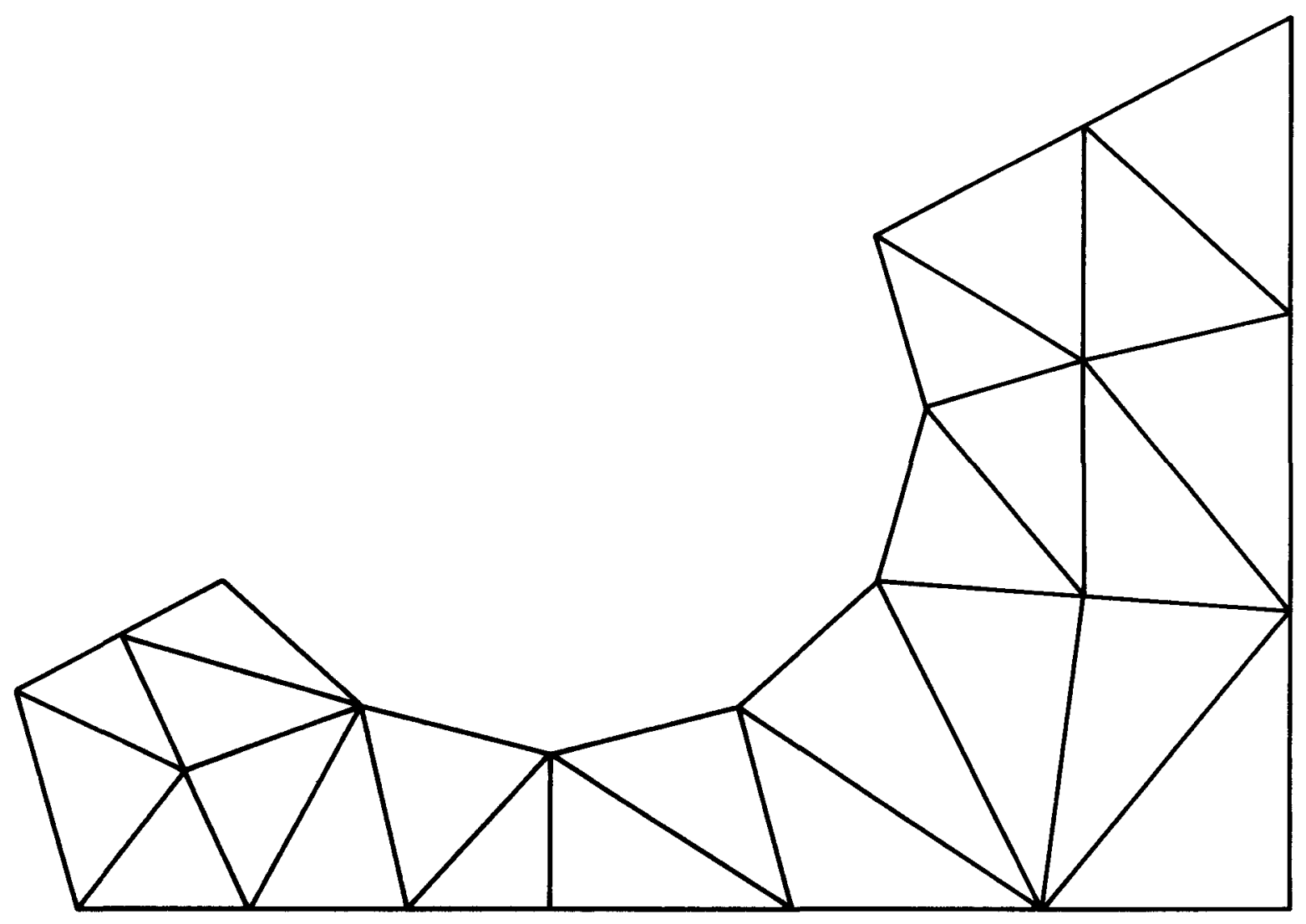

Fig. A2. One-twelfth sector of seven hole element (Mesh C1) 


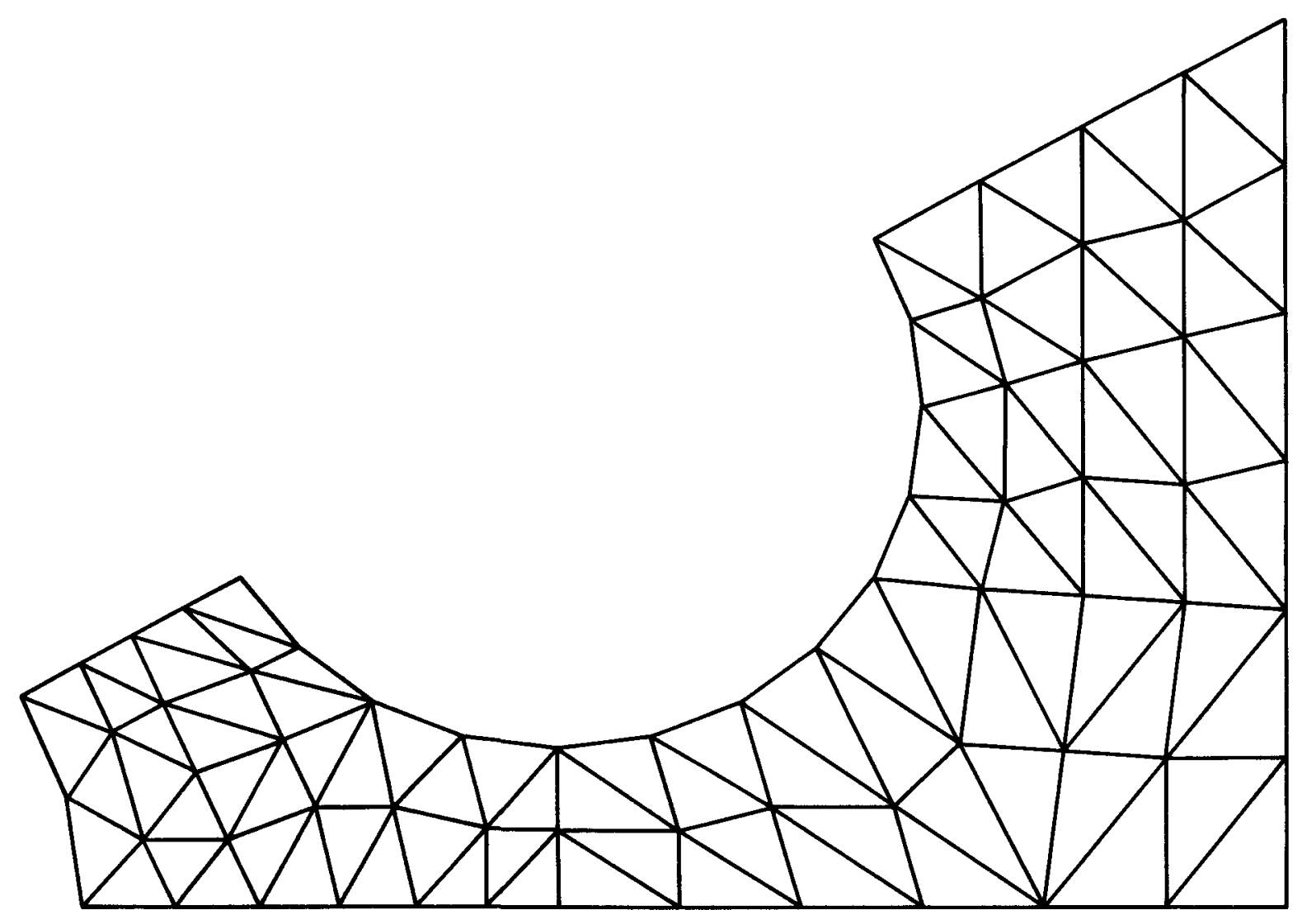

Fig. A3. One twelfth sector of seven hole element (Mesh B2) 


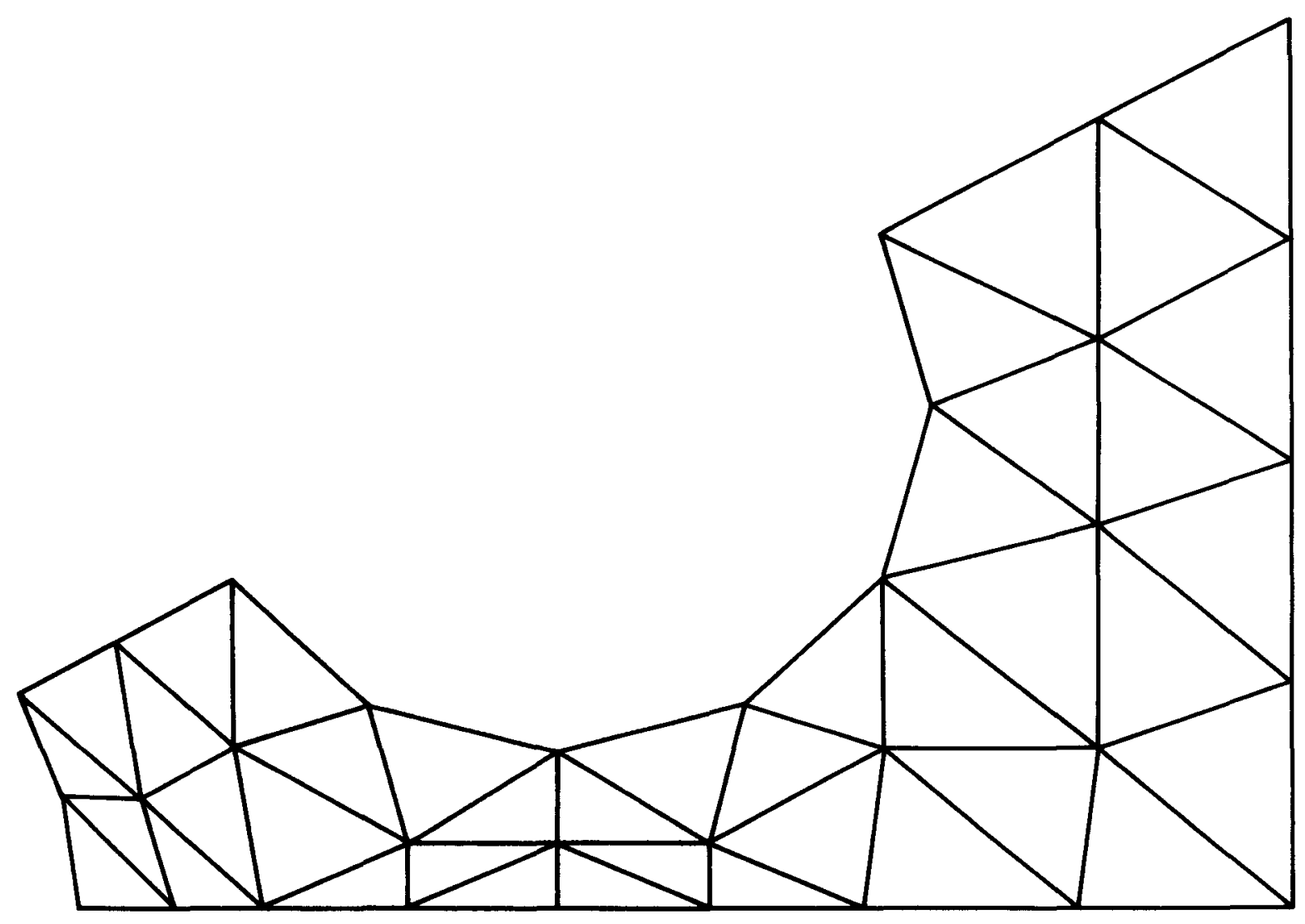

Fig. A4. One-twelfth sector of seven hole element (Mesh C2) 


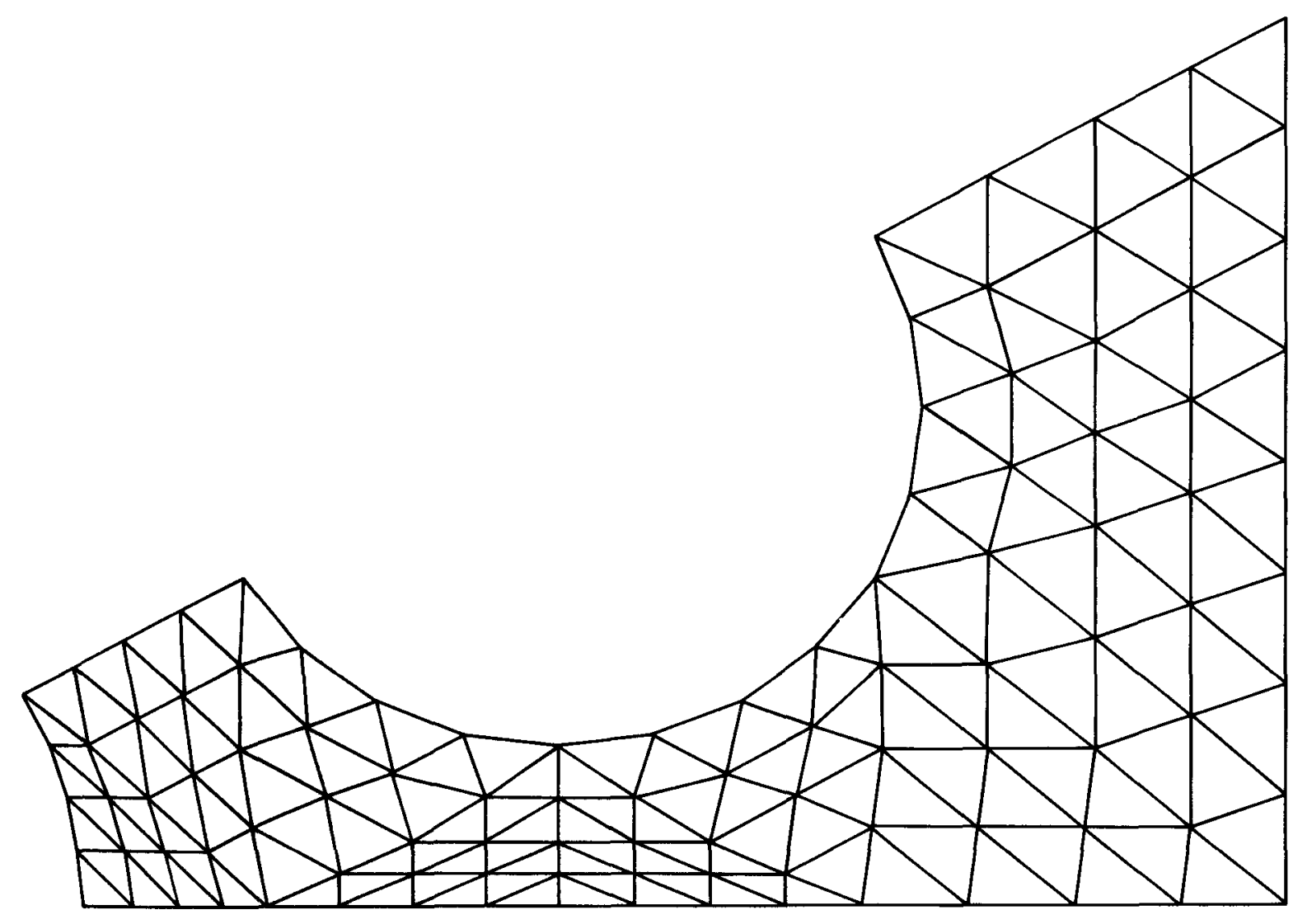

Fig. A5. One-twelfth sector of seven hole element (Mesh B3) 


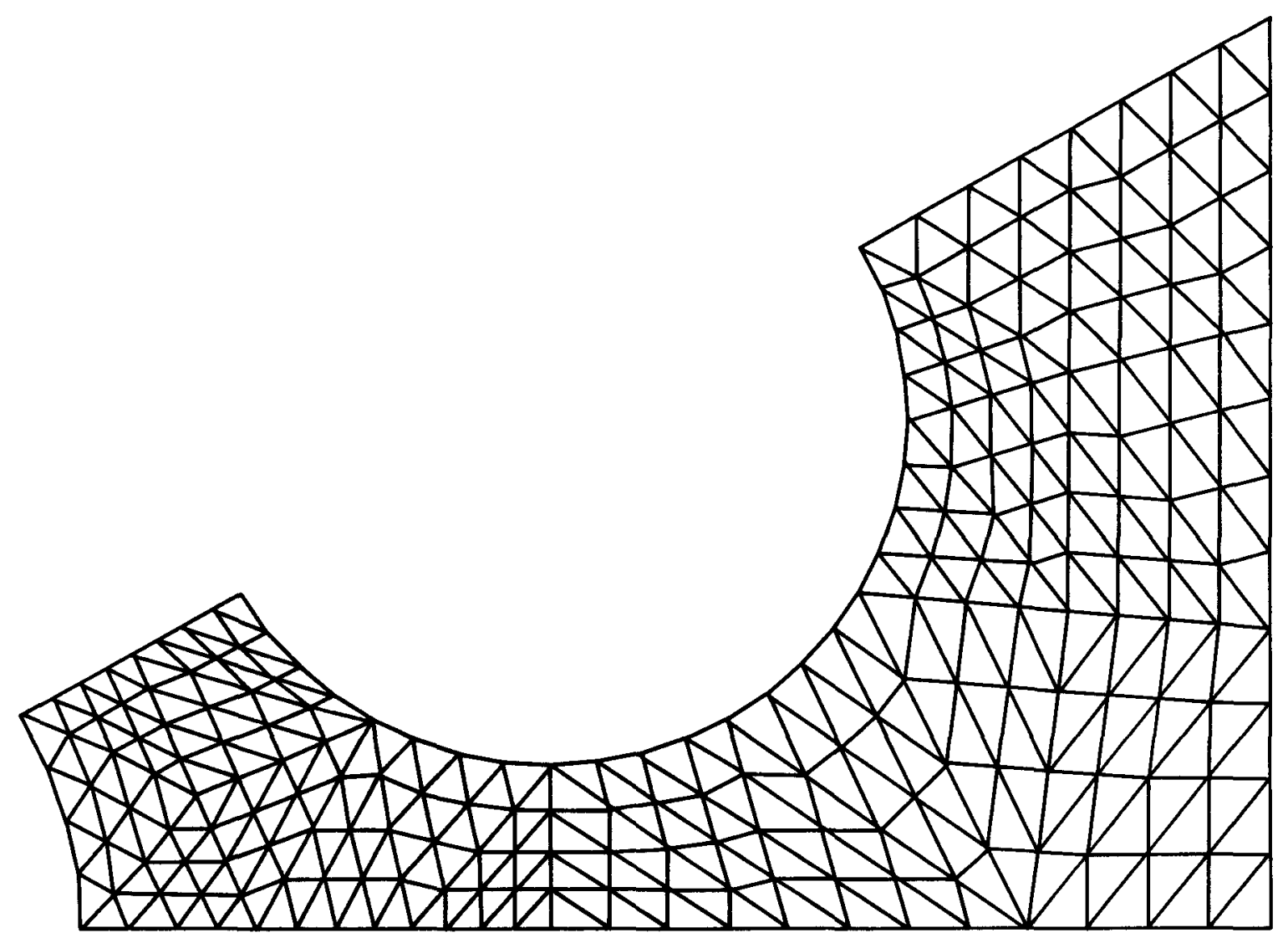

Fig. A6. One-twelfth sector - seven hole element (Mesh C3) 


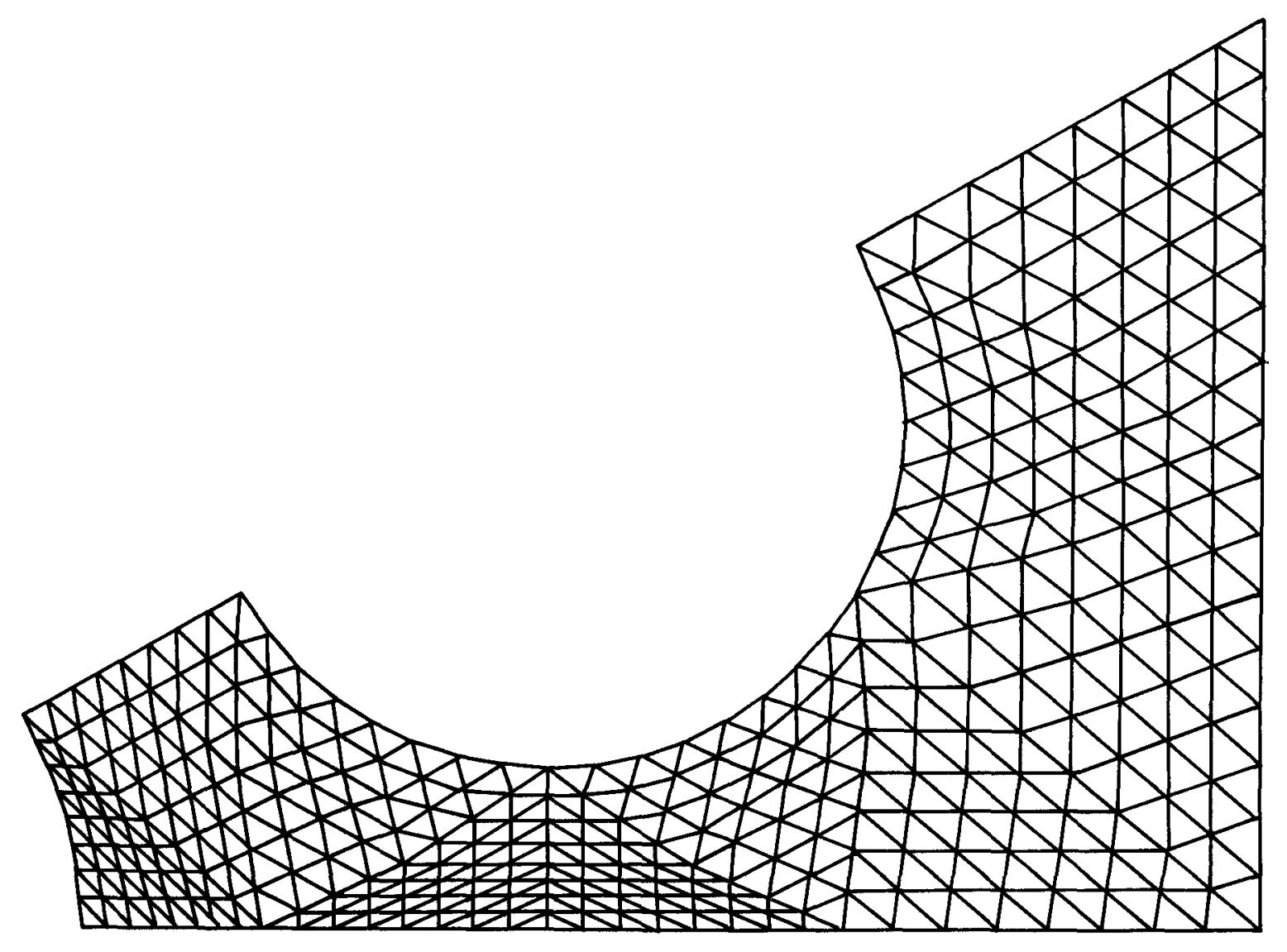

Fig. A7. One-twelfth sector - seven hole element (Mesh B4) 


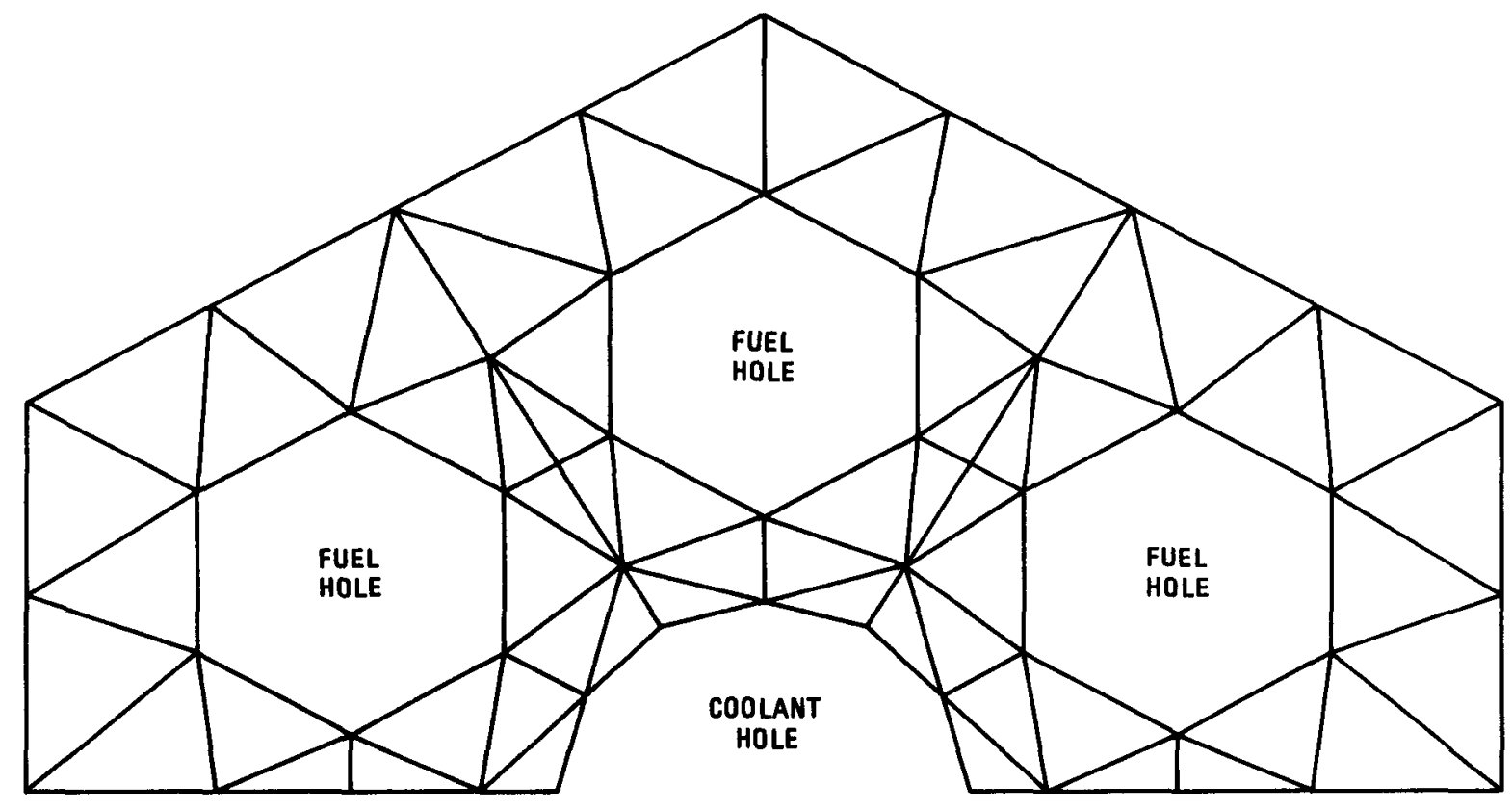

Fig. A8. One-half seven hole element (Mesh HB1) 


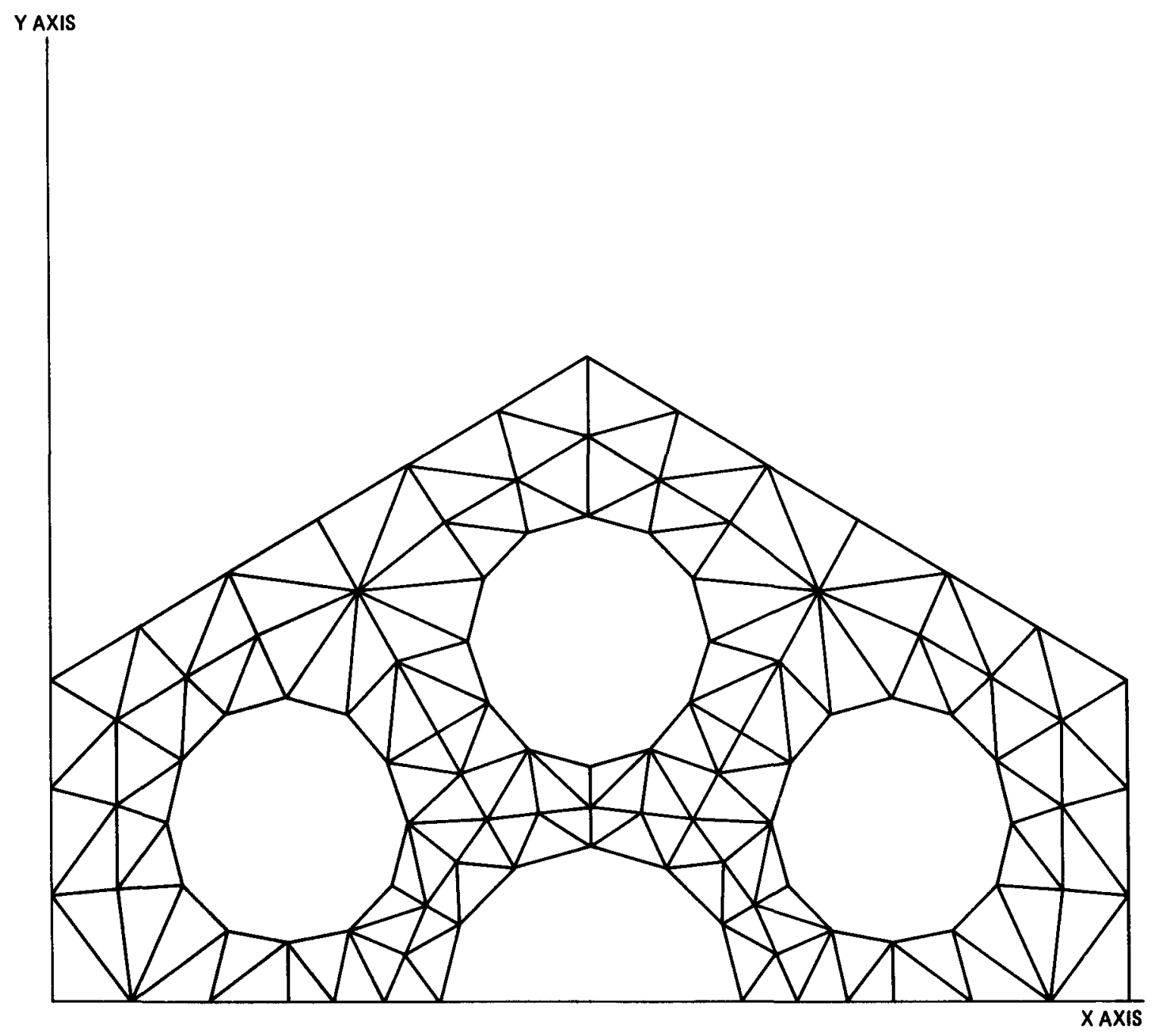

Fig. A9. One-half seven hole element (Mesh HCl) 


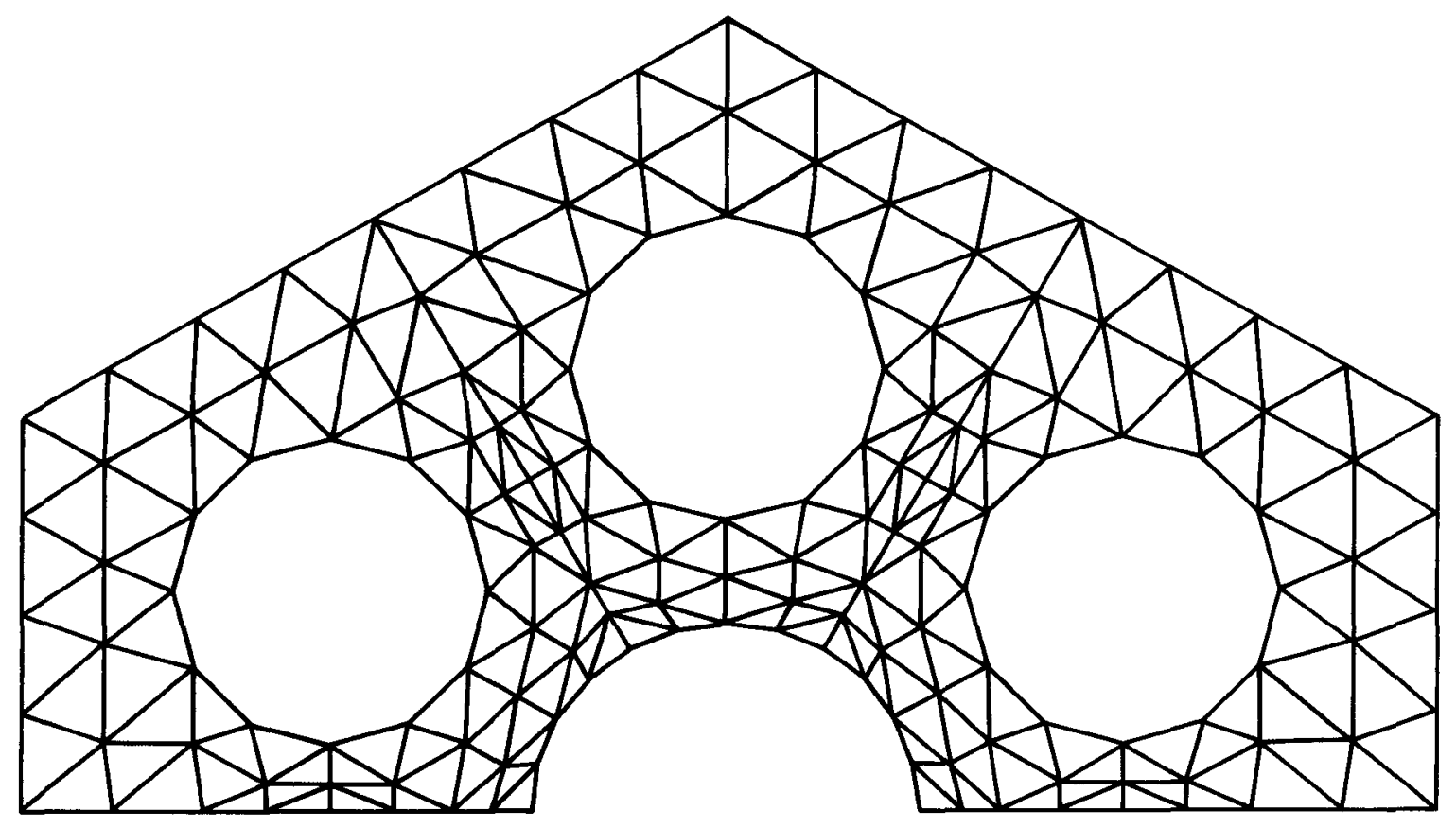

Fig. Al0. One-half seven hole element (Mesh HB2) 



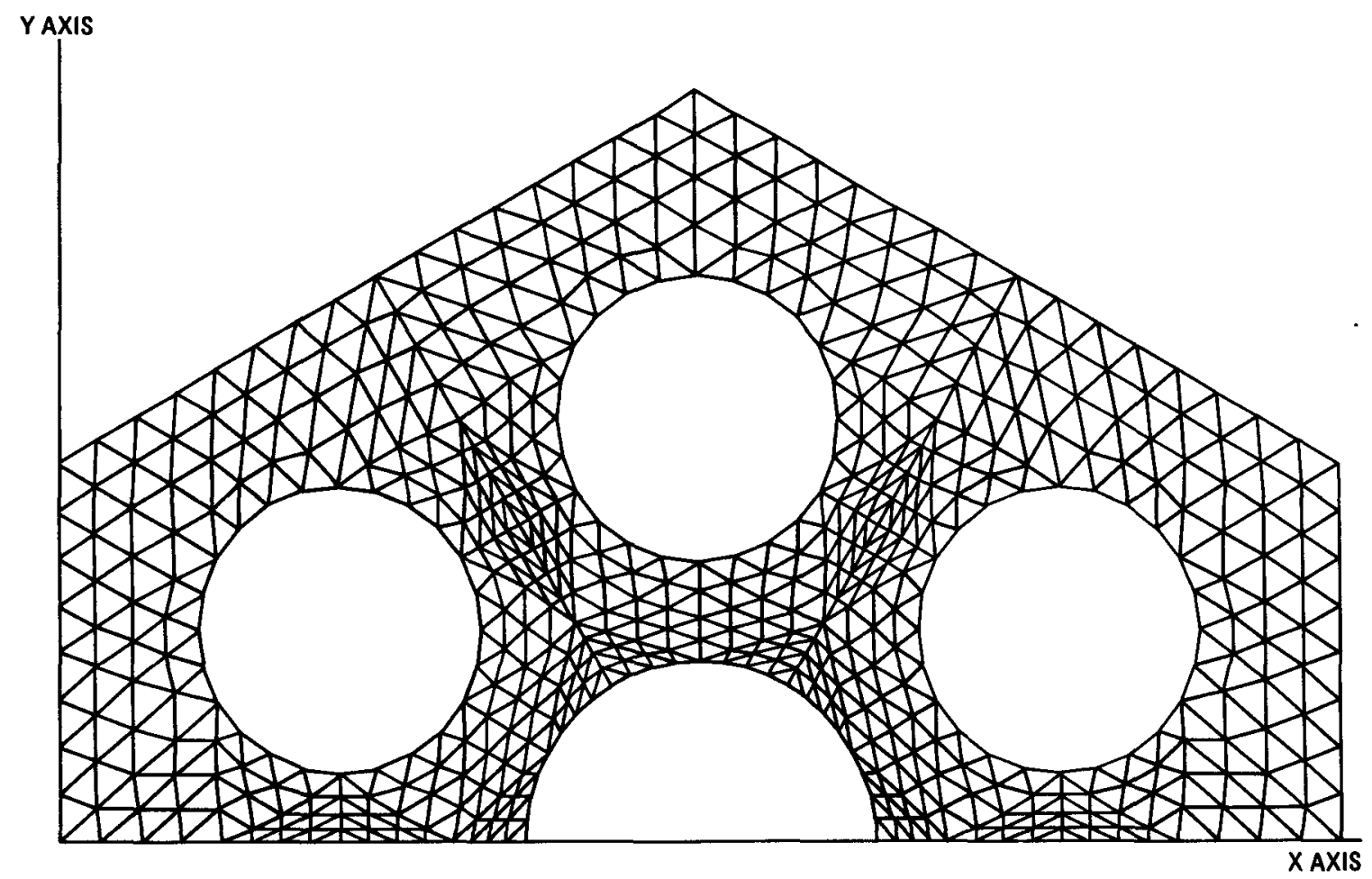

Fig. A12. One-half seven hole element (Mesh HB3) 


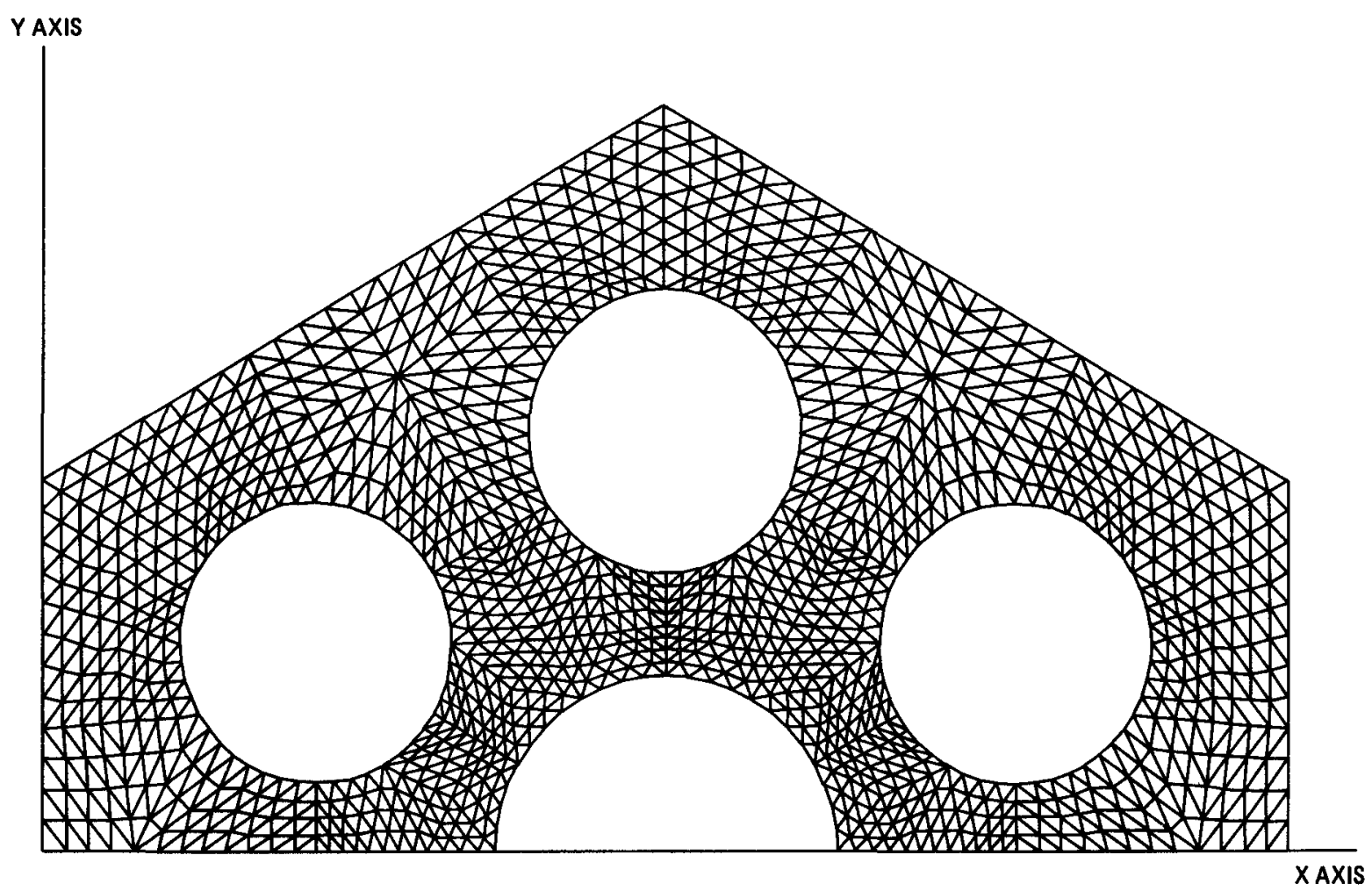

Fig. A13. One-half seven hole element (Mesh HC3) 


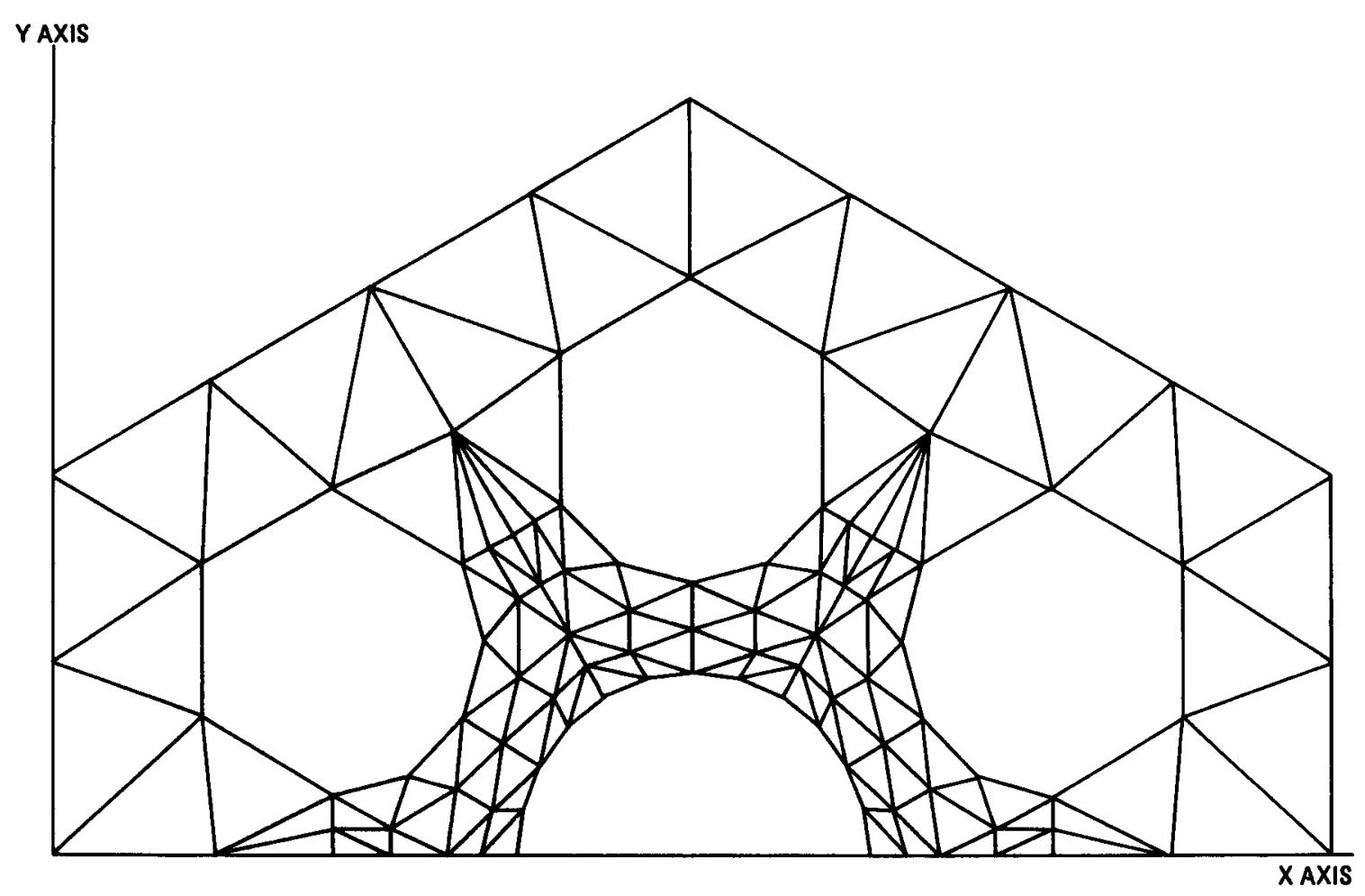

Fig. A14. One-half seven hole element (Mesh HB1EMB1) 


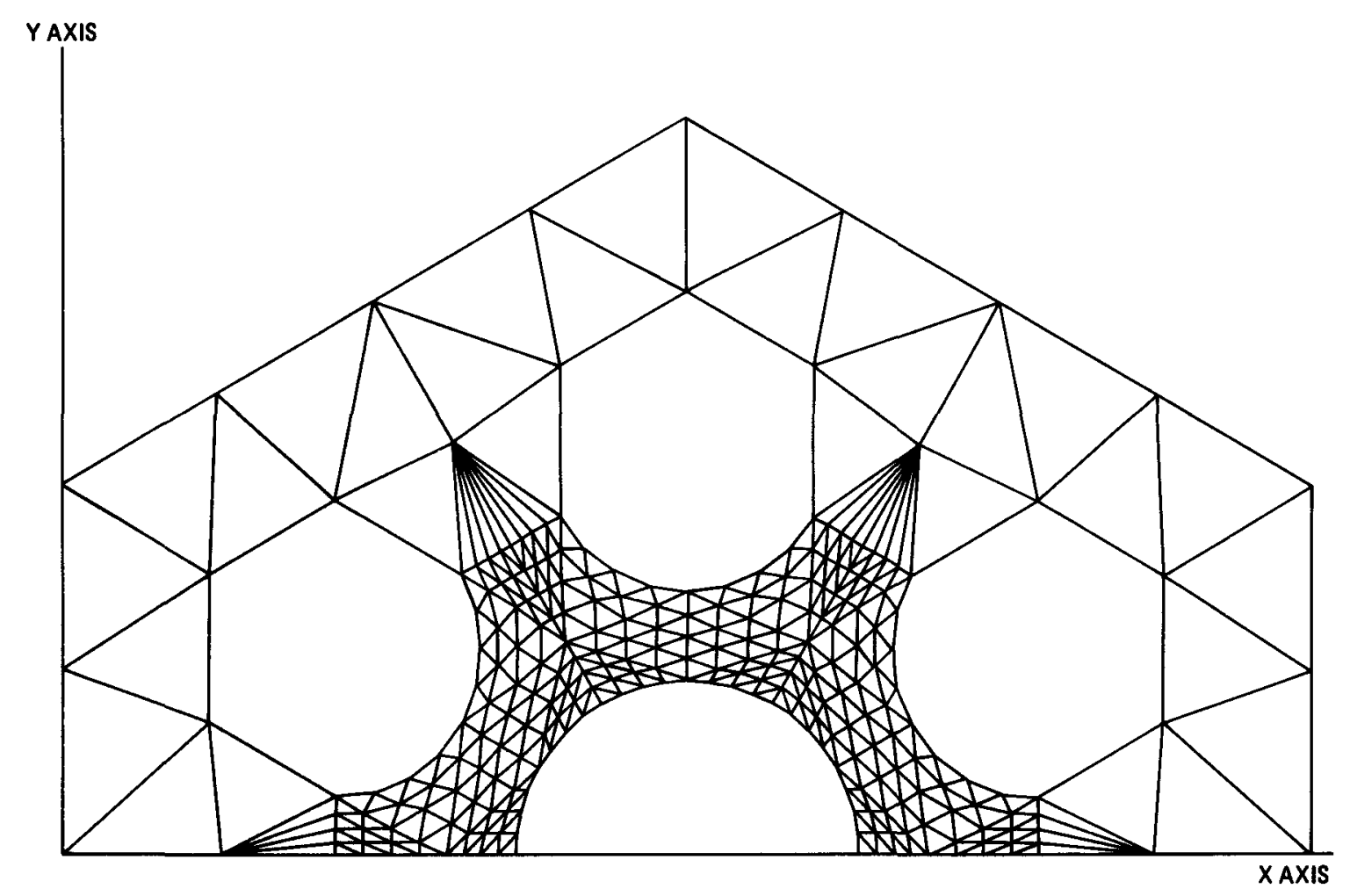

Fig. A15. One-half seven hole element (Mesh HB1EMB2) 


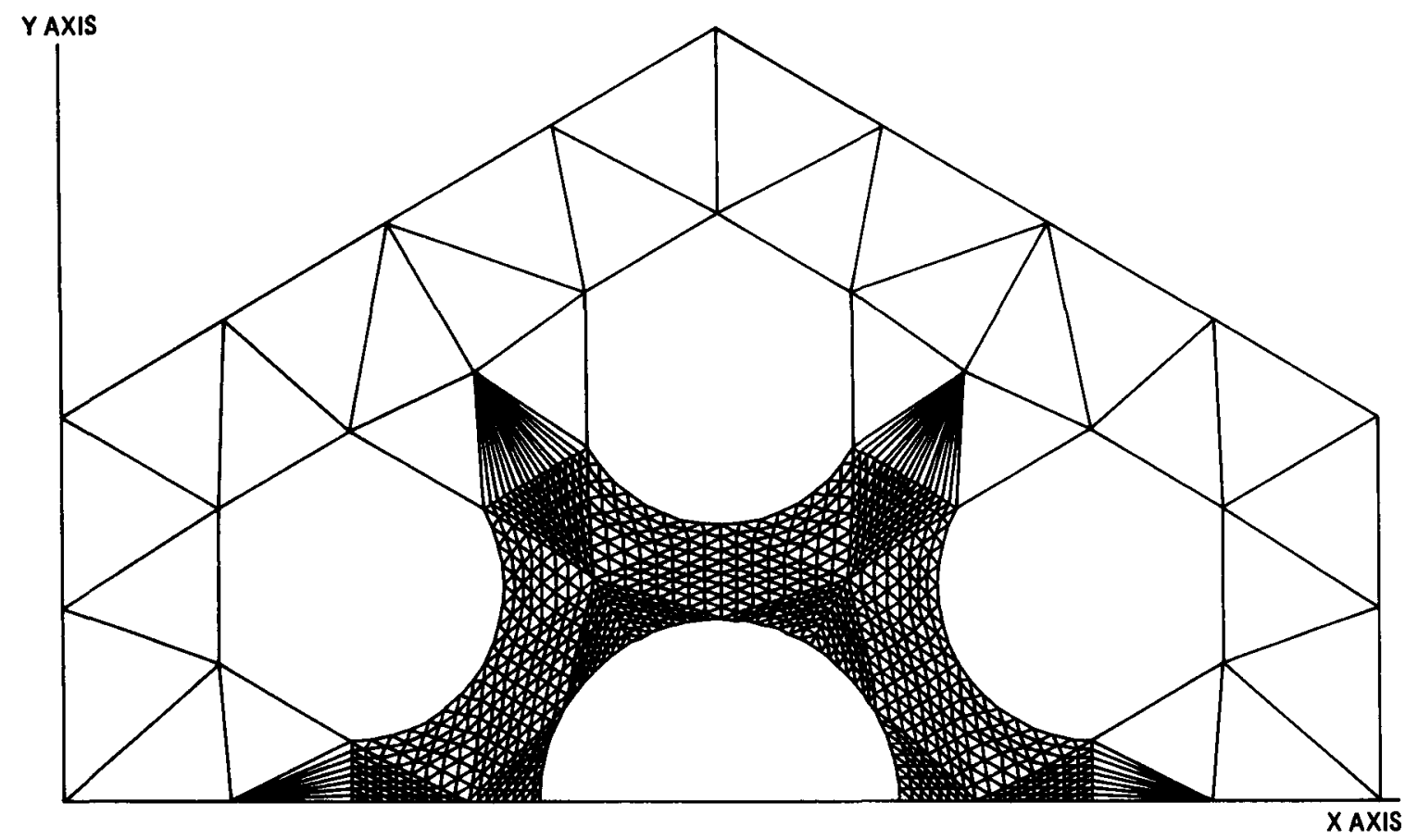

Fig. A16. One-half seven hole element (Mesh HB1EMB3) 


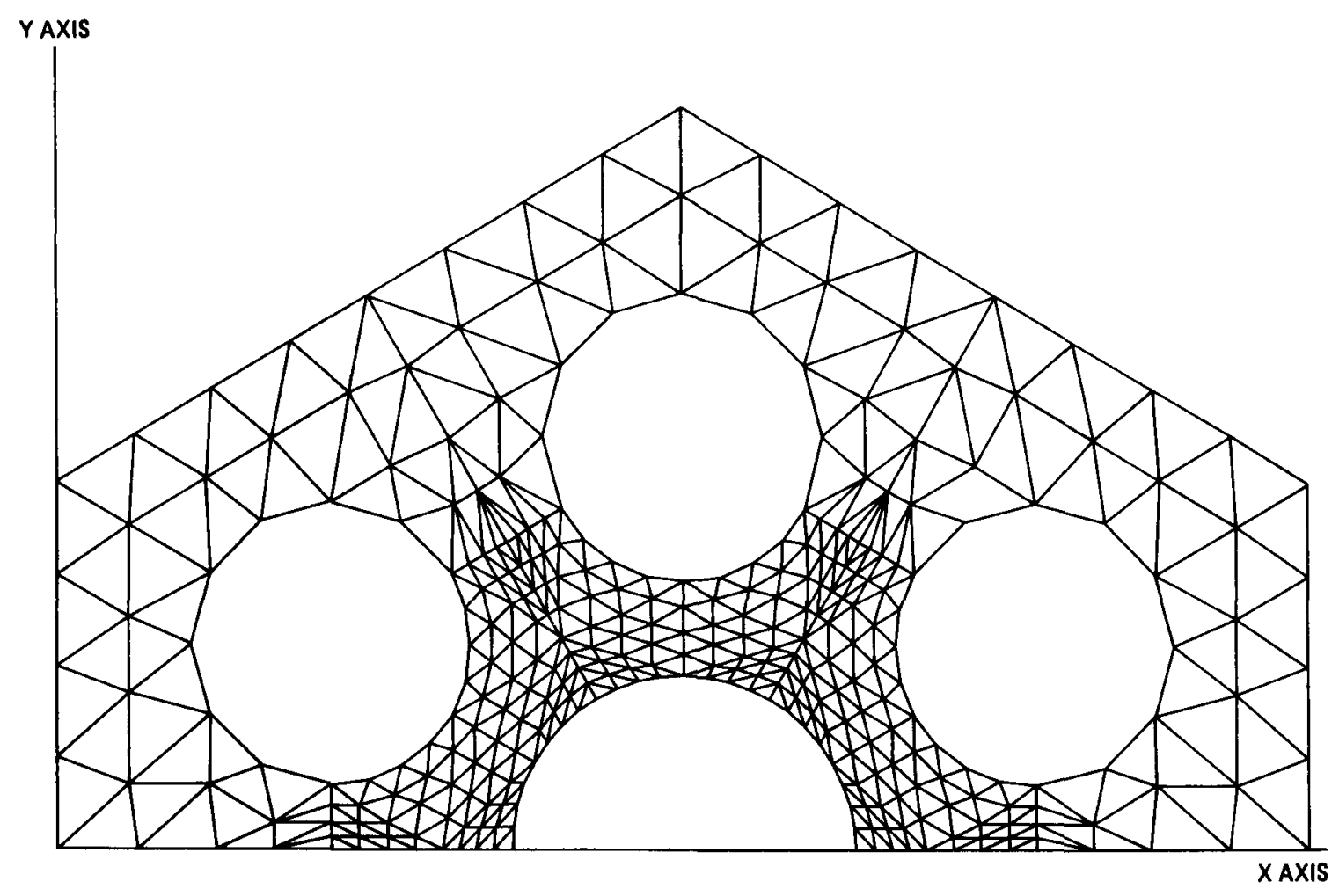

Fig. A17. One-half seven hole element (Mesh HB2EMB1) 


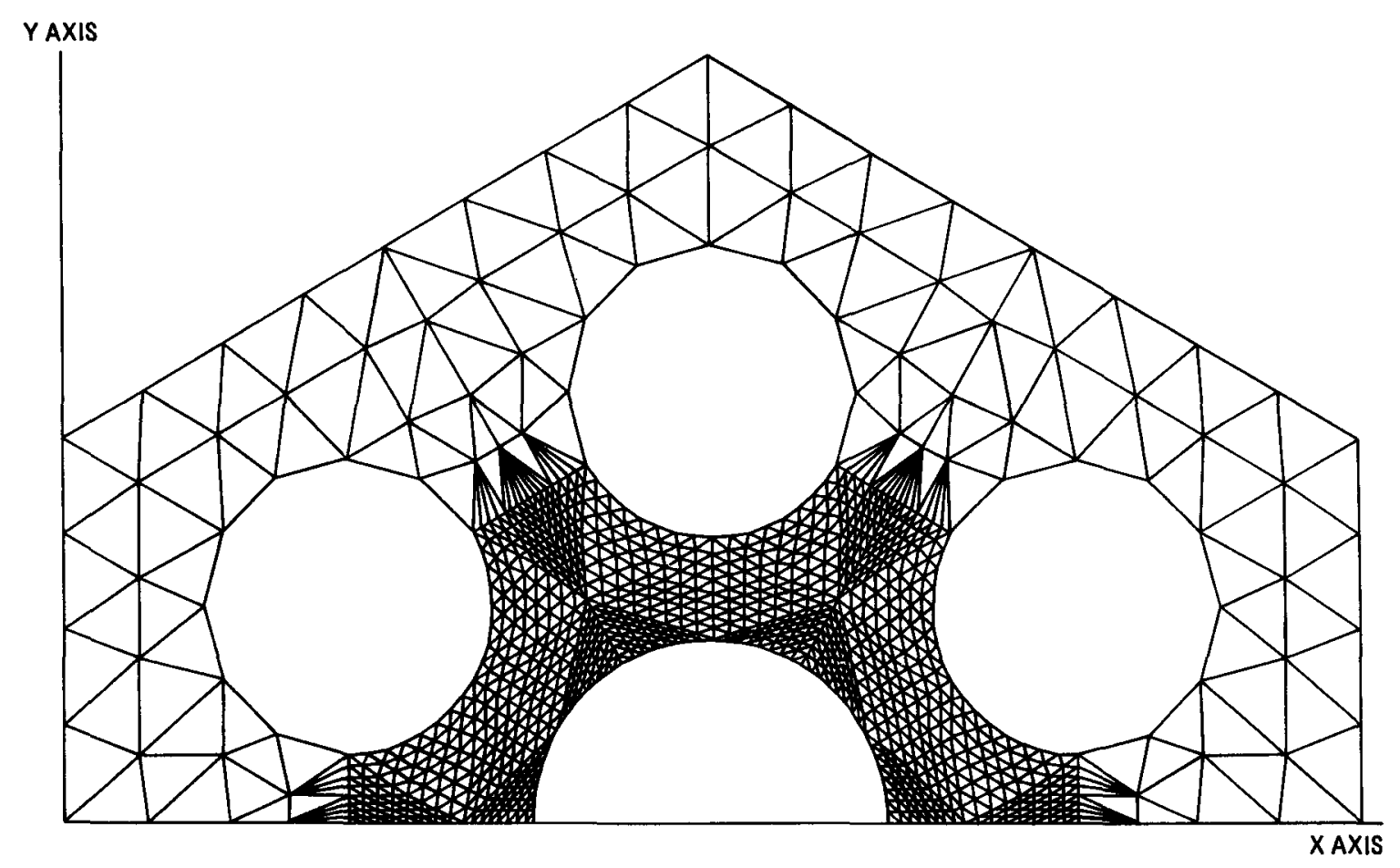

Fig. A18. One-ha1f seven hole element (Mesh HB2EMB2) 


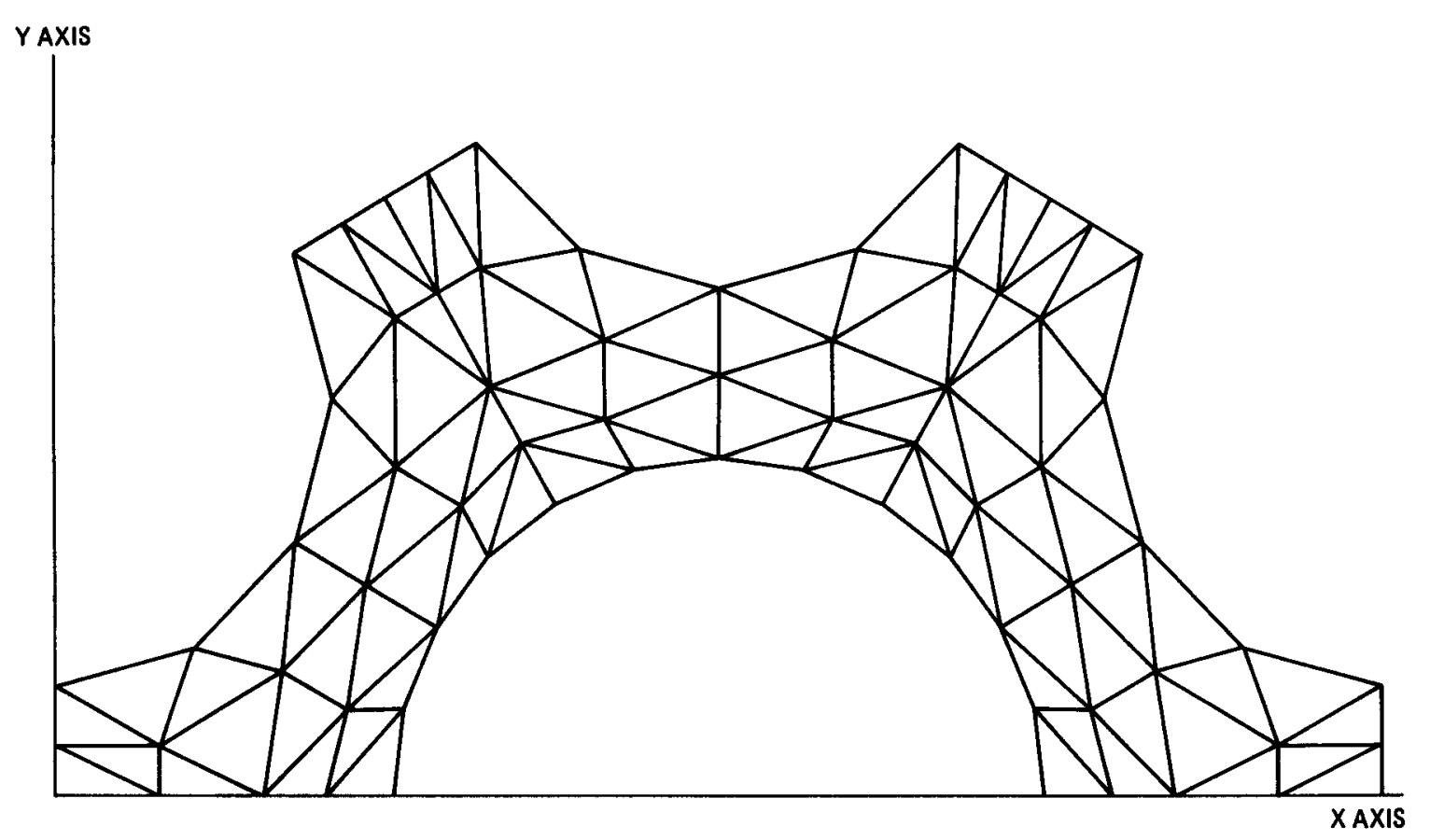

Fig. A19. 1st refine. of extract. from Mesh HB1, Mesh HB1EXT1 


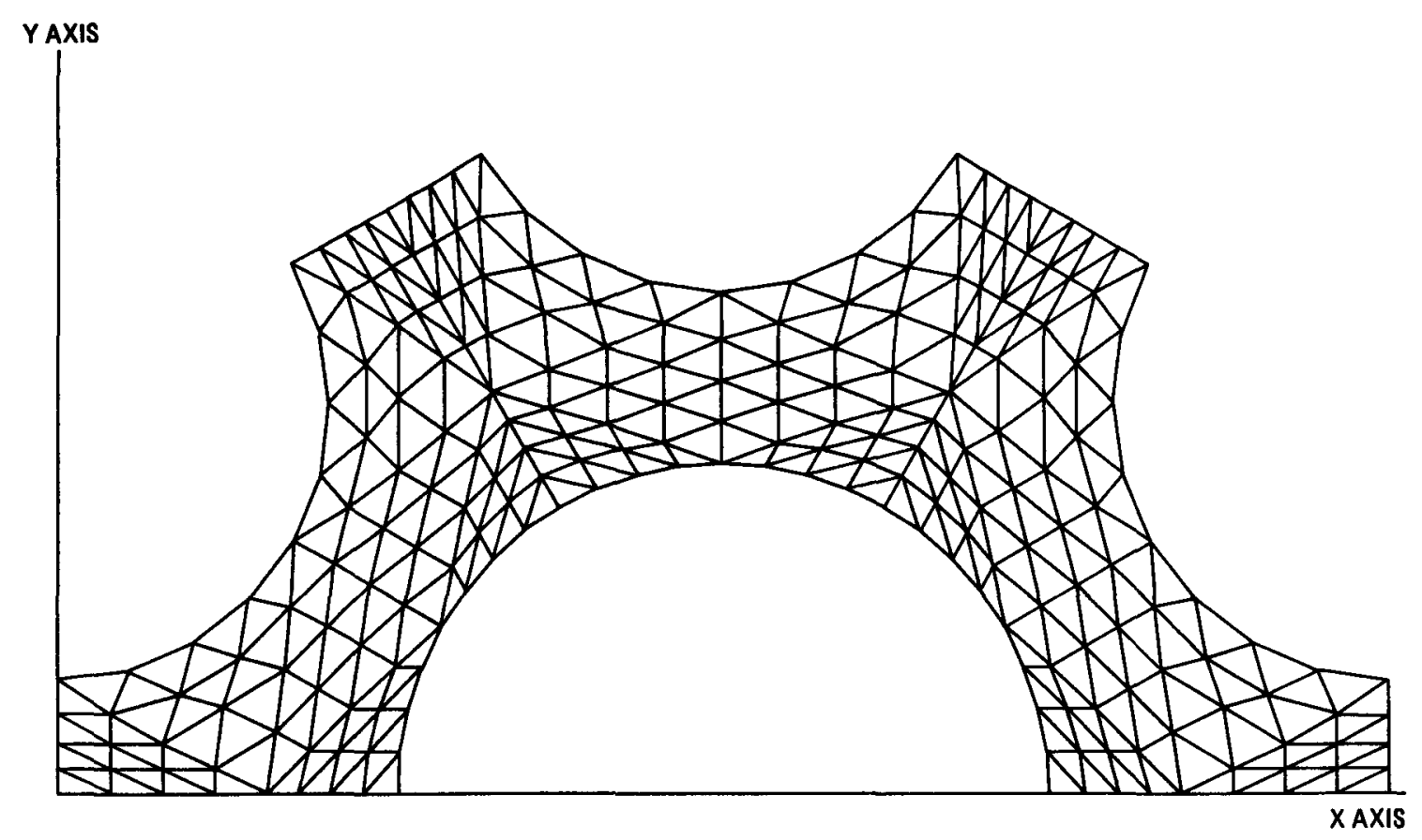

Fig. A20. 2nd refine. of extract. from Mesh HB1, Meshes HB1EXT2 and HB2EXT1 


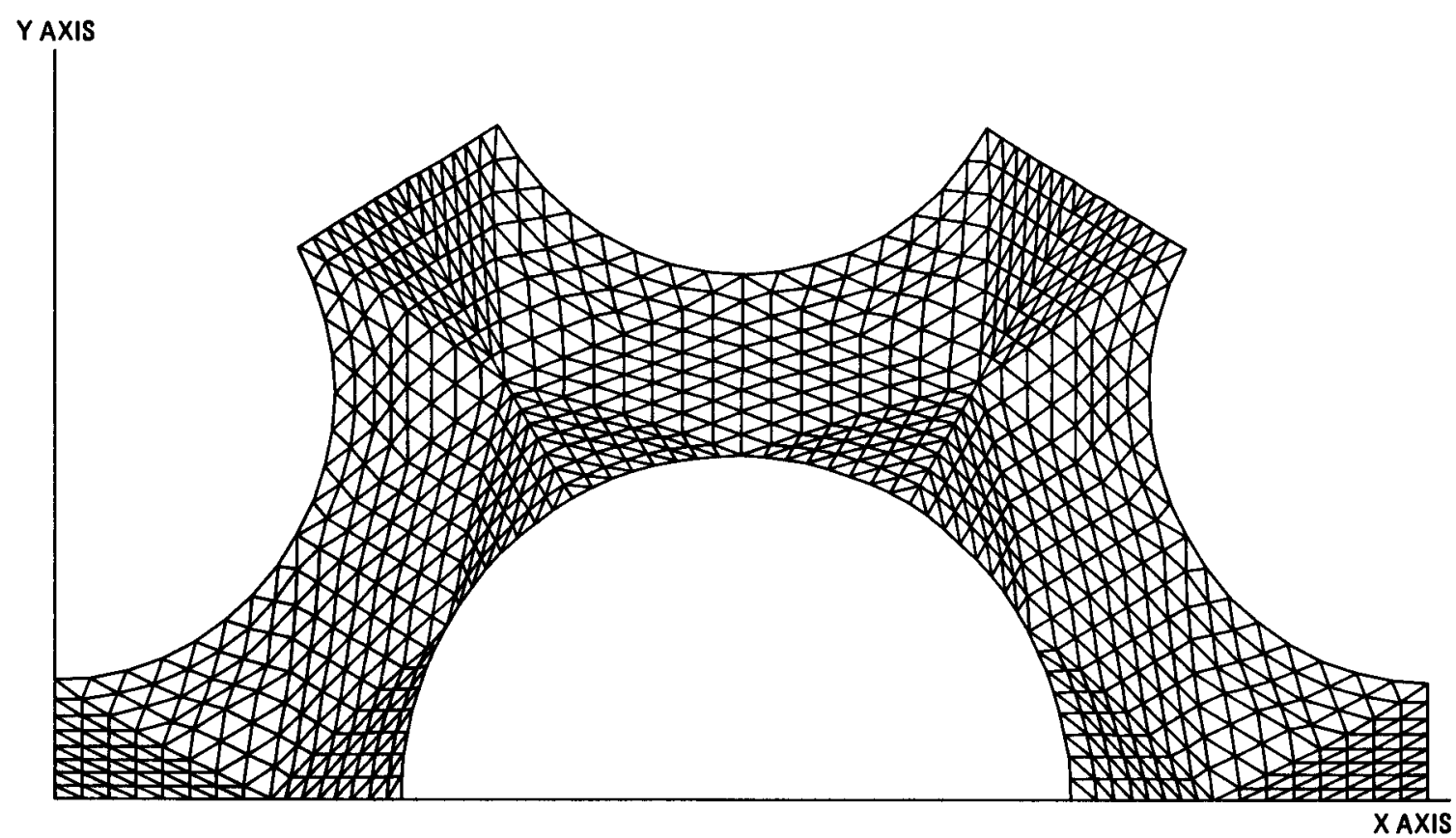

Fig. A21. 3rd refine. of extract. from Mesh HB1, Mesh HB2EXT2 


\section{APPENDIX B}

ONE-TWELFTH SECTOR THERMAL ANALYSIS

\section{B. 1 INTRODUCTION}

The two dimensional finite element code, TEPC-2D, was used for the symmetrical one-twelfth sector analysis. TEPC-2D solves the two dimension heat conduction equation:

$$
\nabla \cdot \mathrm{k} \nabla \mathrm{T}+\dot{q}^{\prime \prime \prime}=\frac{\mathrm{d}}{\mathrm{dt}} \rho \mathrm{cT}
$$

where

$$
\begin{aligned}
& \nabla=\hat{\mathbf{i}} \frac{\mathrm{d}}{\mathrm{dx}}+\hat{\mathrm{j}} \frac{\mathrm{d}}{\mathrm{dy}} \text {, the vector differential operator, } \\
& \mathrm{k}=\text { thermal conductivity, } \mathrm{Btu} / \mathrm{h}-\mathrm{ft}-{ }^{\circ} \mathrm{F} \text {, } \\
& \mathrm{T}=\text { local temperature, }{ }^{\circ} \mathrm{F} \text {, } \\
& \dot{\mathrm{q}}^{\prime \prime \prime}=\text { volumetric heat generation rate, Btu/h-ft }{ }^{3} \text {, } \\
& \rho=\text { material density, } 1 \mathrm{~b} / \mathrm{ft}^{3}, \\
& \mathrm{c}=\text { specific heat, } \mathrm{Btu} / 1 \mathrm{~b}{ }^{\circ} \mathrm{F} \text {, and } \\
& t=\text { time, hr. }
\end{aligned}
$$

Various boundary conditions (adiabatic, heat flux, etc.) may be imposed. A steady-state solution of this equation for the geometrical web of symmetry with zero axial heat conduction and with constant material properties may be found in Ref. B-1. For the one-twelfth sector no such analytic solution exists, and a numerical solution was used to solve the steady-state problem with zero volumetric heat generation and constant thermal conductivity. The above equation then reduces to the Laplace's equation in $\mathrm{T}$

$$
\nabla^{2} \mathrm{~T}=0
$$


where $\quad \nabla^{2}=\frac{d^{2}}{d x}+\frac{d^{2}}{d y}$

The boundary conditions employed were convective cooling on the center hole, a surface heat flux on the other hole, and adiabatic conditions on the two lines of symmetry and the outer surface.

\section{B-2 PROBLEM DESCRIPTION}

For the seven hole element (Fig. 1), the 0.625 in. diameter center hole was considered as a coolant hole with a mass flow rate of $300 \mathrm{lbm} / \mathrm{hr}$, a centerline coolant temperature of $1200^{\circ} \mathrm{F}$, and a convective heat transfer coefficient for fully turbulent flow. The six 0.5 in. diamter surrounding holes on a 0.74 in. pitch circle were considered as fuel holes with uniform surface heat fluxes of $48,800 \mathrm{Btu} / \mathrm{hr}-\mathrm{ft}^{2}$. All of the thermal and flow data were taken as representative of HTGR conditions; however, for the purposes of this study in which only differential temperatures are important, other values could have been equally well employed.

A one-twelfth sector (Fig. 2) has two lines of geometrical symmetry which were treated as adiabatic boundaries. For simplicity, the outer surface was also considered as adiabatic.

\section{B-3 FLOW AND MATERIAL CONDUCTIVITY DATA}

For turbulent flow in the center coolant hole, the following equation from Ref. B-2 was used for the convective heat transfer coefficient, $h$ :

$$
\mathrm{h}=0.02 \frac{\mathrm{K}_{\mathrm{h}}}{\mathrm{D}} \mathrm{N}_{\operatorname{Re}} 0.8^{\mathrm{N}}{ }_{\operatorname{Pr}}^{0.4} \mathrm{Btu} / \mathrm{hr}-\mathrm{ft}{ }^{2}-{ }^{\circ} \mathrm{F} \quad\left(\text { for } \mathrm{N}_{\mathrm{Re}}>6000\right)
$$

where $\quad K_{h}=$ coolant thermal conductivity evaluated at local bulk coolant temperature, $\mathrm{T}_{\mathrm{c}}, \mathrm{Btu} / \mathrm{hr}-\mathrm{ft}-{ }^{\circ} \mathrm{F}$,

$\mathrm{D}=$ coolant hole diamter, $\mathrm{ft}$, 


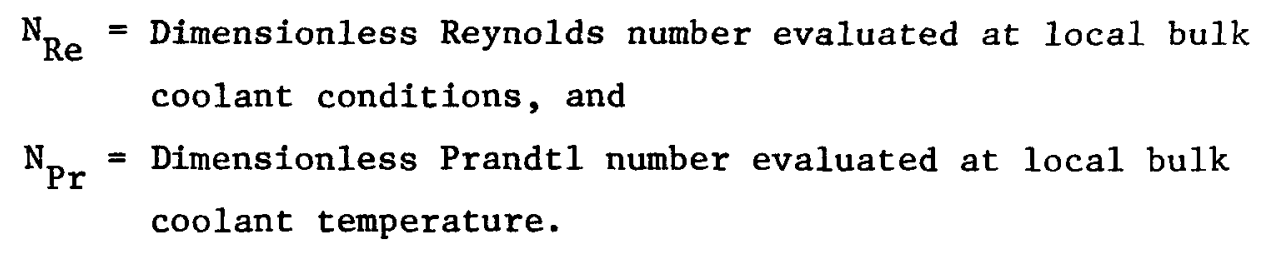

The Reynolds number is defined as

$$
\text { where } \quad \begin{aligned}
\mathrm{N}_{\mathrm{Re}} & =\mathrm{VD} \rho / \mu, \\
\mathrm{V} & =\text { flow velocity, } \mathrm{ft} / \mathrm{hr}, \\
\rho & =\text { fluid density, } 1 \mathrm{~b}_{\mathrm{m}} / \mathrm{ft}^{3}, \text { and } \\
\mu & =\text { fluid viscosity, } 1 \mathrm{~b}_{\mathrm{m}} / \mathrm{ft}-\mathrm{hr} .
\end{aligned}
$$

Since the mass flow rate, $\dot{M}$, is given by

$$
\begin{aligned}
\dot{\mathrm{M}} & =\dot{\rho} \mathrm{VA}, \mathrm{A}=\text { hole area in } \mathrm{ft}^{2}, \\
& =\rho \mathrm{V} \pi \mathrm{D}^{2} / 4, \\
\text { then } \quad \operatorname{VD} \rho & =4 \dot{\mathrm{M}} / \pi \mathrm{D},
\end{aligned}
$$$$
\text { so } \quad \mathrm{N}_{\operatorname{Re}}=4 \dot{\mathrm{M}} / \pi \mu \mathrm{D} \text {. }
$$

The Prandtl number is defined as

$$
\mathrm{N}_{\mathrm{Pr}}=\mathrm{c}_{\mathrm{p}} \mu / \mathrm{K}_{\mathrm{h}} \text {, }
$$

where $\quad c_{p}=$ specific heat of fluid, Btu/1 $b_{m}{ }^{\circ} F$.

From Ref. B-2 for helium

$$
\begin{aligned}
c_{p} & =1.242, \\
\mu & =6.9 * 10^{-4} T_{c} 0.674, \\
K_{h} & =1.29 * 10^{-3} T_{c} 0.674 .
\end{aligned}
$$

The Prandt 1 number is then

$$
\mathrm{N}_{\mathrm{Pr}}=0.664 .
$$


For a typical HTGR coolant hole mass flow rate of $3001 \mathrm{~b} / \mathrm{hr}$ with a center line coolant temperature of $1200^{\circ} \mathrm{F}\left(1660^{\circ} \mathrm{R}\right)$ and of $0.625 \mathrm{in}$. (0.0521 ft) diameter, the Reynold's number is then

$$
\mathrm{N}_{\mathrm{Re}}=71800 \text {, }
$$

which is clearly fully turbulent.

The convective heat transfer coefficient for a circular hole is then

$$
\mathrm{h}=478 \mathrm{Btu} / \mathrm{hr}-\mathrm{ft} \mathrm{t}^{2}-^{\circ} \mathrm{F} \text {. }
$$

This value is modified by a wetted perimeter factor for a circular hole when modeled by a equal sided polygon as discussed in Section B.5.

For simplicity, the graphite conductivity, $\mathrm{K}_{\mathrm{g}}$, was taken as a constant. The value of $16.0 \mathrm{Btu} / \mathrm{hr}-\mathrm{ft}-{ }^{\circ} \mathrm{F}$ that was used was typically employed in prior HTGR fuel element thermal analyses for zero to one year old graphite (Ref. B-1).

\section{B.4 FUEL HOLE SURFACE HEAT FLUX}

The magnitude of the fuel hole surface heat flux, $q_{\mathrm{FH}}^{\prime \prime}$, was set, in conjunction with the other heat transfer parameters, to be representative of that in HTGR fuel elements. The value used was $48800 \mathrm{Btu} / \mathrm{hr}-\mathrm{ft}^{2}$. For the purposes of this numerical accuracy study, its value was arbitrarily chosen such that the overall element temperature difference be representative of that found in HTGR fuel elements.

\section{B.5 WETTED PERTMETER FACTORS}

Both the center coolant hole heat transfer coefficient, $h$, and the fuel hole surface heat flux, $q^{\prime \prime} \mathrm{FH}$, were modified to account for the increase in perimeter resulting from modeling circular holes by regular polygons.

Since the hole area, A, is preserved during the refinement process,

$$
\mathrm{A}=\frac{\pi \mathrm{d}^{2}}{4}=\frac{\mathrm{na}^{2}}{4 \tan \alpha}
$$


where

$\mathrm{d}=$ hole diameter,

$\mathrm{n}=$ number of sides of regular polygon,

$a=1$ ength of side of polygon, and

$\alpha=$ one half of the central angle substended by a side

of length a

$=360^{\circ} / 2 \mathrm{n}$.

Solving for a,

$$
\mathrm{a}=\mathrm{d}\left(\frac{\pi \tan \alpha}{\mathrm{n}}\right)^{1 / 2} .
$$

The polygon perimeter, $P$, is na. The wetted perimeter factor $F_{w p}$, is then

$$
\mathrm{F}_{\mathrm{wp}}=\frac{\mathrm{c}}{\mathrm{p}}=\frac{\pi \mathrm{d}}{\mathrm{na}}=\left(\frac{\pi}{\mathrm{n} \tan \alpha}\right)^{1 / 2},
$$

which approaches unity as $\mathrm{n}$ goes to infinity.

The following table gives the wetted perimeter factors for the seven meshes used for the one-twelfth sector thermal analysis.

\begin{tabular}{|c|c|c|c|c|}
\hline \multirow{2}{*}{ Mesh } & \multicolumn{2}{|c|}{$\mathbf{n}$} & \multicolumn{2}{c|}{ Fwp } \\
\cline { 2 - 5 } & Fuel Hole & Coolant Hole & Fuel Hole & Coolant Hole \\
\hline B1 & 6 & 12 & .9523 & .9885 \\
C1 & 12 & 12 & .9885 & .9885 \\
B2 & 12 & 24 & .9885 & .9971 \\
C2 & 24 & 24 & .9971 & .9971 \\
B3 & 24 & 48 & .9971 & .9993 \\
C3 & 48 & 48 & .9993 & .9993 \\
B4 & 48 & 96 & .9993 & .9998 \\
\hline
\end{tabular}

\section{B.6 TEPC SAMPLE PROBLEM}

Table B-1 lists the input data for the one-twelfth sector mesh B1. The TEPC output is shown in Table B-2 for this problem. Other cases were all similar. 
TABLE B. 1

TEPC SAMPLE PROBLEM INPUT DATA

DEO KIMS*THERMALUATA. THSBI

REALI-UNLY MULIE

LASE UFFER ASSUMED

EII $15 R 26 A-B$ - TUE-01:08/80-14:47:26-10.)

E[IT

()) $X N N^{\circ}$

1: *** SLVEN HOLE BLUCK - DNE TWELFIH SECIOK (MESH H1) **:

$2:$

3:PLANE THEKHA

4:GEOMET

$5: \quad 10 \quad 12 \quad 0 \quad 10 \quad 12$

6: $\quad 1 \quad 1 \quad 12 \quad 4 \quad 1$

$7: \quad 2 \quad 2 \quad 3 \quad 4 \quad 1$

8: $3 \quad 3 \quad 3 \quad 4 \quad 5 \quad 1$

9: $4 \quad 4 \quad 4 \quad 5 \quad 6 \quad 1$

10: $5 \quad 5 \quad 5 \quad 3 \quad 8 \quad 1$

$11: \quad \begin{array}{llllll}6 & 5 & 7 & 8 & 1\end{array}$

12: $7 \div 8010$

13: $8 \quad 8 \quad 7 \quad 10 \quad 11 \quad 1$

14: $9, i \quad 9 \quad 11 \quad 1$

15: $\quad \begin{array}{lllll}10 & y & 11 & 12 & 1\end{array}$

16: $\quad 1 \quad .3198$

$17: \quad 2 \quad .2770$

18: $3 \quad .4028$

19: $4 \quad .4400$

20: $5 \quad .6404$

21: $6 \quad .6409$

22: 7.8790

23: $8 \quad .8500$

24: $9 \quad .8790$

25: 10

26: 11

$27: \quad 12$

28: THERMA

29: $\quad 1$

30: 1

31: 1

$32: 1200.1200$.

33: 300, $.664 \quad .625 \quad .9885$

$34: 48800 . .9523$

35: 0 NO GAPS

36: 0 NO FIXED NODAL TEMPERAIURES

37: 1 ONE HEAT FLUX BOUNDARY FOR FUEL KOO

38: $\quad 14$

39: $3 \quad 5 \quad 79$

40: 10

41: 112

42: $\quad 1$

EOF : 43

43: $\quad 1$.
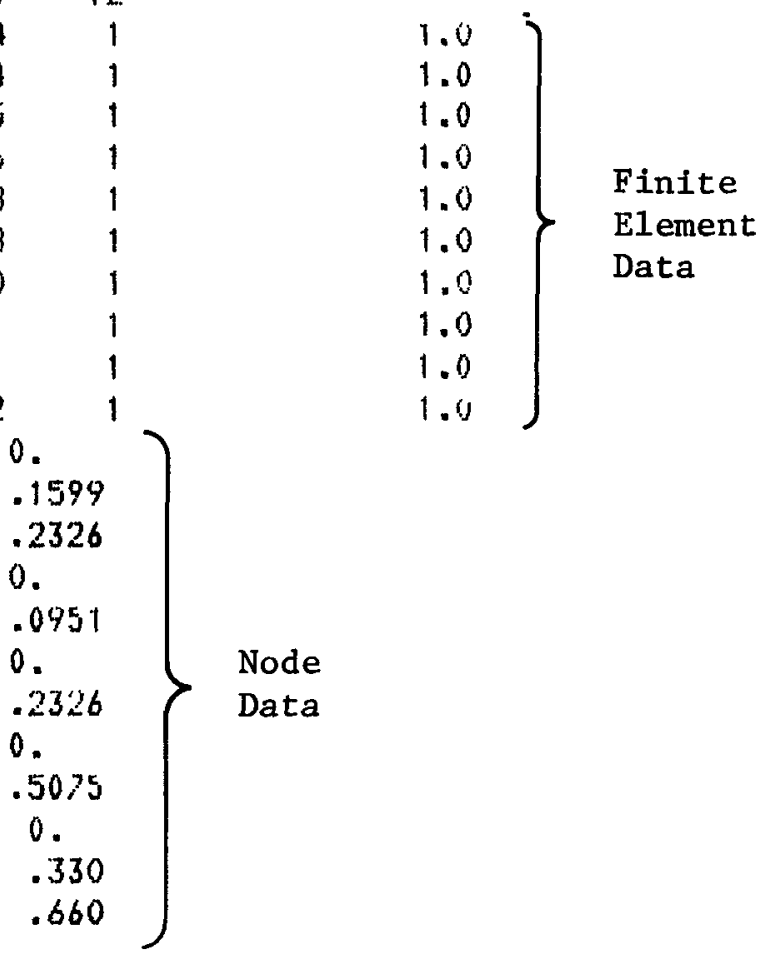

\section{2}

1.14315

1.14315

1.14315

OOL_ANT HOLE

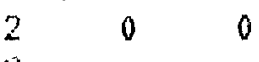


TABLE B. 2

TEPC OUTPUT MODEL B1

PLANE

* * SEVEN HOLE ELOCK THEDMA

- ONE TWELFTH SECTOP (MODEL B1)

\#\#

\section{SEOMET}

NUMBER OF ELEMENT

$=$

10

2

NUMQER OF NODES

$=12$

NUMEER OF ELOCKS OF YESH GENERATION

NUMEER OF ELEMENTS TO FE REAO FROM CAROS $=27$

MUMGER OF NOQES TO $L F$ PEAD FRON CAROS = 12

\begin{tabular}{|c|c|c|c|c|c|c|}
\hline & ELEMENT & I & $J$ & $k$ & MATEDIAL & VOLUME \\
\hline & 1 & 1 & 4 & 2 & 2 & $9.6100-93$ \\
\hline & 2 & 2 & 4 & 3 & 1 & $1.5983-02$ \\
\hline & 3 & 3 & 4 & 5 & 1 & $2.5134-32$ \\
\hline & 4 & 4 & 6 & 5 & 1 & $9.552 B-23$ \\
\hline & 5 & 5 & 6 & 8 & 1 & $3.9427-93$ \\
\hline & 6 & $=$ & 8 & 7 & 1 & $2.5697-02$ \\
\hline & 7 & 7 & 8 & 10 & 1 & $3.4093-02$ \\
\hline & 8 & 7 & 10 & 11 & 1 & $4.3585-02$ \\
\hline & 9 & 7 & 11 & 9 & 1 & $3.6307-02$ \\
\hline & 10 & 9 & 11 & 12 & 1 & $4.3585-02$ \\
\hline
\end{tabular}

\begin{tabular}{|c|c|c|c|c|c|}
\hline NOOE & $x-0,0$ & $Y-O R D$ & HOUE & $x-O F O$ & $Y-O R D$ \\
\hline 1 & $.3178 \mathrm{Cr}$ & - 0ก00E & 4 & $.44000 ?$ & .000 .100 \\
\hline 2 & $.27700=$ & .159920 & 5 & .640900 & .095100 \\
\hline 3 & .452800 & $.23260 \mathrm{C}$ & 6 & .640900 & .000000 \\
\hline 7 & $.87900=$ & .232620 & 10 & 1.143150 &.$\widehat{000000}$ \\
\hline 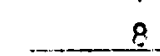 & $.85000 \mathrm{C}$ & .000000 & 11 & 1.143150 & 330000 \\
\hline 9 & .879000 & .507500 & 12 & 1.143150 & .660000 \\
\hline
\end{tabular}

THERMA

* * $*$ COOLANT HOLE

RLOCKNO. $=1$ NODES $=2$ IFT $=$ IHE C

\section{LIST OF NOOES IN THIS RLOCK}




\section{TABLE B2 (Concluded)}

INITIAL FLUID TEMPERATURE

1250.0127 .00

"ASS FLO $=30 . \overline{O S}$ LM/FR

PRAMOTL NUMBFR $=.564$

COOLANT HOLE UIA. $=$ G. 5 IN.

CCOLINT HCLE PERIMETFR FACTOR $=.988$

EUEL RCO HEAT FLUX $=40900$. STU/1IR/FT-50

FUEL HOLE FEPIMETER FACTOR $=.952$

***.....

NO.FIXEL NOOAL TEMPERATURES

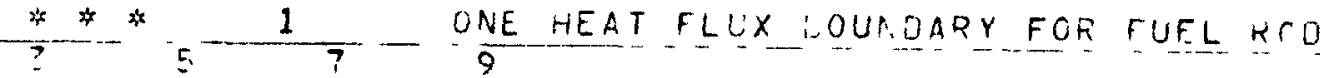

NECR NUGAP NDFIX NDFLLX

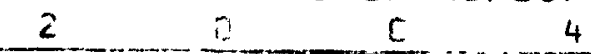

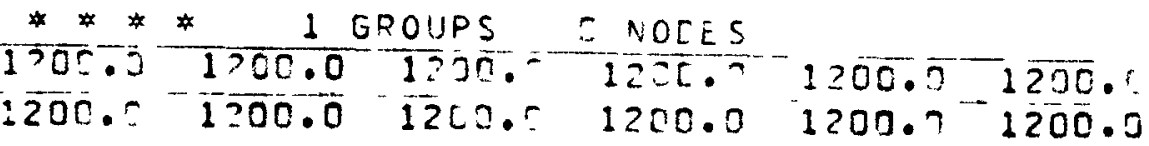

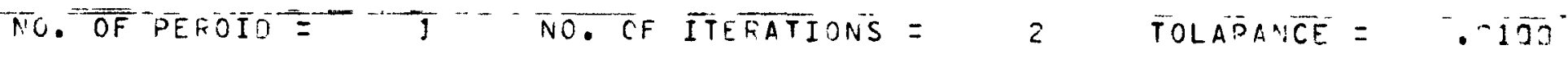

TIME INCREMENT $=-1 .-20307$

$M C$. OF STEPS $=$

NO. CF PFINT FRECUENCY

STEADYY STATE,

VAPIAELE CONDUCTIVITY,

FADIATION, $\mathrm{C}$

\section{TCTAL HEAT EENETATED IS :OOCE BTUTHF}

TIME RE JUIPET TO ASSEMBLE THER A AL CONOUCTANCE MATRIX $=$. 316 SECONDS

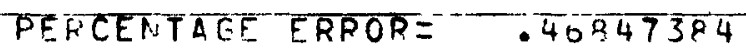

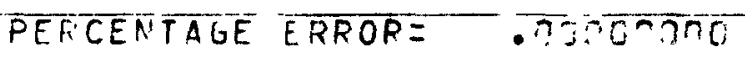

\begin{tabular}{|c|c|c|c|c|c|}
\hline NODAL & TEMPERA & TURES & FOR TIME $=$ & & 1.00000 \\
\hline NODE & TEMP . & NODE & TEMP. & NOOE & TEMP \\
\hline 1 & 1699.77 & 3 & $18: 1.49$ & 5 & 2037.92 \\
\hline 2 & 1681.35 & 4 & 1829. & 6 & 2.229 .12 \\
\hline 1 & 2216.03 & 9 & 2257.65 & 11 & 2228.00 \\
\hline 8 & 2153.47 & 10 & 2194.96 & 12 & 2245.15 \\
\hline
\end{tabular}




\section{B.7 REFERENCES}

1. Saeger, J., "HEXT, A special Purpose Heat Conduction Code for the HTGR Core," GAMD-10534, March 3, 1971.

2. Shenoy, A.S., and D. W. McEachern, "HTGR Core Therma1 Design Methods and Analysis," GA-A12985, December 31, 1974. 


\section{APPENDIX C \\ STRESS ANALYSIS OF ONE-TWELETH AND \\ ONE-HALF SECTORS}

The two dimensional linear finite element code, SAFIRE, was used for the twelfth sector thermal stress and half sector mechanical load analyses. Nodal temperatures from the TEPC code were used in the generalized plane strain analyses of the one-twelfth sector. Due to the geometrical and structural symmetry of this sector, the axial strain is constant across the cross section (zero beam curvatures). To allow for the stress free thermal expansion of the sector, roller boundary conditions are employed on the two lines of symmetry of the sector as shown in Fig. 9. These conditions allow free movement of the sector radially outward along the symmetry lines but yield zero net force across these lines. Since these lines have zero rotation, an in-plane bending moment results. The axial strain condition also leads to a self equilibrated axial bending moment. The input data listing for the one-twelfth sector mode1 B1 is shown in Table C1. The SAFIRE output is given in Table C2. Other twelfth sector cases were similar.

The one-half sector problem has only one line of loading symmetry and roller conditions were also utilized on this line as shown in Fig. 30. A uniform pressure of $100 \mathrm{psi}$ was applied on one face and roller conditions were also employed on the opposite face to simulate a rigid frictionless surface that supplies the reaction force. The input data listing for the half element mode1 HB1 is shown in Table C3. The SAFIRE output for this case is given in Table $\mathrm{C} 4$. Other half sector cases are similar.

The material properties used for all cases were from the built-in H-451 graphite module. The element thickness was taken as unity with a hex flat ( $\log$ radius) dimension of $1.32 \mathrm{in.} \mathrm{(the} \mathrm{radius} \mathrm{of} \mathrm{the} \mathrm{seven} \mathrm{hole} \mathrm{element}$ mode1). The complete set of material properties (assuming a transversely isotropic $\log$ ) are listed in Table $\mathrm{C} 2$ as part of the SAFIRE code output. 
TABLE C. 1

SAFIRE SAMPLE PROBLEM INPUT DATA

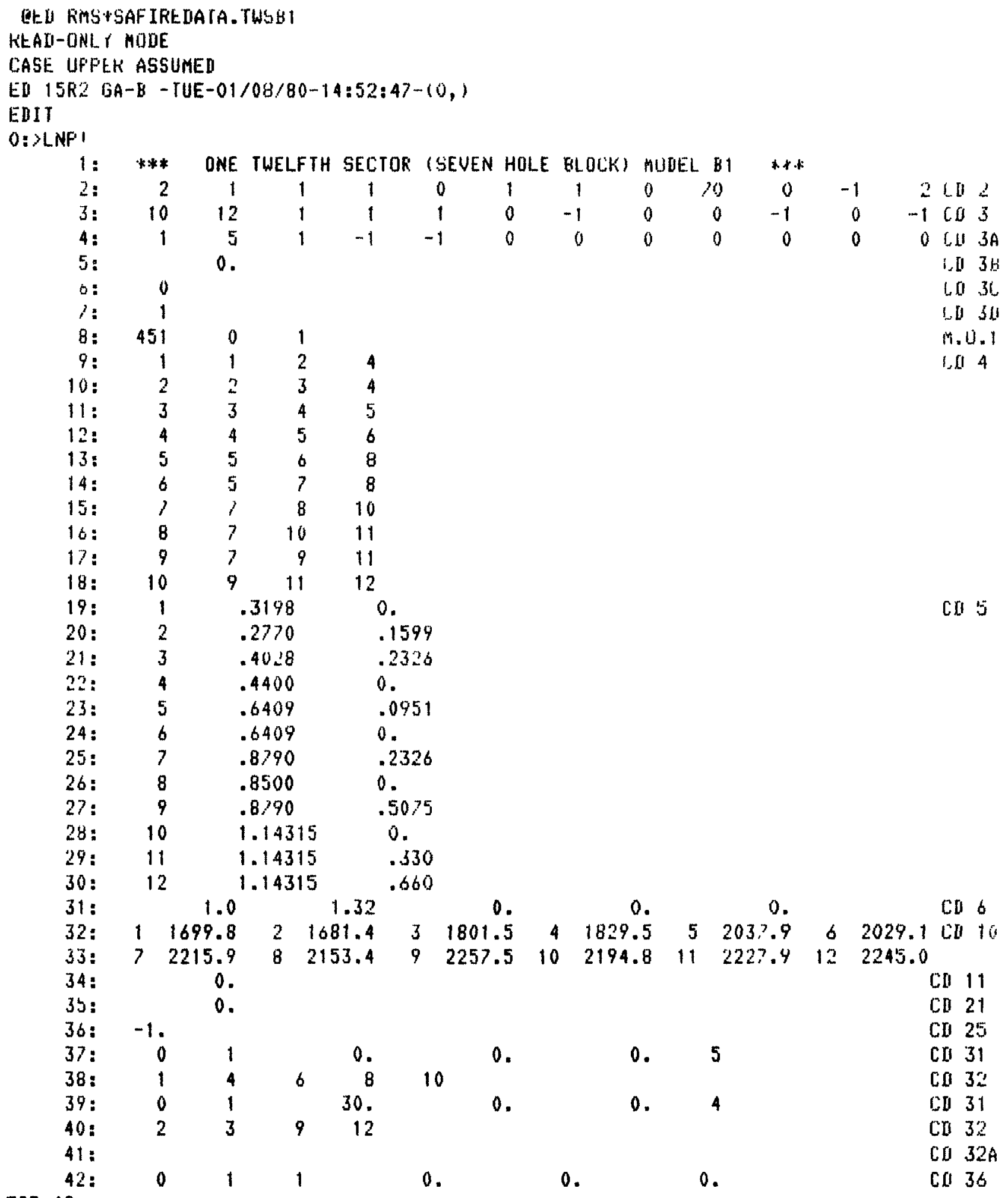




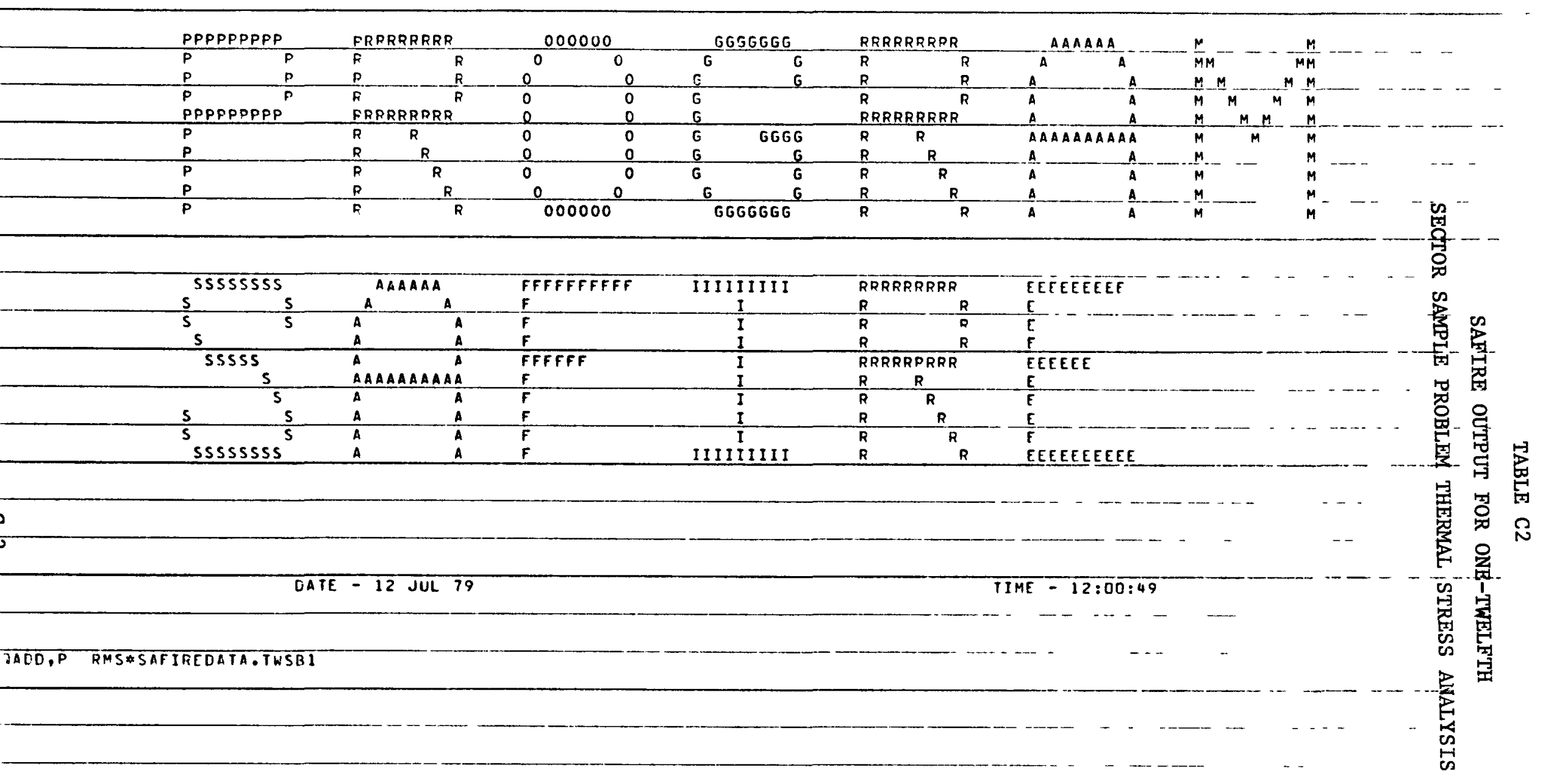


RT,TL POTANFASATIRE UF.

IRPUD 27R3 GA-A E33 SL7?K1 07/12/79 12:00:42

\section{ITANG *SAFIRE4F(1) ELEMENT TABLE}

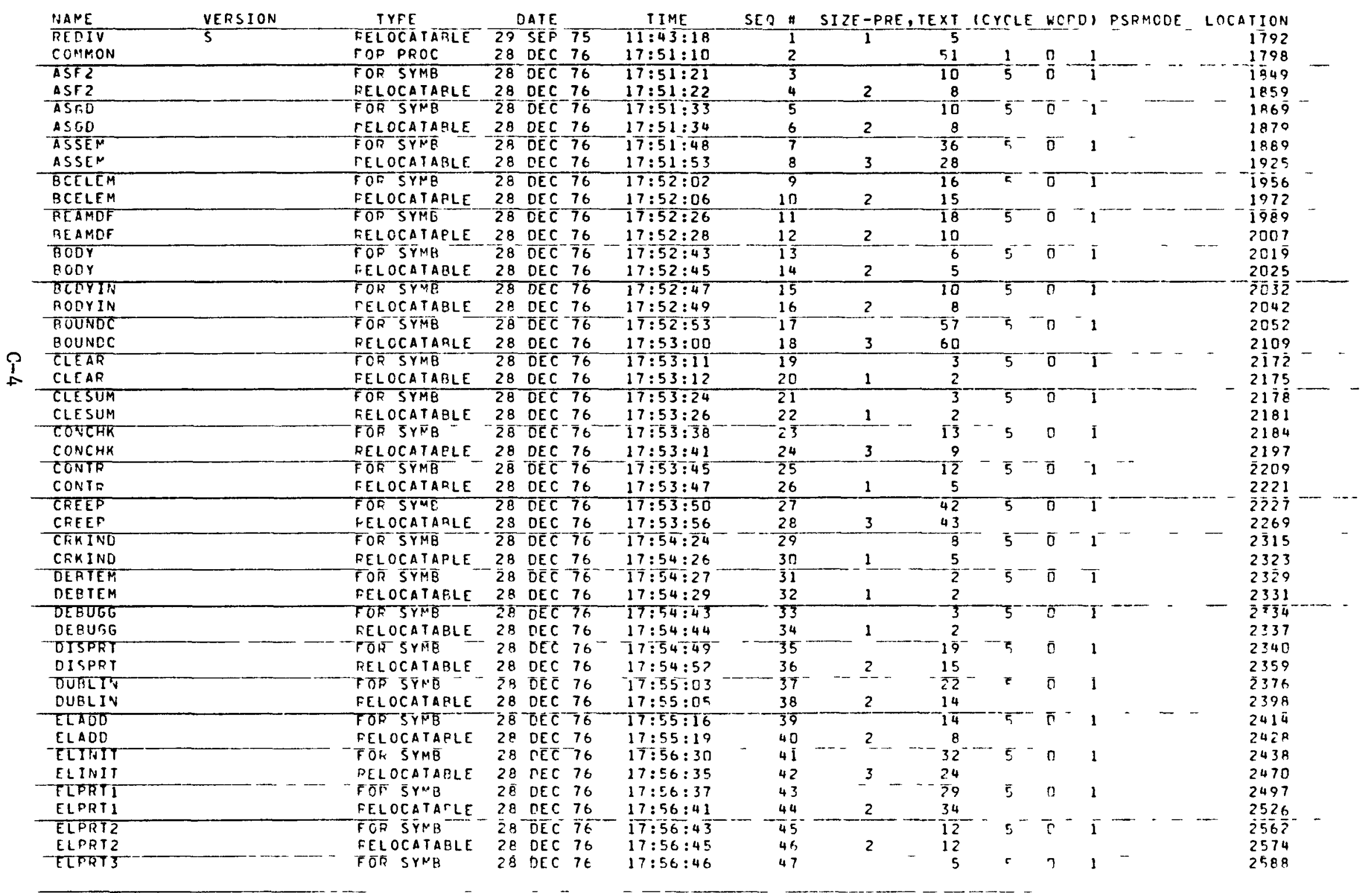




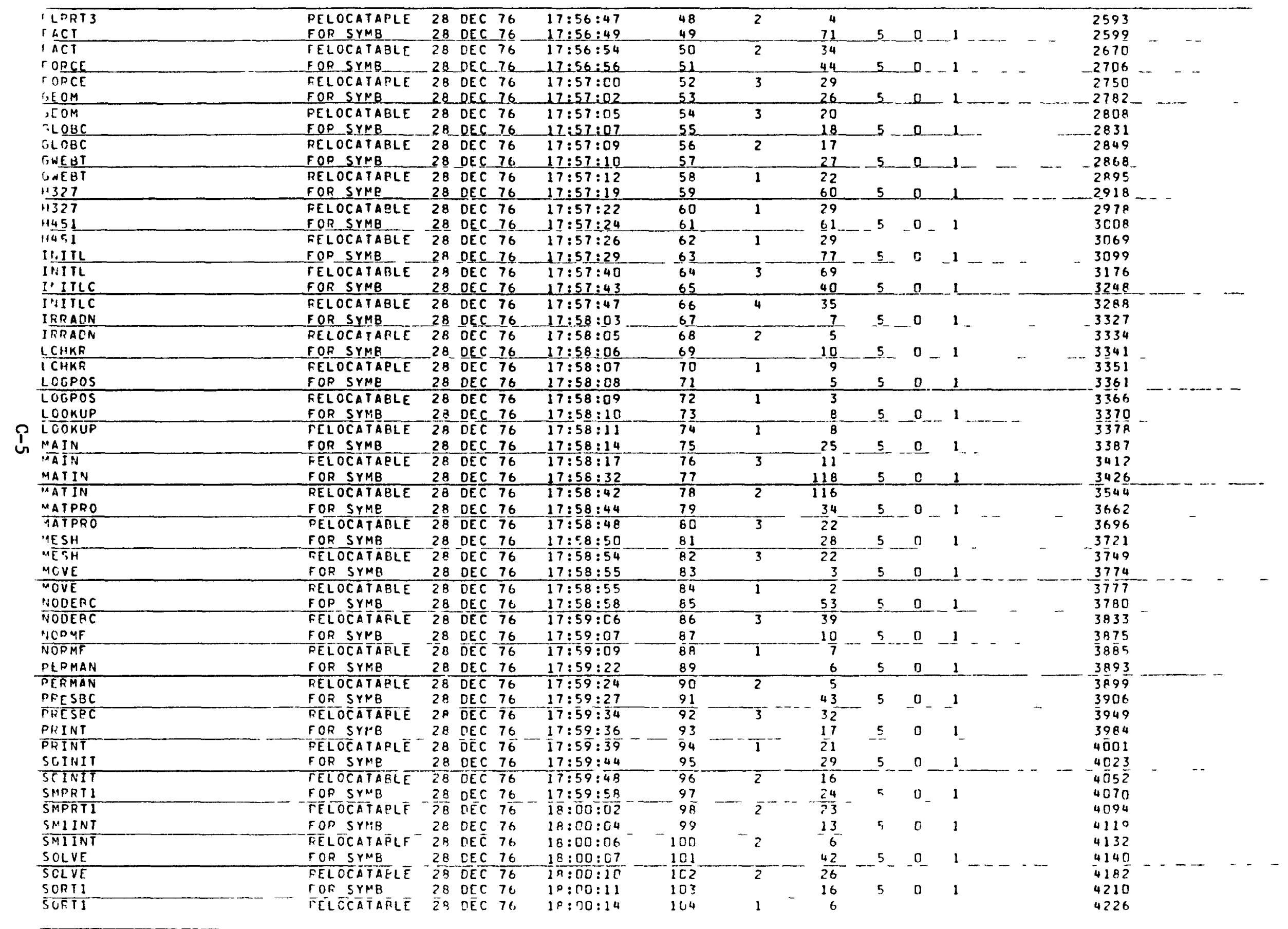




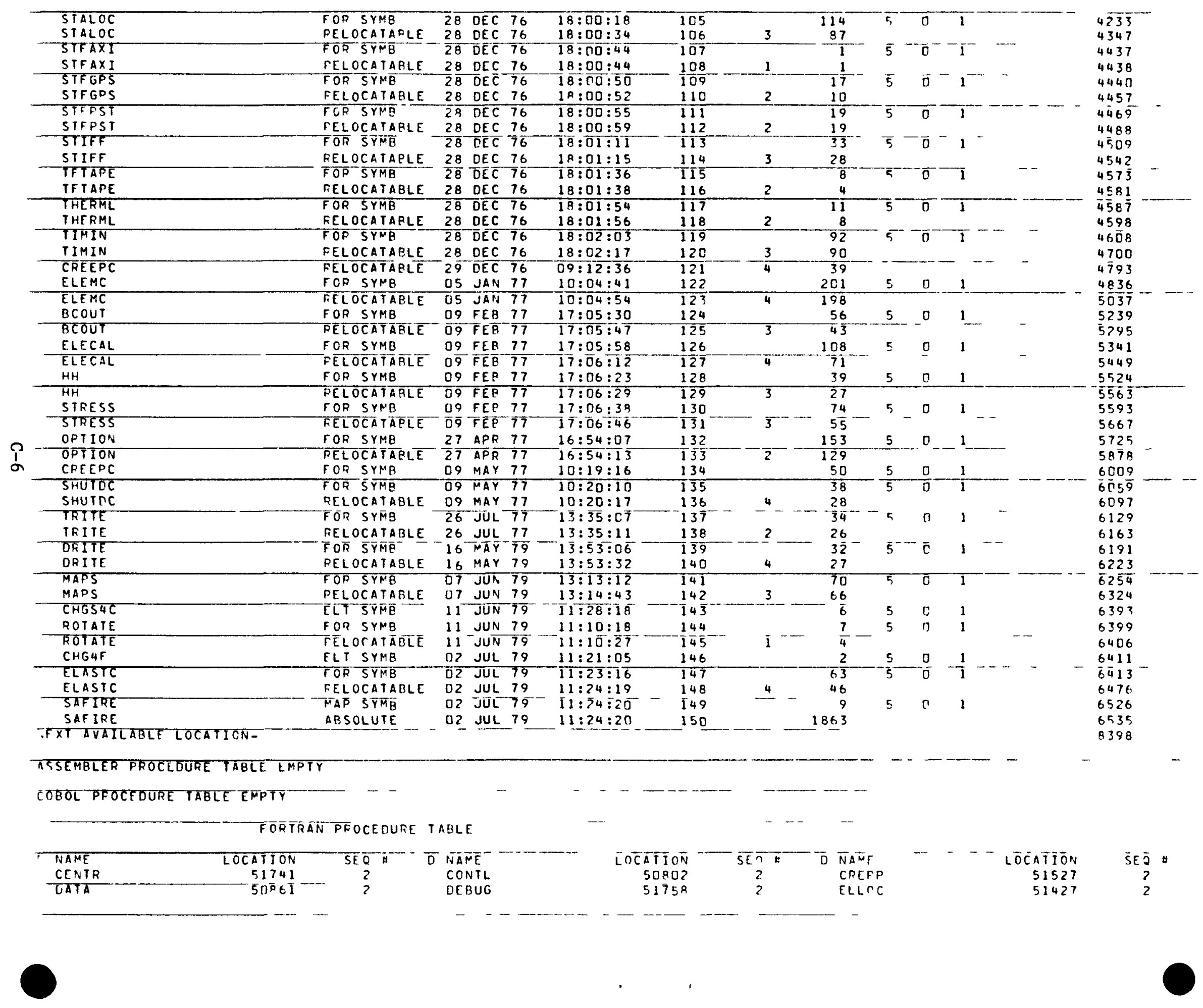




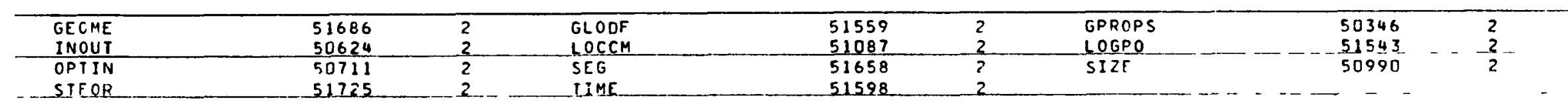

\section{ENTRY POINT TABLE EMFTY}

\section{JELT,D RMS SAF IREDATA.TR'SBI}

ELI BRI S7401C 07/12/79 12:00:45 101

END ELT. ERROFS: NONE. IIME: C.104 SEC. IMAGE COUNT: 42

QASG,A RMS*SAFTWSB1.

DUSE 9, RMS SAFTHSBI

aXOT POTANG SAFIRE 4F.SAFIRE

i

T

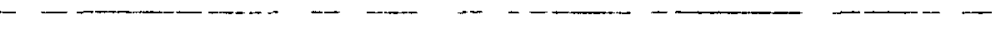


CARO 2 - OPTIONS

TNDELT ITTYPE IFTYPE NTEMP NCOSE NTEMUN NTIMUN NSTEP NCMAX NORM NRSTAR ITAPE

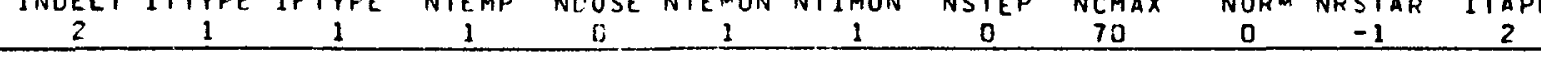

(2.

THIS IS A GENERALIZED PLANE STFAIN ANALYSIS

TEMPS INPUT ON NODAL POINT BASIS

DOSES INPUT ON NODAL POINT BASIS

TEMPERATURES VARY SPATIALLY, CONSIANT WITH IIME

RAST FLUX IS UNIFOFM AND CONSTANT

TEMPERATURES ARE INPUT AND OUTFUT IN DEG F

TIMES ARE INPUT AND OUTPUT IN TAYS

TIME STEP IS CONSTANT FOR ALL STEPS

P CORE SIZE FOR THIS RUN IS $70 \mathrm{~K}$ WORDS

D INFINITY NORM (MAXIMUM ABSOLUTE VALUE)

PO RESTART TAPES TO BE MOUNTED. ALL INPUT ON CARDS

CISPLACEMENTS AS WELL AS STRESSES, STRAINS, AND STRESS RATIOS WILL BE SAVED ON TAPE

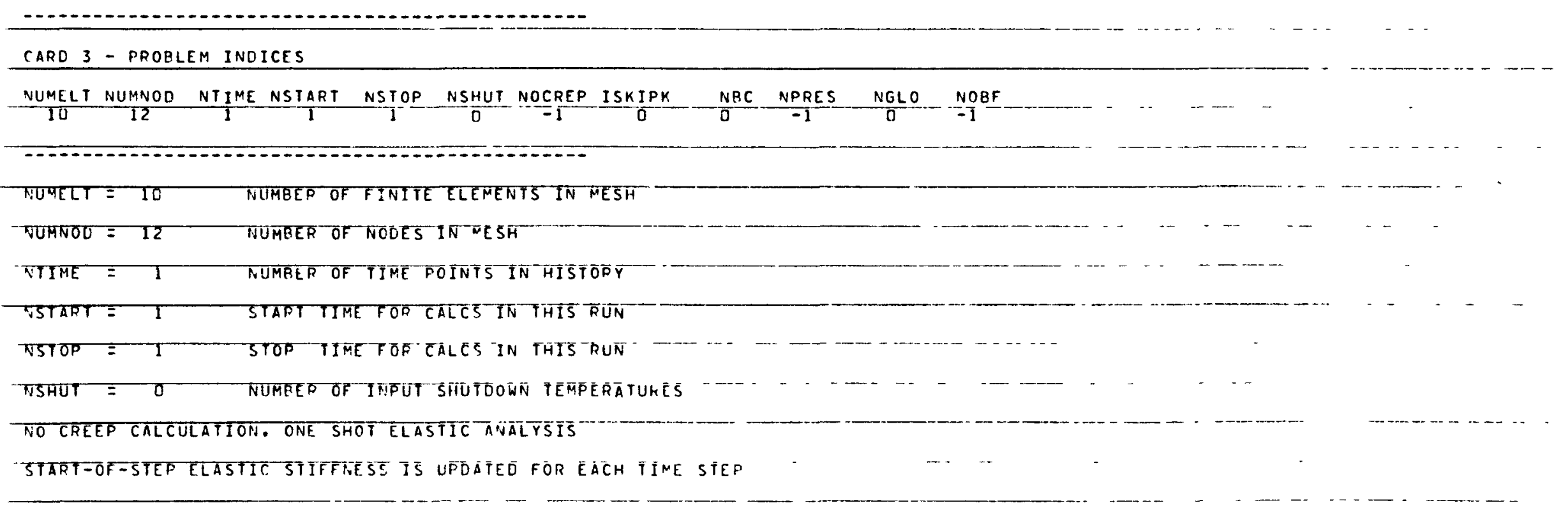


IN-PLANE BOUNDARY CONDITIONS ARE CONSTANI

- Ne PRESSURF LOADS

OUT-OF-FLANE BOUNDAPY CONDITIONS ARE CONSTANT

NO BOOY FORCE BEING CONSIDERED

-

CARO 3A - PRINTOUT OPIIONS

$-\frac{\text { IFAIL, NPTSUN, NSORT }}{1}$ (NPPINTII), IE1,4)

IIPPINI(I), I=1,4) NCRAK

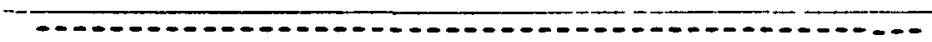

FAILURE CRITERION PASES ON MAXIMUM TENSILE OR COMPRESSIVE STRESS

NPTSUM $=5$ NUMEER OF SFATIAL POINTS PRINTED IN STRESS/STRAIN SUMMARY

SUMMARY PRINT SORTEO BY MAXIMUM NORMAL STRESS/STRENGTH RATIO

TIME STEP PRINTOUT OPTIONS FOR FOUR ELOCKS GIVEN BELOW

$P$ INPRINTIIILO PRINT ALL TIME STEPS

(1) NPRINT (I) $=0$ NO PEINTOUT FOR THIS BLOCK

NPRINT (I) $>0$ PRINT NPRINT TI PE SIEPS

NPRINTII) $=-1$ OPTION FOR OPERATING STRESS SUMMARY

MPRINTI2) = - 1 OPTION FOP OPERATING STRESS OETAILS

NPRINTI3I $=0$ OPTION FOR SHUTDOWN STRESS SUMMARY

NPRINT(4) $=D$ OPTION FOF SHUTDOWN STRESS DETAILS

PRINTOUT CONTENT OPTIONS FOR FOUR BLOCKS GIVEN BFLOW

\begin{tabular}{ll}
\hline IPRINIII) & PRINT FULL INFORMATION \\
IPRINTIII) & PRINT MAIN RESULT IN ONE TABLE \\
\hline IPRINTIII)O & PRINT MAIN AND SECONOARY RESULTS
\end{tabular}

PRINT MAIN AND SECONDARY RE SULTS IN TWO TABLES

IPRINTII $=O$ OPTION FOC OFERATING STRESS SUMMAT

IPRINTI2I $=0$ OPTION F OF OPE TATING STREESS DETAILS

IPRINTI3) $=$ OPTION FOF SHUTDOW'A STRESS SUMMARY

IPRINTI4) $=0$ OPIIONFOF SHUTOOWN STRESS OETAILS -

NO CRACKING ALLOWED

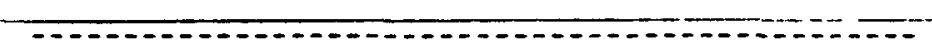

CATD $\overline{3 P}$ - FELAXATION PAFAMETEF 
RELAXP $=1.00000 J$

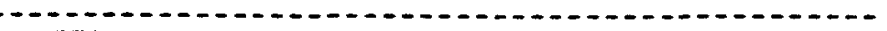

CARD 3C - SUBSTEP CPTIONS

NSUES $=0$ NO SURUIVISION $1=1$ SORSIEPI

CARD 30 - OPTIONS FOR STRESS RATIO IN SCRTING PRINTOUT

IRATIO $=1$ STRESS RATIO IS CONSTANTFOR ALL IIME STEPS

$\stackrel{0}{\mathfrak{1}}$ 
MATERIAL PROPERTY INPUT OPTIONS

MATERL $=451$

MCHG $=0$

\section{QUILT-IN DATA FOR HUSI HAS BEEM INITIALIZED}

BUILT-IN DATA FOR MATEPIAL 4 SI SET I

ULTIMATE TENSILE STFENTTH (AXIAL) VS. POSTTION IN THE LOG

\begin{tabular}{lrrrr} 
ENL CENTER & END EDGE & MID-L CENT & MID-L & EDGE \\
\hline $.225000+04$ & $.2728 C 0+04$ & $.176400+04$ & $.333700+04$
\end{tabular}

ULTIHATE TENSILE STRENGTH (RADIAL) VS. POSITION IN THE LOG

\begin{tabular}{lrrrr} 
END CENTER & ENO EDGE & MID-L CENT & MID-L EOGE \\
\hline $.219500+04$ & $.234200+04$ & $.142500+04$ & $.236500+04$
\end{tabular}

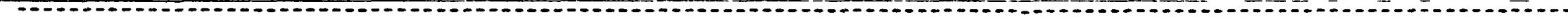

EUILT-IN DATA FOR MATERIAL 451 SET 2

I AXIAL YOUNG'S MODULUS

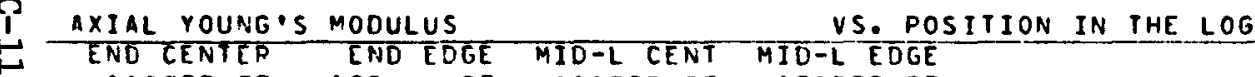

\begin{tabular}{rrrr}
$.118000+07 \quad .129000+07 \quad .111000+07 \quad .138000+07$ \\
\hline
\end{tabular}

PADIAL YOUNG'S MOOULUS

\begin{tabular}{llll}
$.110000+117 \quad .107000+07 \quad .980000+06 \quad .112000+07$ \\
\hline
\end{tabular}

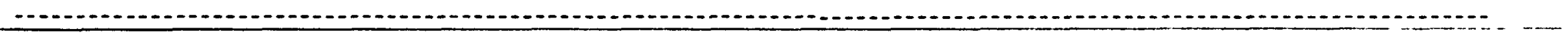

PUILTIIN OATA FOR MATERIAL 4EI SET 3 -

STRENGTH VS. MODULUS EX PONENTS

AXIAL - ISZ/SZOI = IEZIEZOI*\$.5OO

RAOTAL - TSRTSPO = TERTERT $\$ .500$

TTMPETATURE DEPENOFNCE OF UNIRPAOTATED YOUTNG 'S MOOOULUS

$E=E 0 * 11.0 * .150000-03 * \mathrm{~T}+.000000 *(T * 2) 1$

$-\cdots$

$-$

EUILT-IN JATA FOR MATERIAL

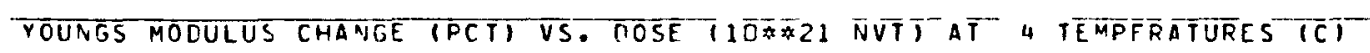

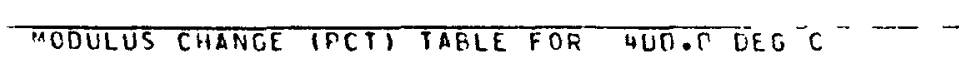

TABULATEO FUT.CTION YTXT NITH $\bar{X} \equiv \overline{D O S E}$ AND $Y=Y M \bar{C}$ 


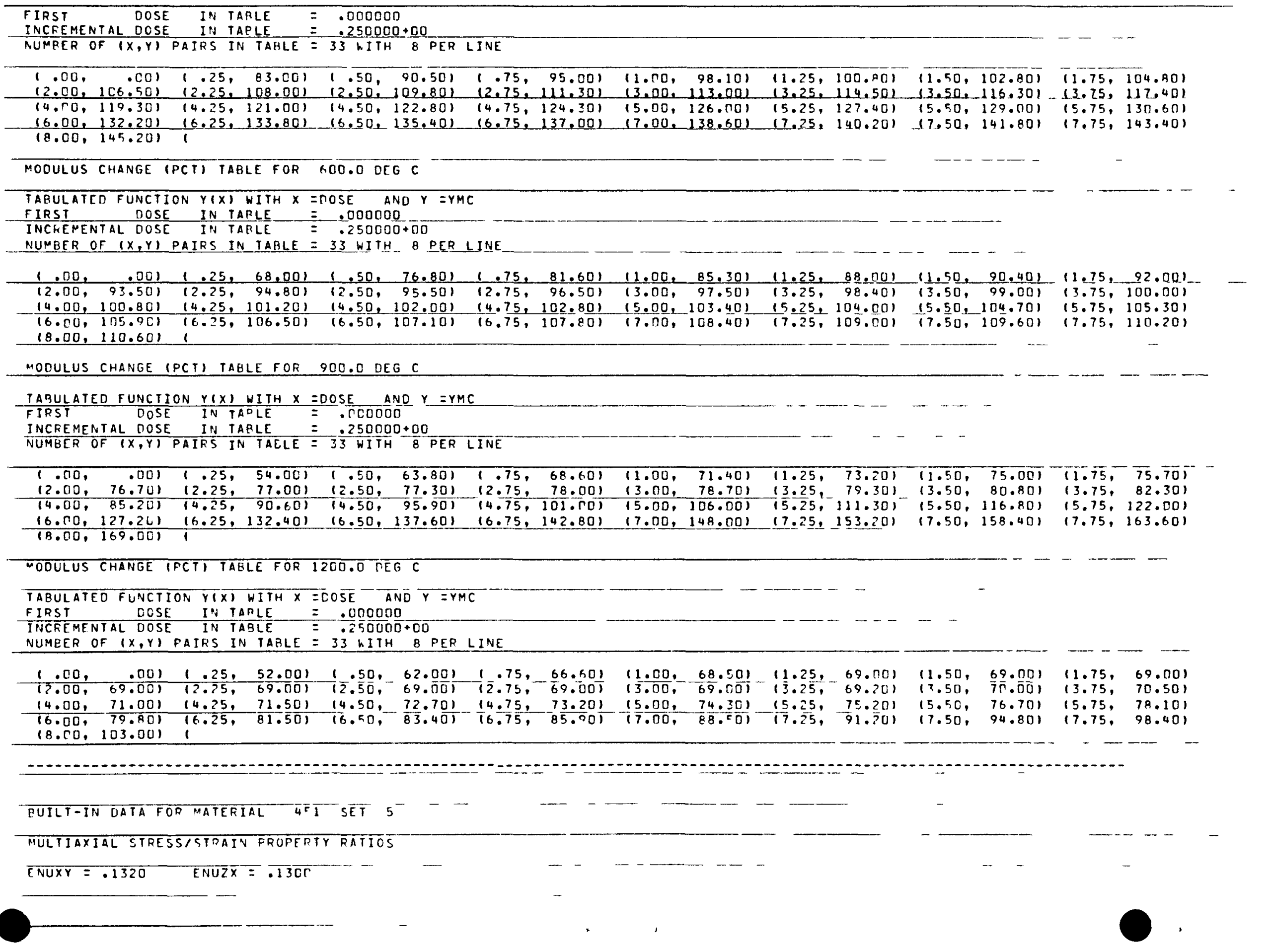




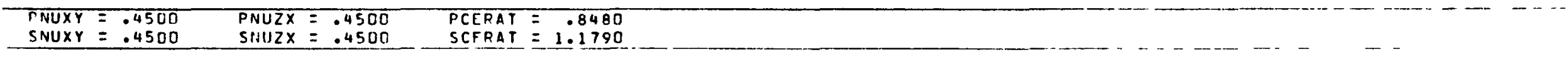

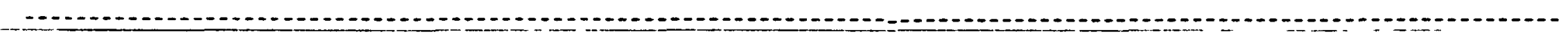

RUILT-IN DATA FOR MATERIAL 451 SET 6

STEADY CAETP MOBTLITY IIC

TABULATED FUNCTION YIX TITH $X$ ETEMP AND $Y=S C F$

FIRST TEMP IV TARLE $=.200000+C 3$

IVCFEMFNTAL TEMP IN TABLE $=.500000+02$

NUMBER OF $(X, Y)$ PAIRS IN TABLE $=25$ HITH B PER LINE

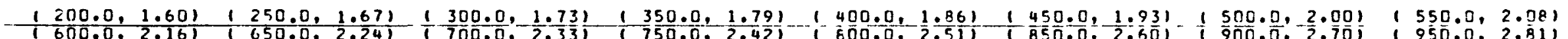

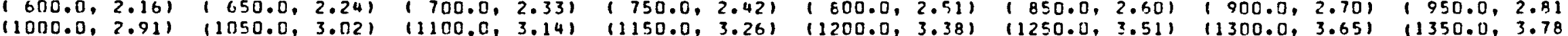

$(1400.0,3.93)$ (

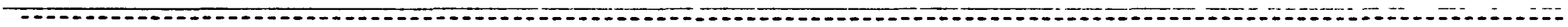

PUILT-IN DATA FOR MATERIAL 451 SET 7

PRIMARY CREEP SPRING MODULUS (PSI) = PCEZRO * PCE (T)

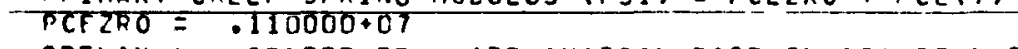

I GRELAX $=.20 U 000+00$ IPELAXATION DOSF IN 10*20 NVTI

$\stackrel{\omega}{\omega}$ PCE (MULTIPLYING FACTOR) VS. TEMP IN DEG C
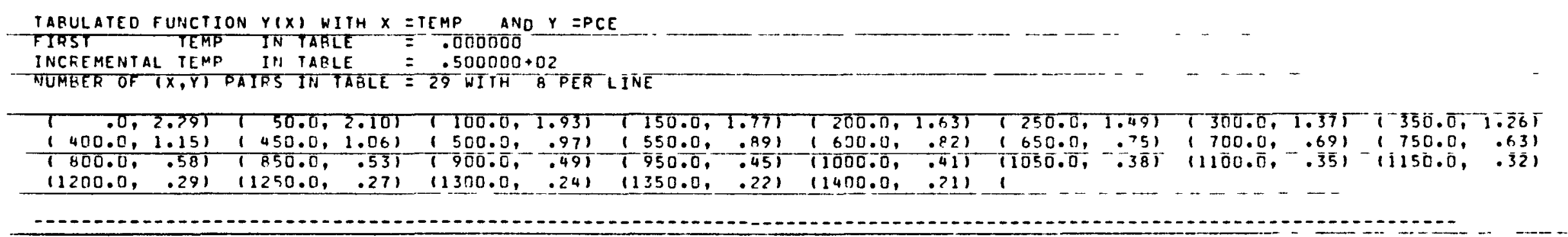

\section{RUILT-IN DATA FOR MATETIAL 4 ET SET $\overline{8}$}

THERMAL STRAIN IUNTRFATIATEOT IN AXIAL IZT DOTRECTIONN TPCTT

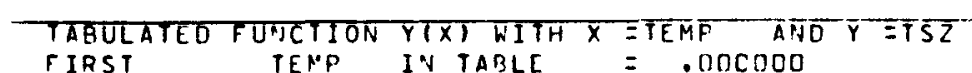

TIRST TENP IN TABLE -

OF $(X, Y)$ PAIRS IN TABLE $=33$ SITHOOLO

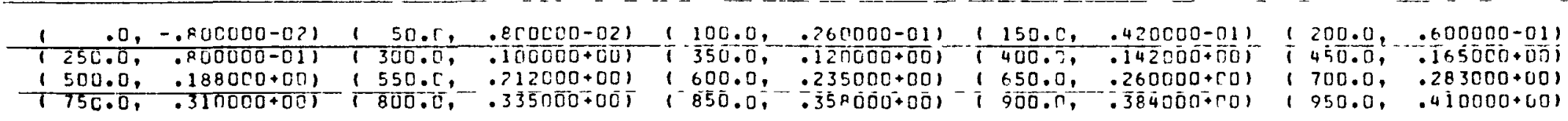




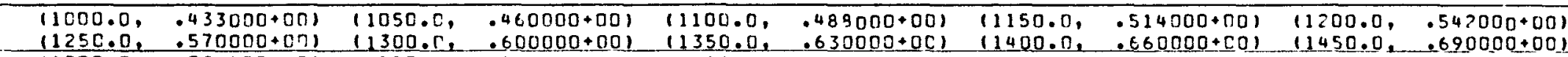

$11500.0, .724000+40)(1550.0, .755000+00)(1600.0, .790000+00) \quad 1$

THERMAL STPAIN IUNIRRAOIATEOI IN RADIAL (X) DIRECTION (PCT)

TARULATED FUNCTION $Y(X)$ WITH $X=$ TEMP AND $Y=T S X$

$\begin{array}{ll}\text { FIRST } & \text { TEMP IN TABLE } \\ \text { INCREMENTAL TEMP IN TAELE } & =.000000 \\ \text { INMBER OF IX } & =0000+02\end{array}$

NUMBER OF $(X, Y)$ PAIRS IN TABLE $=33$ KITH 5 PER LINE

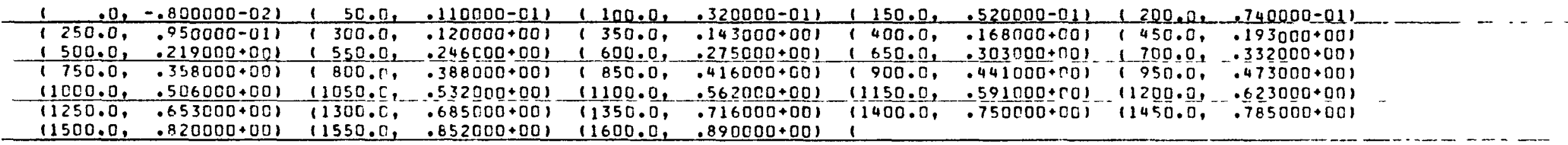

-

PUILT-IN DATA FOR MATERIAL 451 SET 9

THERMAL STRAIN CHANGE (PCT) VS. COSE (10\#21 NVT) AT 3 TEMPERATURES (C)

$P$ STPAIN CHG (PCT) AT $T=600.0$ OEG C

f

TABULATED FUNCTION $Y(X)$ WITH $X=$ COSE AND $Y=T S C Z$

\begin{tabular}{lll} 
FIRST & DOSE IN TABLE & $=.000000$ \\
\hline INCREMENTAL DOSE IN TARLE & $=.500000+00$
\end{tabular}

NUMBER OF $(X, Y)$ PAIPS IN TABLE $=17$ WI IH 8 PER LINE

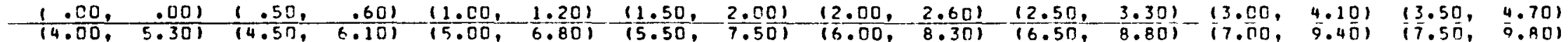

$(8.00,10.39) 1$

Z STRAIN CHG (PCT) AT T $=900.0$ DEG C

TABULATEO FUNCTION Y X XI WITH X = OOSE ANO Y $=T S C Z$

FIRST DOSE IN TABLE $=.000$ DOO

IP.CPEMENTAL DOSE IN TARLE $=.500000+00$

DUMBER OF $(X, Y)$ PAIRS IN TABLE $=17$ WITH B PER LINE

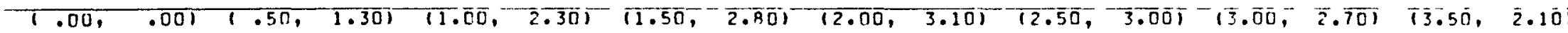

$(4.00,1.20) \quad 14.50, \quad .201 \quad 15.00,-.80) \quad(5.50,-2.201 \quad 16.00,-3.40) \quad 16.50,-4.701 \quad 17.00,-6.00)(7.50,-7.40)$

$18.00,-8.701$

Z STPAIN CHG (PCT) AT T $=1200.0$ CEG C

TABULATED FUNCTION Y(X) WITH $\bar{X}=\overline{C O S E}$ AND $Y^{-} \overline{\text { TTSCZ}}$

$\begin{array}{lll}\text { FIRST DOSE IN TABLE } & =.000000 \\ \text { INCREMENTAL DUSE IN TAPLE } & =.500000+\overline{D O}\end{array}$

NUMBEF OF $(X, Y)$ PAIRS IN TARLE $=17 \mathrm{hITH} B$ PEP LINE

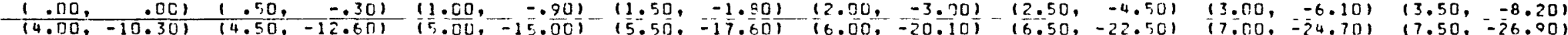


$18.00,-29.0011$

$X$ STRAIN CHG (PCT) AT $=600.0$ DEG $C$

TARLLATED FUIJCTION YIXI WITH $\bar{X}=\overline{D O S E} \triangle A N D Y=T S C \bar{X}$

\begin{tabular}{lll} 
FIRST DOSE IV TAFLE & $=.000000$ \\
\hline
\end{tabular}

INCFCMCNTAL DOSE IN TABLE $=.500000+00$

NUMAER OF $(x, y)$ PAIRS IN TABLE $=17$ HITH 8 PER LINE

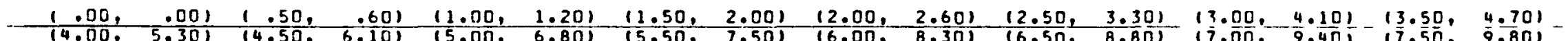

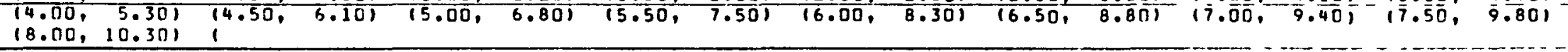

$X$ STPAIN CHG (PCT) AT T $=900.0$ DEG C

TARULATED FUNCTION $Y(X)$ WITH $X=$ DOSE AND $Y=$ TSCX

FIRST DOSE IN TARLE $=.000000$

INCREMENTAL DOSE IN TARLE $=.500000+00$

NUMRER OF $(X, Y)$ PAIPS IN TABLE $=17$ WITH 8 PER LINE

\begin{tabular}{|c|c|c|c|c|c|c|c|c|c|c|c|c|}
\hline $\begin{array}{l}1.00 \% \\
14.00\end{array}$ & $\begin{array}{r}.001 \\
1.201 \\
\end{array}$ & $\begin{array}{l}1.50, \\
14.50 \\
\end{array}$ & $\begin{array}{r}1.301 \\
.201 \\
\end{array}$ & $\begin{array}{l}11.00 \\
15.00 \\
\end{array}$ & $\begin{array}{l}2.301 \\
-.801\end{array}$ & $\begin{array}{l}11.50 \\
15.50 \\
\end{array}$ & $\begin{array}{r}2.801 \\
-2.201 \\
\end{array}$ & $\begin{array}{l}12.00 \\
16.00\end{array}$ & $\begin{array}{r}3.101 \\
-3.401 \\
\end{array}$ & $\begin{array}{l}12.50,3.001 \\
16.50,-4.70)\end{array}$ & $\begin{array}{l}13.00,-2.705 \\
17.00,-6.001\end{array}$ & $\begin{array}{l}13.50, \quad \overline{2} .20)^{-} \\
(7.50,-7.401\end{array}$ \\
\hline
\end{tabular}

\section{$X$ STRAIN CHG IFCT AT T $=1200.0$ DEG C}

TABULATEO FUNCTION YIXI WITH $X$ EDOSE AND $Y$ ETSCX

$P$ FIRST DOSE IN TARLE $=.000000$

I INCREMENTAL DOSE IN TARLE $=0500000+00$

$\rightarrow$ NUMBER OF $(X, Y)$ PAIRS IN TABLE $=17 \mathrm{WITH} 8$ PER LINE

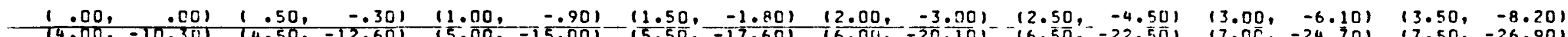

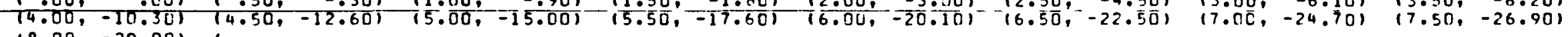
$18.00,-29.00)($

PUILT-IN DATA FOR MATERIAL 451 SET TO

IRRAOIATION STRAIN POLYHOMIAL COFFFICIENTTS

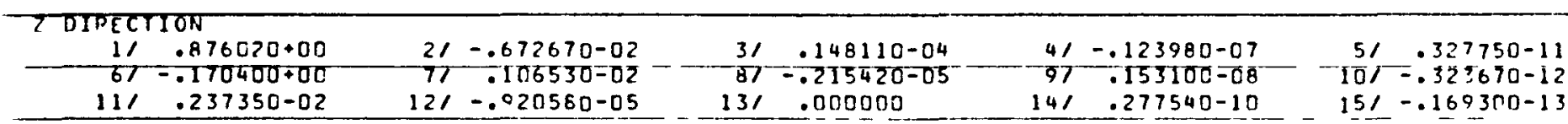

$x$ DIRECTION

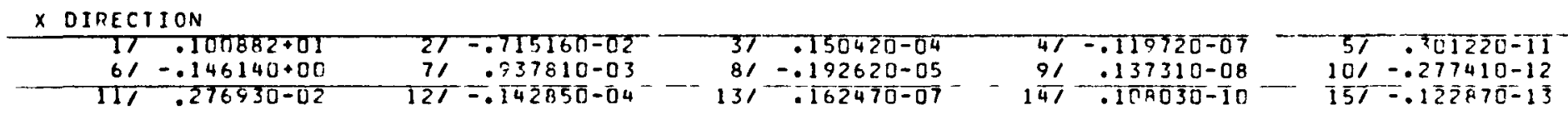

PUILT-IN OATA FOR MATERIAL 451 SET 11 


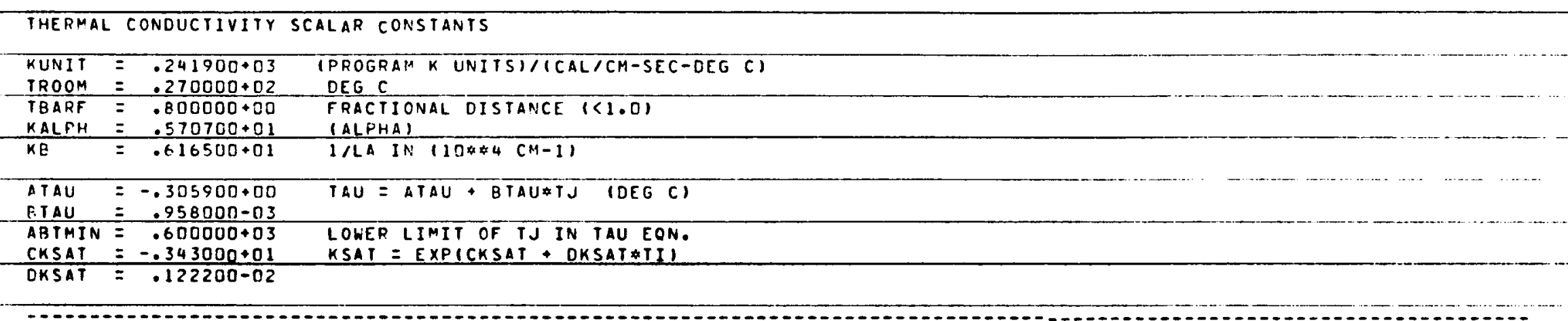

\section{QUILT-IN DATA FOR MATERIAL $4 E 1$ SET 12}

\section{KUT FUNCTION}

TABULATED FUNCTION $Y(X)$ HITH $X=T E M P$ AND $Y=K U T$

FIRST TEMP IN TAPLE $=-.173000+03$

INCREMENTAL TEMP IN TABLE $=.500000+02$

NUMBER OF $(X, Y)$ PAIRS IN TARLE $=35$ WITH 6 PER LINE

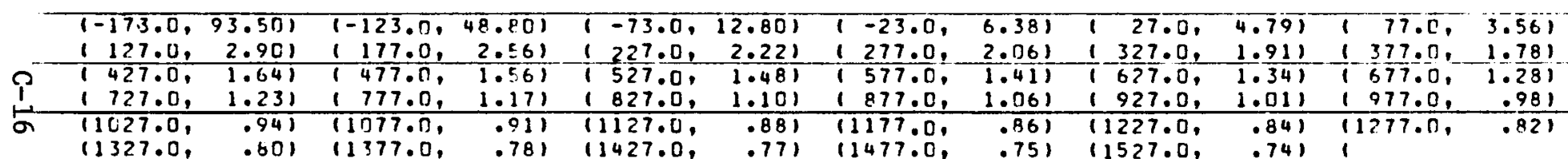

(1327.0,

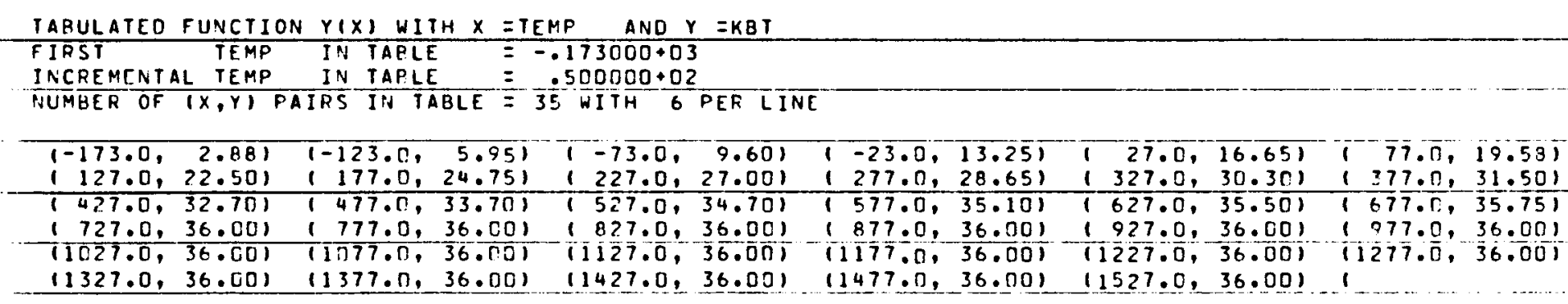

KDT FUNCTION

TAEULATED FUNCTION Y $(X)$ WITH $X=T E M P$ AND $Y=K D T$

FIRST TEMP IN TARLE $=-.173000+03$

INCREMENTAL TEMP IN TARLE $=.500000+02$

NUMEER OF $(X, Y)$ PAIFS IN TABLE 35 WI TH 8 PER LINE

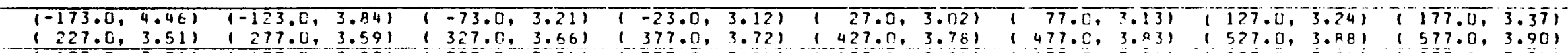

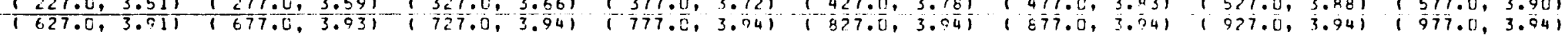


ENO OF POOPERTY PRINTOUT

\begin{tabular}{|c|c|}
\hline बASG, T & $13,0 / 1 / T R K / 100000$ \\
\hline TASG, & LUSEGC,D/RI/TRK/IDOOOOO \\
\hline 2ASG, T & LULOAD,0/7E/TRK/100000 \\
\hline DASG, T & LUTIME, $0 / 34 /$ TRK/100000 \\
\hline D̄ASG, & LUIBC-,0/24/TRK/100000 \\
\hline ลASG, $\bar{T}$ & LUELEM, F $2 / 1 / P O S / 27$ \\
\hline
\end{tabular}

$\stackrel{p}{1}$

-FINITE ELEMENT MESH - ELEMENT EESCRIPTIONS

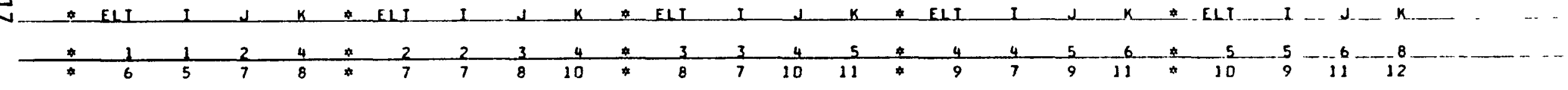

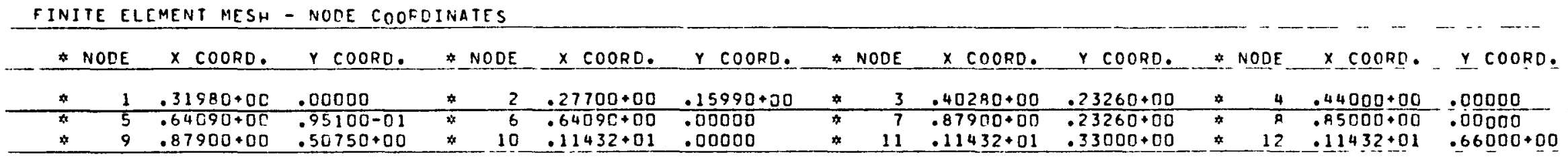

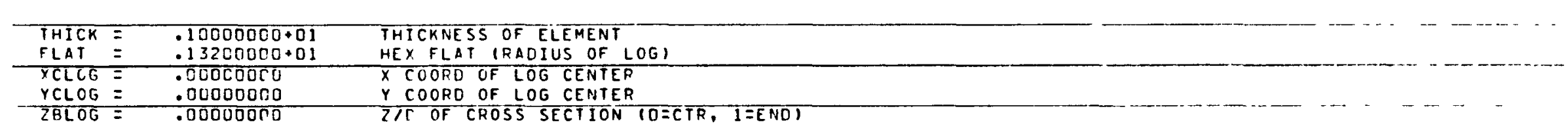




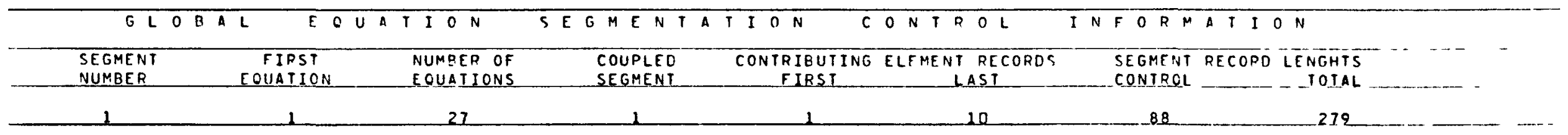

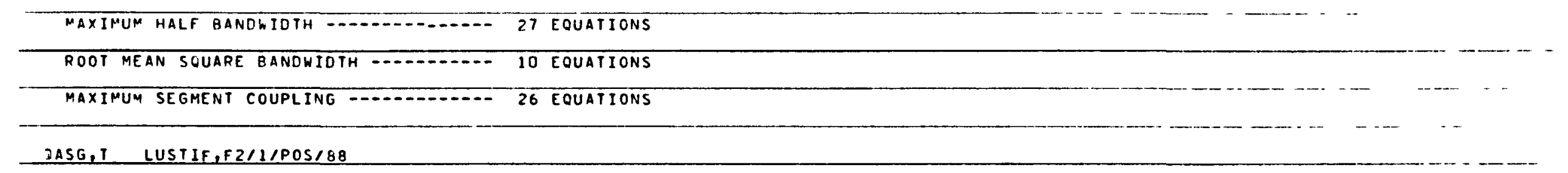

\section{* TEMPERATURE ELOCK INPUT (DEG F) * *}

INFOPMATION BELOW IS BY NODE INDICES

P TEMP MAP IS SPATIALLY VAPYING RUT CONSTANT WITH TIME

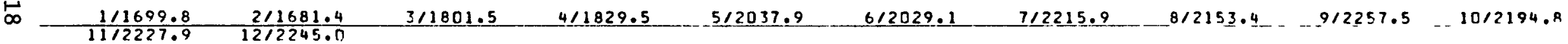

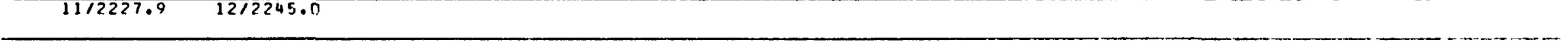

\#\#\# FAST FLUX INPUT \$\#\#

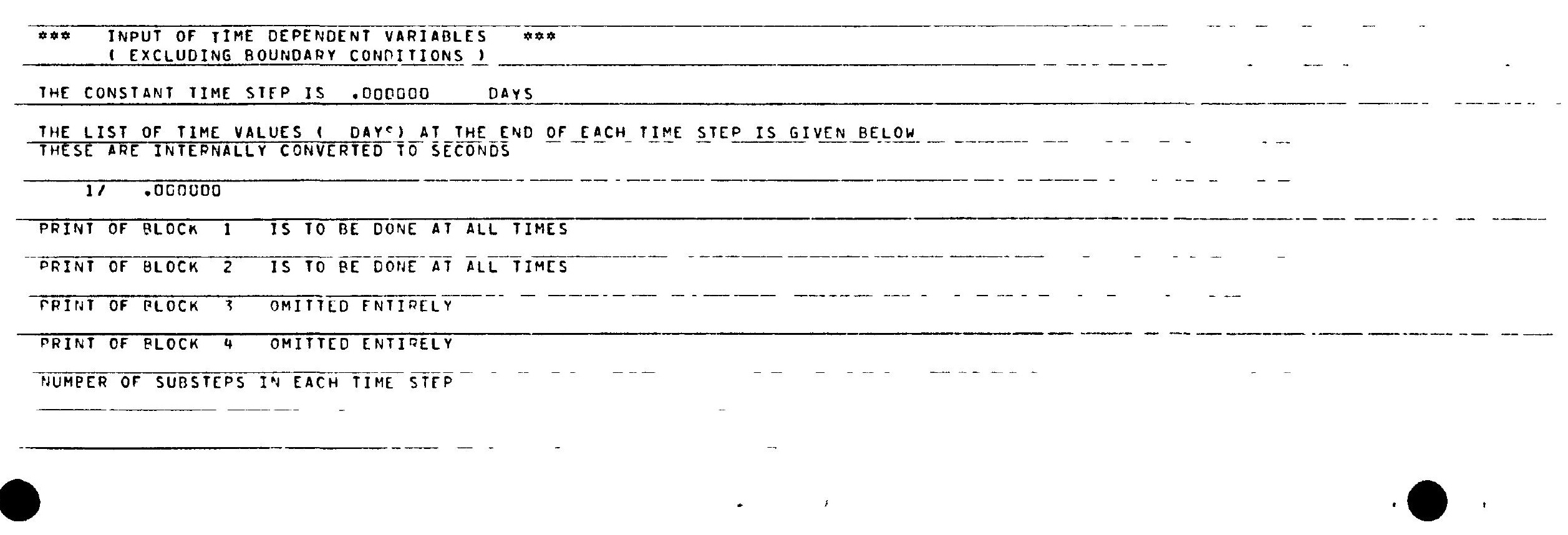




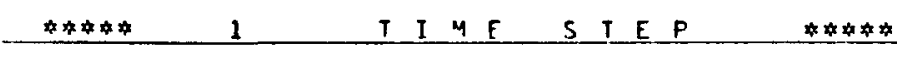

$\#$ \#IAFI TIME $\equiv .00000$ DAY DND IIME = .00000. DAYS \#\#

* * * * * INPUI OF OPERAIING OOUNDARY CONDIIIONS FOR IHE EIRST IIME SIEP

IHIS INCLUDES:UL IN PLANE BOUNDARY CONOLIIONS (CONCENIRAIED FORCES AND LOR OLSPLACEMENISI

(2) IN PLANE NORMAL PRESSURE FORCES (FOR PRESSURE LOAOING CASE ONLY)

(3) THREE GLORAL OUT OF PLANE BOUNDARY CONDITIONS IFOR GPS ELEMENT ONLY)

+ INPUT OF IN PLANE BOUNOAFY CONDITIONS +4

THIS IS CONE BY GROUPS. FOR EACH GROUP, THE FOLLOWINGS ARE INPUT:

1. (IBCGP(I), $I=1,2)-$ ROUNDARY CONOIIION CODES (OEFOECE), (1IDOISP, 1.

2. BETA - - SKEW BOUNDARY ANGLE IN PADIANS BETWEEN $X$ AND ROTATED $X$ AXIS

3. (BCGPII), I=1,2) - STECIFIED CONCENTRATED FORCES IN LB. (WHEN IBCGP=O) OR NODAL TISPLACEMENTS

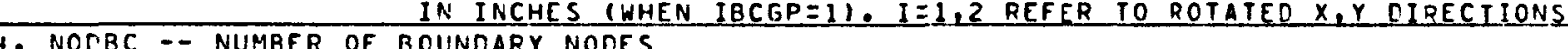

5. A LIST OF ROUNDARY NORE NUMBERS

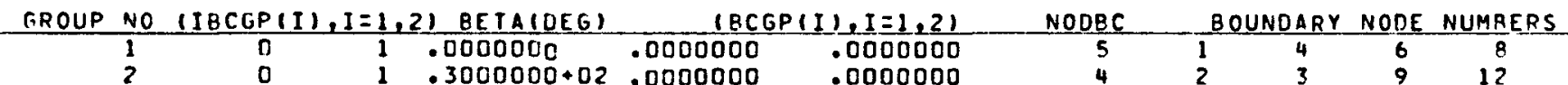

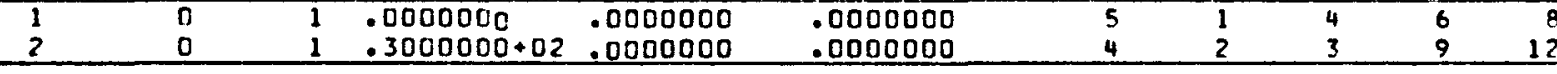

狊+ +

INPUT OF OUT OF PLANE BOUNDARY CONOITIONS +4

FORCE/STRAIN OPTION

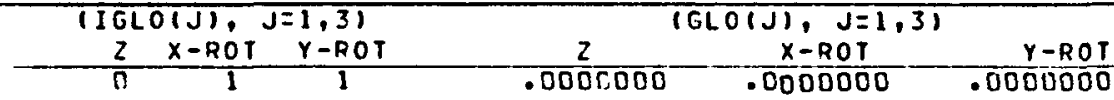

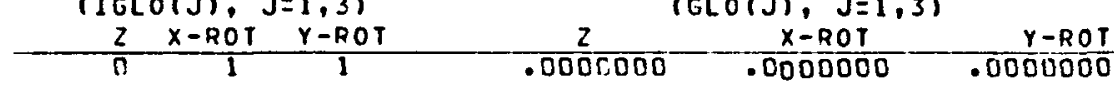

FORCE/STRAIN VALUE

AXIAL Z STRAIN EOUNDARY CONDITION IS A FORCE IN LB.

X ROTATION I Y-Z PLAMT, GOUNDARY CONOITION IS A CURVATURE IA PACIANIIN.

$Y$ POTATION $1 x-2$ PLANT, BOUNOARY CONDIIION IS A CURVATURE IN RAOIANIIN. 


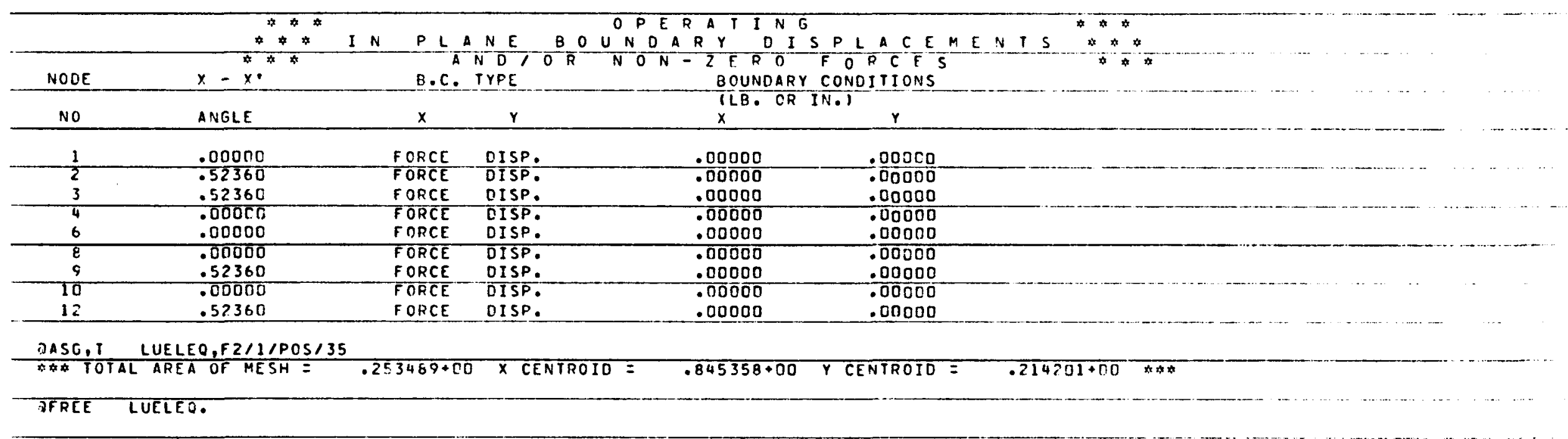

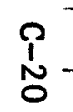




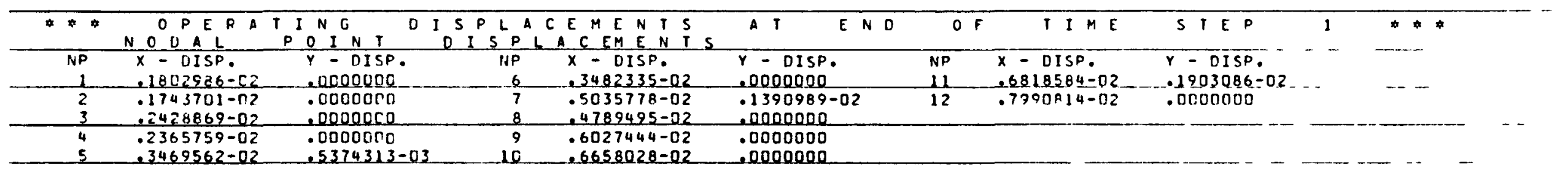

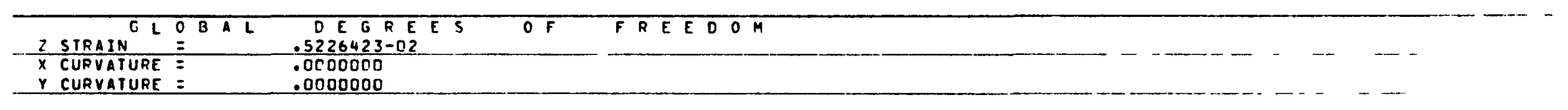

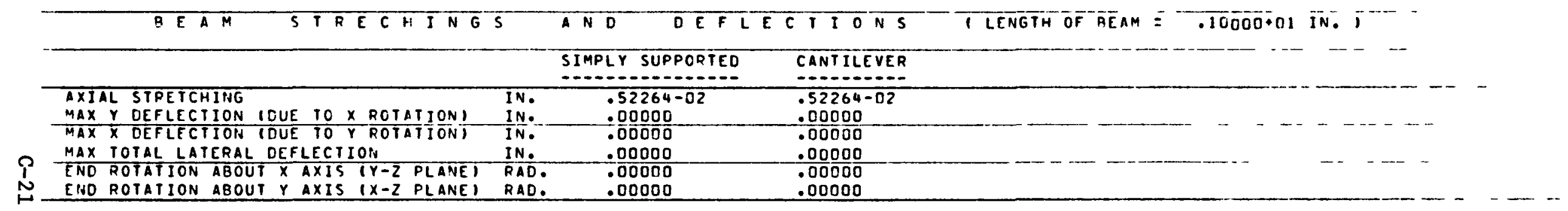

\footnotetext{
A MEANING OF CRACK INCICATOP ICRK IRDI IN THE ELEMENT STRESS STRAIN RESULTS PRESENTED ON NEXT PAGE - - - - - -

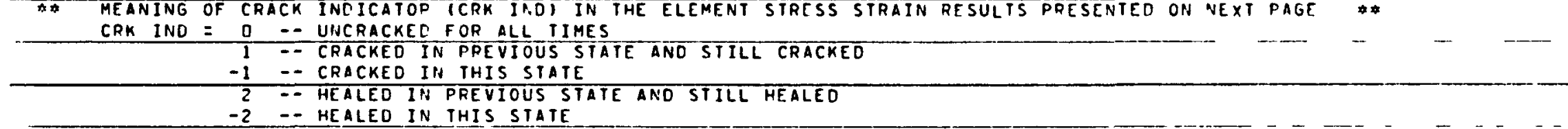

* WE ASSUME THAT THE CRACKEC STATE AT END OF SIEP IS THE SAME AS THAT CALCULATEO AT START OT STEP. I.E. WE ASSUME THAT IN-STEP CFEEP MAKES NO CHANGES IN THE START-OF-STEP CRACKED CONF IGURATIOH
} 


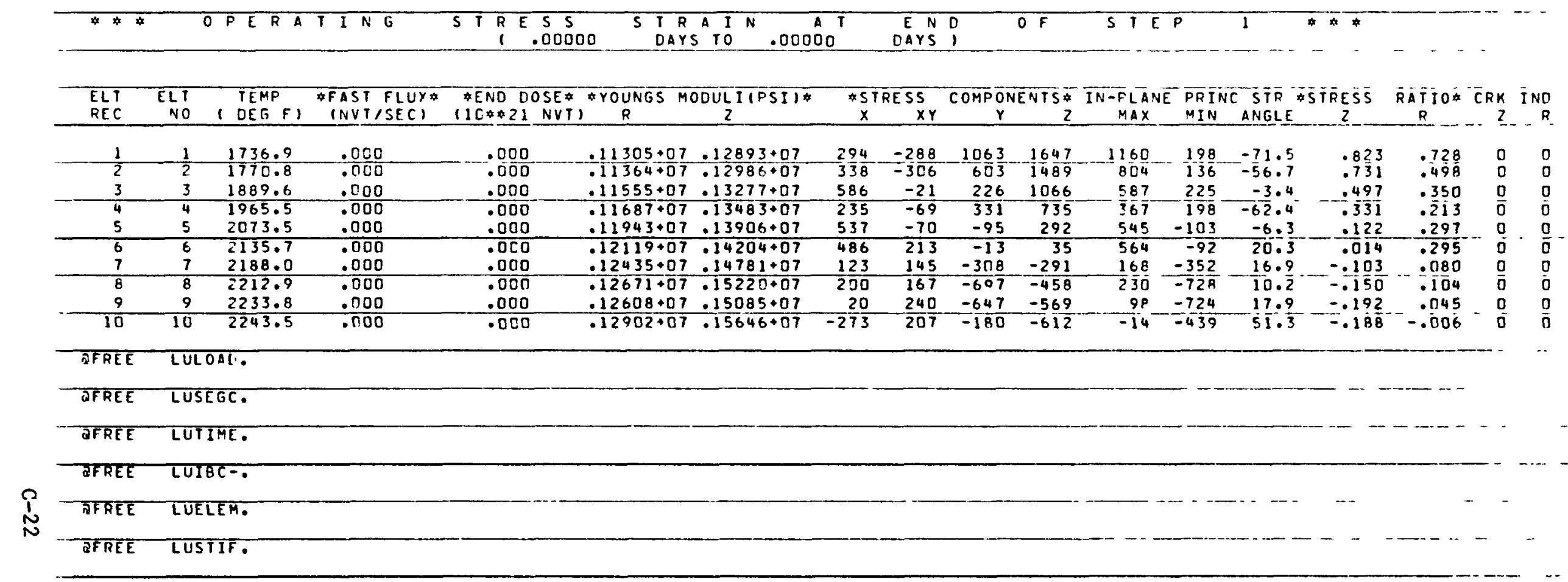

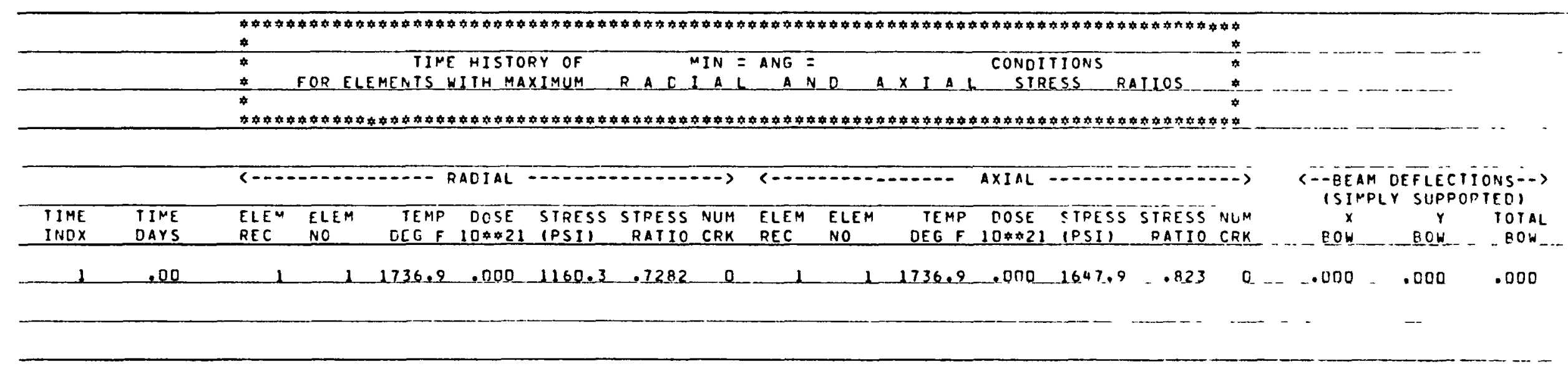


TABLE C. 3

SAFIRE SAMPLE PROBLEM INPUT DATA

ONE HALF ELEMENT ANALYSIS

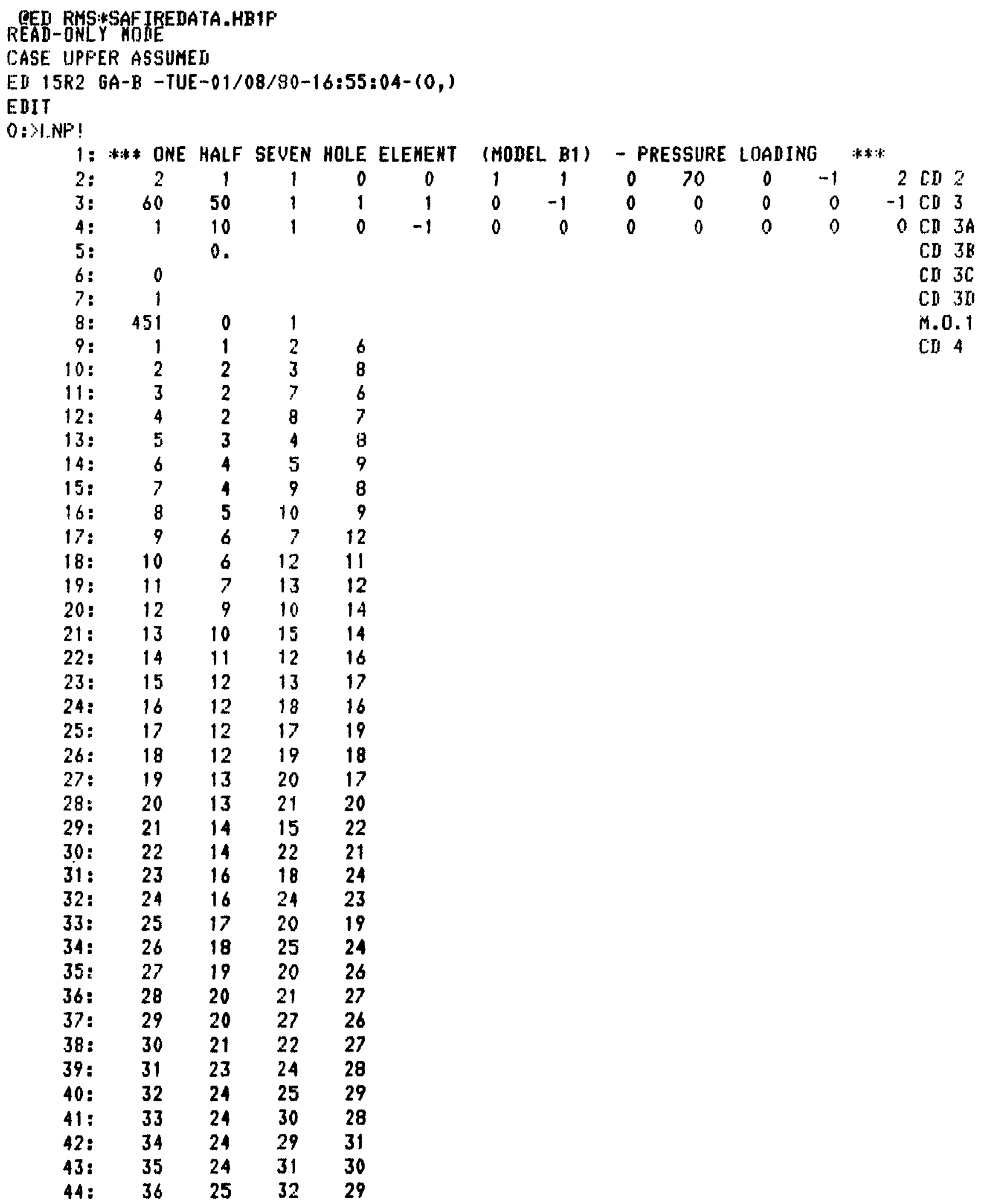


TABLE C.3 (Continued)

SAFIRE SAMPLE PROBLEM INPUT DATA ONE HALF ELEMENT ANALYSIS

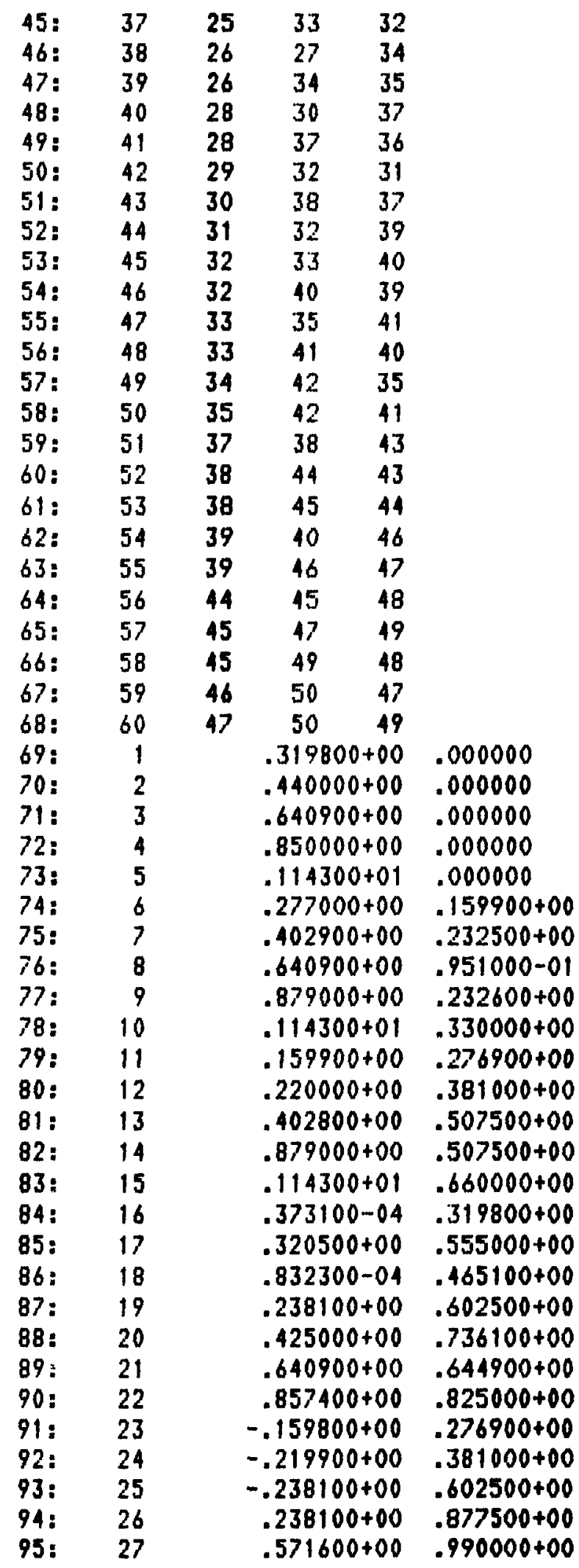


TABLE C.3 (Concluded)

SAFIRE SAMPLE PROBLEM INPUT DATA

ONE HALF ELEMENT ANALYSIS

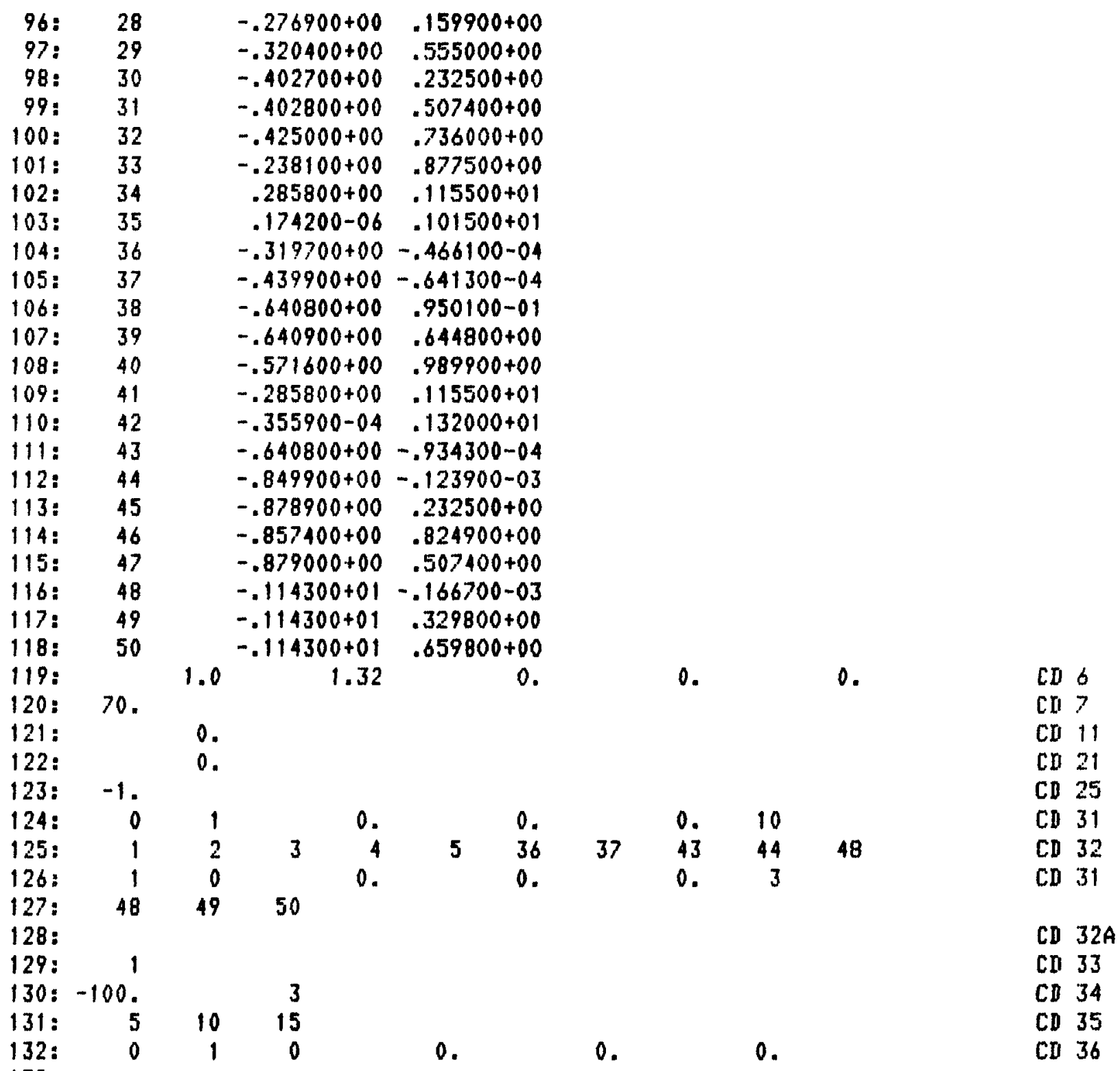


CARD 2 - OPTIONS

$\begin{array}{cccccccccc}\text { I VOELT ITTYPE } & \text { IFTYPE } & \text { NTEMP } & \text { NOOSE } & \text { NTEMUN NTIMUN } & \text { NSTEP } & \text { NCMAX } & \text { NORA NRSTAR ITAPE }\end{array}$

THIS IS a genERALIZEO PLANE STRAIN ANALYSIS

TEMOS IVPUT ON NODAL POINT BASIS

DOSES IVPUT ON NODAL POINT BASIS

TEMPERATURES UNIFORH ANO CONSTANT

FAST FLUX IS UNIFORM ANO CONSTANT

TEMPERATURES ARE INPUT AND OUTPUT IN CEG $F$

TIMES ARE INPUT AND OUTPUT IN DAYS

TIME SIEP IS CONSTANT FOP ALL STEPS

CORE SIZE FOP THIS RUN IS TO K WORDS

P INFINITY NORM (maXimum absolute VAlUe)

O NO TESTART TAPES TO EE MOUNTEO. ALL IMPUT ON CARCS

DISPLACEMENTS AS WELL AS SIRTSSES, STAIINS, ANO STRESS RATIOS WILL BE SAVED ON IAPE

CARJ 3 - PROBLEM INDICES

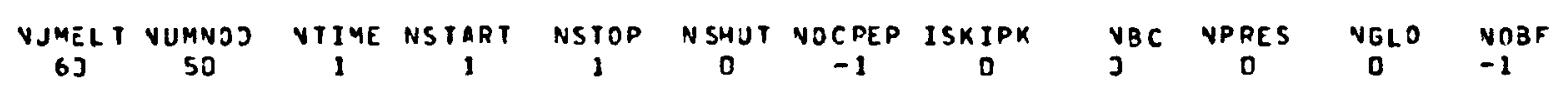

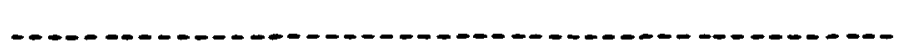

NJMELT $=60$ NUMBER OF FINITE ELEMENTS IN MESH

NUMYOD $=50$ NUMBEP OF NODFS IN MESH

NTIME $=1$ NUMBER OF TIME POINTS IN HISTORY

NSTART = I START TIME FOR CALCS IN THIS RUN

NSTOP $=1$ STOP IIMF FOR CALCS IN THIS FUN

NSHUT $=0$ NUMBEF OF INFUT SHUTOCHN TEMPFRATURES

VO SREEP CALCULATION. ONF SHOT ELASTIC AVALYSIS

START-OF-STEF ELASTIC STIFFNFSS IS UPDATED FOR EACH TIML STEP 
IV-OLAVE BOUVDARY COVJITIONS ARE COVSTAVT

EJGE NOZYAL DRESSURES ARF CONSTANT

OUT-OF-PLANE BOUNDARY CONDITIONS APE CONSTANT

NO $3 O D Y$ FORCE BEING CONSIDERED

CARD 3A - PRINTOUT OPIIONS
IFAIL, NPTSUM, NSORT
1
${ }_{-1}^{(N P R I N T I 1), 1=1,4)} 0$
o
IIPRINTII), I=1.41, NCRAK

FAILURE CRITERION BASES ON MAXIMUM TENSILE OR COMPRESSIVE STRESS

NPISUM $=12$ NUMBER OF SPATIAL POINTS PRINTED IN STRESS/SITAIN SUMMARY

SUMYARY PRINT SORTED RY MAXIMUM NORMAL STRESS/STRENGTH RATIO

TIME STEP PRINTOUT OPTIONS FOR FOUR BLOCKS GTVEN BELOH

\section{VORINTIIISO PRINT ALL IIME STEPS}

NPRINIIIII $=0$ NO PRINTOUT FOR THIS BLOCK

N NPRINTIIIDO PRINT NPRINT TIME STEPS
NPRINTII) $=$
OPTION FOR OPERA IING STRESS SUMMARY
VPRINT(2)=-1
OPIION FOR OPERATING STRESS DETAILS
NPRINTI3) $=0$
OPTION FOR SHUTDOWN STRFSS SUMMARY
NPRINT(4) $=0$
OPIION FOR SHUTOCHN STRESS DETAILS

PRIVTOUT CONTENT OPTIONS FOR FOUR BLOCKS GIVEN BELOW

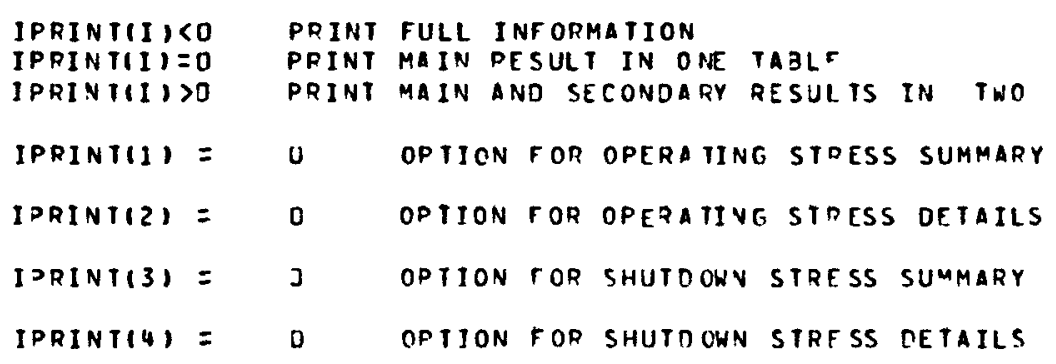

NO GRACKING ALLOWED

CARD 38 - RELAXATION PARAMETER 
PELAXO $=1.000000$

CARD 3C - SUBSTEP OPTIONS

NSUAS $=0$ NO SUADIVISION $1=1$ SUBSTEPI

CARO 30 - OPIIONS FOR STRESS RATIO IN SORIING PRINTOUT

IRAIIO $=1$ SIRESS RATIO IS CONSTANTFOR ALL TIME STEPS

FINITE ELEMENT MESH - ELTMENT DESCRIPIIONS

$\begin{array}{rrrrrrrrr}* E L I & 1 & J & * & * & \text { ELI } & 1 & J \\ * & 1 & 1 & 2 & 6 & * & 2 & 2 & 3 \\ * & 6 & 4 & 5 & 9 & * & 1 & 4 & 9 \\ * & 11 & 7 & 13 & 12 & * & 12 & 9 & 13 \\ * & 12 & 18 & 16 & * & 17 & 12 & 17 \\ * & 14 & 15 & 22 & * & 22 & 14 & 22 \\ * & 18 & 25 & 24 & * & 27 & 19 & 20 \\ * & 31 & 23 & 24 & 28 & * & 32 & 24 & 25 \\ * & 41 & 25 & 32 & 29 & * & 37 & 25 & 33 \\ * & 45 & 32 & 49 & 38 & * & 42 & 29 & 32 \\ * & 51 & 37 & 38 & 43 & * & 47 & 33 & 35 \\ * & 53 & 44 & 45 & 48 & * & 57 & 45 & 47\end{array}$

$\begin{array}{rrr}K & * E L T \\ 8 & * & 3 \\ 8 & 8 & \\ 14 & 13 & 1 \\ 19 & 18 & 1 \\ 21 & 23 & 1 \\ 26 & 28 & 2 \\ 29 & 33 & 2 \\ 32 & 38 & 2 \\ 31 & 43 & 3 \\ 41 & 48 & 33 \\ 43 & 53 & 3 \\ 49 & 58 & 4\end{array}$

\begin{tabular}{|c|c|c|}
\hline$J$ & $x$ & - ELT \\
\hline 7 & 6 & $*$ \\
\hline $\begin{array}{l}10^{\circ} \\
15\end{array}$ & $14^{-7}$ & $\begin{array}{r}-9 \\
-\quad 14\end{array}$ \\
\hline & & * \\
\hline $\begin{array}{l}21 \\
30\end{array}$ & $\begin{array}{l}27 \\
28\end{array}$ & * \\
\hline $\begin{array}{l}27 \\
38\end{array}$ & $\begin{array}{l}34 \\
37\end{array}$ & * \\
\hline 41 & 40 & 49 \\
\hline 45 & 44 & 54 \\
\hline 49 & 48 & 59 \\
\hline
\end{tabular}

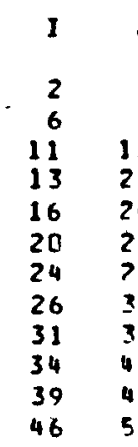

\begin{tabular}{|c|c|c|c|c|}
\hline K & * ELI & 1 & $J$ & $x$ \\
\hline 7 & $*$ & 3 & 4 & A \\
\hline 17 & 10 & 6 & 12 & 11 \\
\hline 16 & $\begin{array}{l}35 \\
20\end{array}$ & 12 & 13 & $\begin{array}{l}17 \\
20\end{array}$ \\
\hline 23 & 25 & $\begin{array}{l}13 \\
17\end{array}$ & 20 & 19 \\
\hline 26 & $\begin{array}{l}30 \\
35\end{array}$ & $\begin{array}{l}21 \\
24\end{array}$ & 22 & $\begin{array}{l}27 \\
30\end{array}$ \\
\hline 35 & 40 & 28 & 30 & 37 \\
\hline 39 & 45 & 32 & 33 & 40 \\
\hline 35 & 53 & 35 & 42 & 41 \\
\hline 46 & 55 & 39 & 46 & 47 \\
\hline 47 & 60 & 47 & 50 & 49 \\
\hline
\end{tabular}


FINITE ELEYEVI YESH - VORE COORDINATES

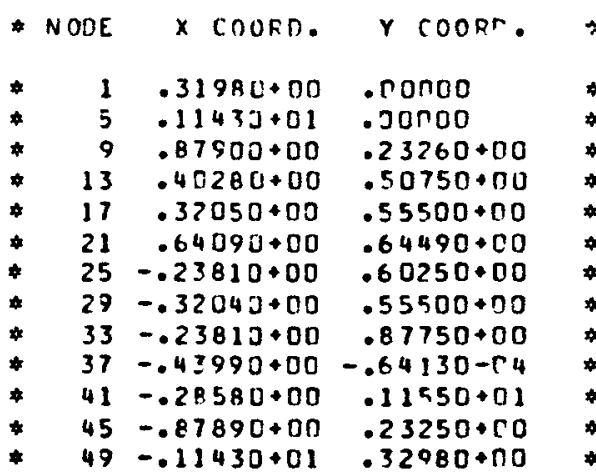

\begin{tabular}{|c|c|c|c|}
\hline & & $X$ rOORD. & $Y C O O R D$. \\
\hline & 2 & $.449 C 0+\Gamma 0$ & $.0 \cap 000$ \\
\hline & 6 & $.27700+00$ & $.15990+30$ \\
\hline$\forall$ & 10 & $.11430+01$ & $.33000+30$ \\
\hline+ & 14 & $.87000+00$ & $.50750+00$ \\
\hline * & 18 & $.83230-04$ & $.46510+30$ \\
\hline * & 22 & $\begin{array}{r}85740+00 \\
.739\end{array}$ & $.82500+00$ \\
\hline * & 30 & $-.43>70+100$ & $.23250+30$ \\
\hline * & 34 & $.28580+00$ & $.11550+01$ \\
\hline * & 38 & $-.64 n 80+n 0$ & $.95010-31$ \\
\hline$*$ & 42 & $-.35590-04$ & $.13200+01$ \\
\hline$\star$ & 46 & $-.95740 * 00$ & $.82490+00$ \\
\hline † & 50 & $-.11430+01$ & $.65980+30$ \\
\hline
\end{tabular}

* NO

$\begin{array}{rrl}\text { NONE } & \text { X COORO. } & \text { Y CONRO. } \\ 3 & .64090+00 & .00000 \\ 7 & .40290+33 & .2325 J+00 \\ 11 & .15990+30 & .27690+00 \\ 15 & .11430+01 & .66000+00 \\ 19 & .23810+30 & .60253+00 \\ 23-.15980+00 & .27690+00 \\ 27 & .57160+00 & .99000+00 \\ 31-.40280+30 & .50740+00 \\ 35 & .17420-06 & .10150+01 \\ 39-.64090+00 & .64480+00 \\ 43-.64080+00 & -.93430-04 \\ 47-.87900+00 & .50740+00\end{array}$

* not x cuOrd.

$Y$ COORO.

THICK

$.10000000+01$

THICKNESS OF ELEMCN

HEX FLAT IPADIUS OF LOG

$F \perp A I=$
$X C L O G=$

$.13200000+01$

$X$ COORD OF LOG CENTER

$X C L D G=$

00000000

$X$ COORO OF LOG CENTER
$Y$ COORD OF LOG CENTER

$23100=.30000000$

$Z / A$ OF CROSS SECTION $10=C T R, 1=E N D$ I 


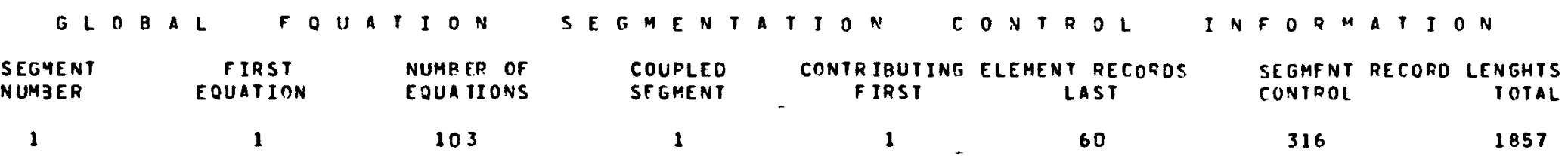

MAXIMUM HALF BANDWIOTH - 103 EOUATIONS

ROOI MEAN SOUAPE BANDWIOTH -......-.- 22 EOUATIONS

MAXIMJM SEGMENT COUPLING -

QASG,T LUSTIF,F2/1/POS/89

*** TEMPERATURE BLOCK INPUT ( OES FI ***

CONSTAVT ANJ UNIFORM IEMPERATURE IS TO.0J DEG $F$

*** FAST FLUX INPUT ***

W CONSTANT ANJ UNIFORY FAST FLUX IS .0ODOODOO N/CM\#\#Z-SEC

* * ivPut of TIHE DEPENDENT VARIables

1 EXCLUDING BOUNDAPY CONDITIONS,

I HE COYSIANT IIVE STEP IS .0UOODO DAYS

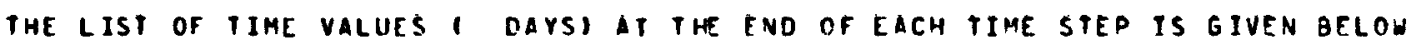

THESE ARE INTERNALLY CONVERTED TO SECONOS

11.000000

PRINT OF BLOCK 1 OHITTED ENTIRELY

PRINT OF BLOCK 2 IS IN BE DONE AT ALL TIMTS

PRINT OF BLOCK 3 OMITTED ENTIRELY

PRINT OF BLOCK 4 OMITTED ENTIRELY

VJMBER JF SJBSIEPS IV EATH TIME STEP

11

SIRESS RATIO IFOP EACH TIME SIEP, BEL OW WHICH STRESS PRINTOJT WILL BE SKIPDEO 


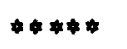
1 T I M F S T E P

* start time $=.00000$ dar

END TIME $=.000 J$

DAYS * *

* * * * input of operating roundar conditions for the first time step

IHIS INCLUDES : $(1)$ IN PLANE ROUNDARY CONDITICNS ICONCENTRATED FORCES AND/OR DISPLACEMENTS

(2) IN PLANE NORMAL PRESSURE FORCES (FOR PRESSURE LOADING CASE ONLY)

(3) THREE GLORAL OUT OF PLANE BOUNOARY CONOITIONS (FOR GPS ELEMENT ONLY)

- INPUT OF IN PLANE BOUNDARY CONDITIONS

\#HIS INOUT OF IN PLANE BOUNDARY CONDITIONS \#+
THIS ISONE BY GROUPS. FOR EACH GROUP. THE FOLLOUINGS ARE IVPUT:

1. IIECGPII), I=1,2) -- POUNDAPY CONDITION CODES IOEFORCE), (1=DISP.). $I=1,2$ REFER TO ROTATED $X, Y$ DIRECTIONS

2. BETA - SKEW BOIJNDARY ANGLE IN RADIANS BETHEEN $X$ AND ROTATED $X$ AXIS

3. IBCGP(1), I=1,2) -- SPECIFIEC CONCENTRATED FORCES IN LB. IWHEN IBCGF=0I OR NOCAL TISPLACEMENTS

IN INCHF S IWHEN IBCGP=1). I=1.2 REFER TO ROTATED X,Y DIRECIIONS

4. NODBC - NUMBER OF POUNDARY NODES

5. A LIST OF gOUNDARY NODE NUMRERS

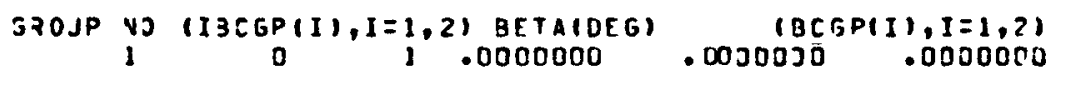

$2 \quad 1 \quad 0.0000000 \quad .0000000 \quad .0000000$

\begin{tabular}{cccc} 
NODBC & \multicolumn{3}{c}{ BOUNDARY NODE NUMBERS } \\
10 & 1 & 2 & 3 \\
3 & 48 & 49 & 50
\end{tabular}

$\stackrel{p}{\omega}$

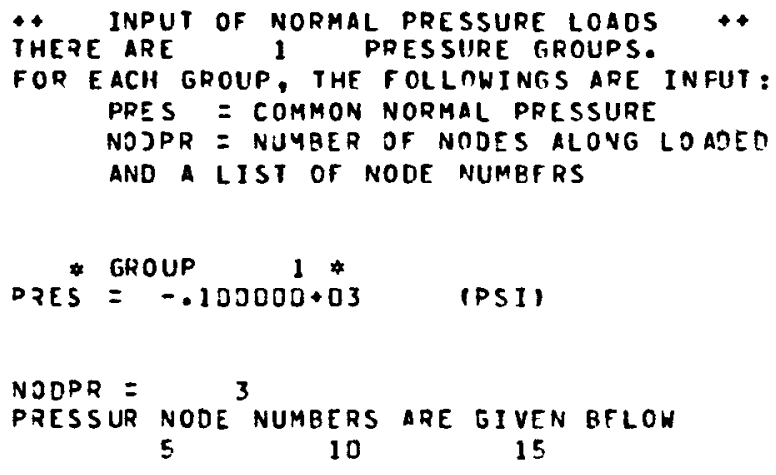




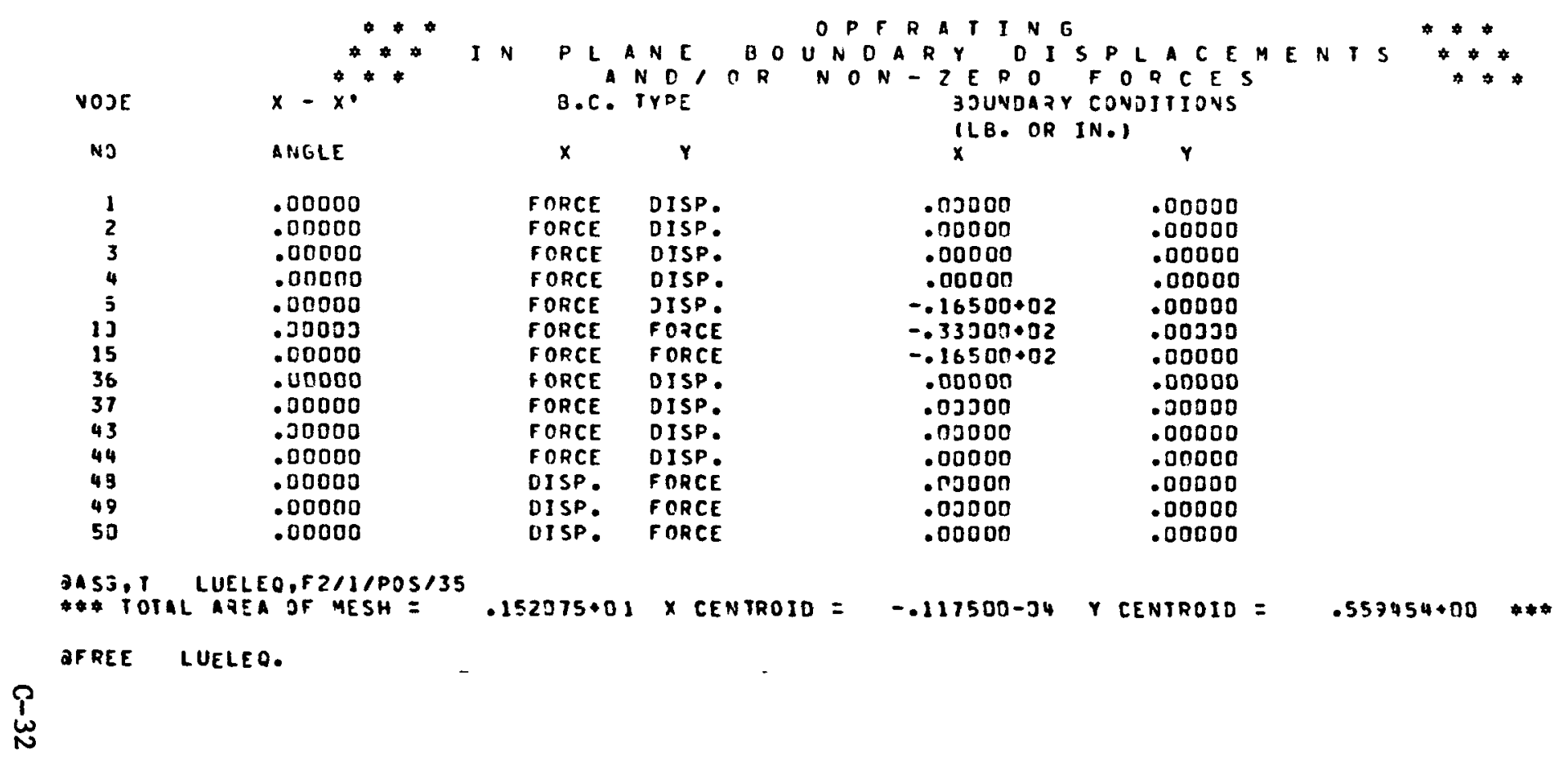




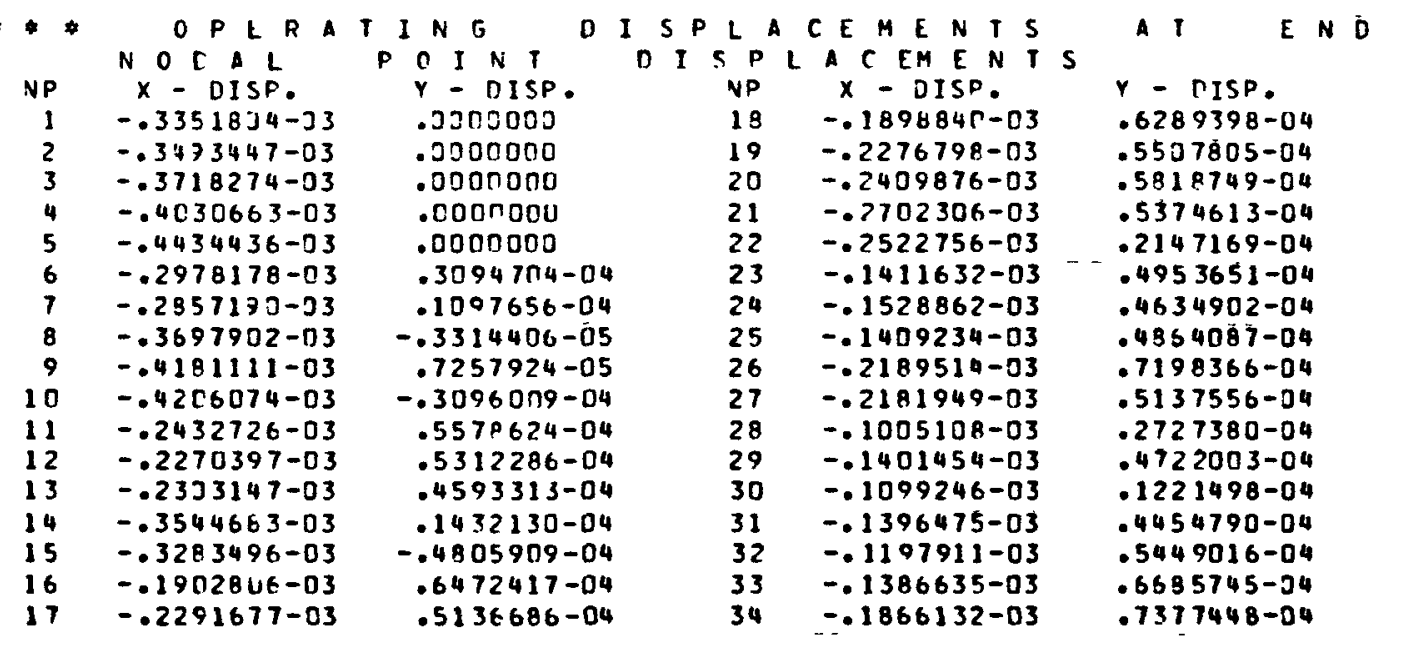

$\begin{array}{ll}\text { OF } & \text { II ME } \\ N P & X-015 D . \\ 35 & -.1790996-03 \\ 36 & -.7230800-04 \\ 37 & -.6119813-04 \\ 39 & -.4555502-04 \\ 39 & -.8813476-04 \\ 40 & -.1390507-03 \\ 41 & -.1727754-03 \\ 42 & -.1811482-03 \\ 43 & -.4532905-04 \\ 44 & -.2374968-04 \\ 45 & -.9330546-05 \\ 46 & -.9358949-04 \\ 47 & -.1409568-04 \\ 48 & .0000000 \\ 49 & -0000000 \\ 50 & .0000000\end{array}$

$S$ T E P 1

$Y$ - CISP. $.8869488-04$ . 000no00 $.00 G 0000$ $-.2959573-05$ $.4538804-04$ $.4638692-04$ $.6913355-04$ $.6913355-04$
$.8583737-04$ $.858 \leq 737-04$
.0000000 .0000000 $.1626801-05$ $.1620408-04$ $.2131806-05$ $-.4014100-07$ $-.6053912-05$ $-.2048353-04$

GLC B A

AXIAL SIRETCHING

MAX Y DEFLECTION IOUE TO X ROTATIONI

MAX X DEFLECTION IOUE TO Y ROTATTONI

MAX TOTAL LATERAL OEFLECTION

END ROTATION ABOUT $X$ AXIS IY-Z PLANE

$\begin{array}{lcc} & \text { SIMPLY SUPPORTES } & \text { CANTILEVER } \\ \text { IN. } & -.20833-05 & -.20833-05 \\ \text { IN. } & .00000 & .0000 \\ \text { IN. } & .90608-07 & -.36243-06 \\ \text { IN. } & .90608-07 & -.36243-06 \\ \text { RAD. } & .00000 & .00000 \\ \text { PAD. } & .36243-06 & .72485-06\end{array}$

* MEANING OF CRACK INTICATOR ICRK INDI IN THE ELEMENT STRESS STRAIN RESULTS PRESENTED ON NEXT PAGE CPA IND $=0$-- UNCRACKED FOR ALL TIMES

$$
\begin{aligned}
& 1 \text { - CRACKEn IN PREV JDUT STATE AND STILL CRACKED } \\
& \text { - CRACKEN IN THIS STATE } \\
& \text { - } \\
& \text {-2 - HEQLED IN THIS STATE }
\end{aligned}
$$

* We assume that the cracker state at evo of STEP is thF same as that calculated at stapt ot stfp. i fo. WE ASSUME THAT IN-STEP CRFEP MAKES NO CHANGES IN THF SIART-OF -STEP CRACKEO CONFIGUTATION 
DAYS

ELT ELT TLMP \#FAST FLUX \#ENODOSE \#YOUNGS MODULIIPSII*
REC NO I DEG FI INVTISECI IO\#\#21 NVT) R

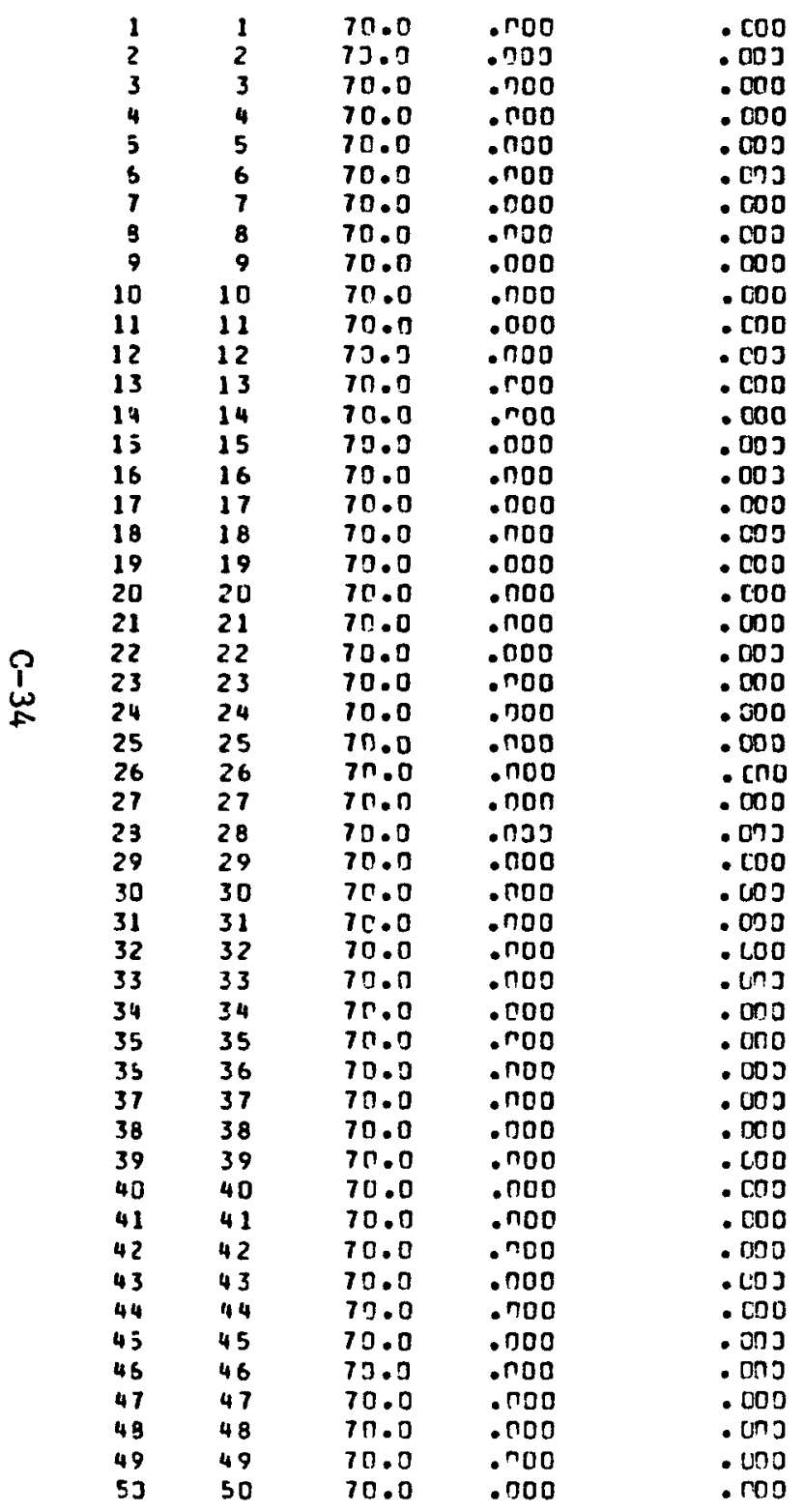

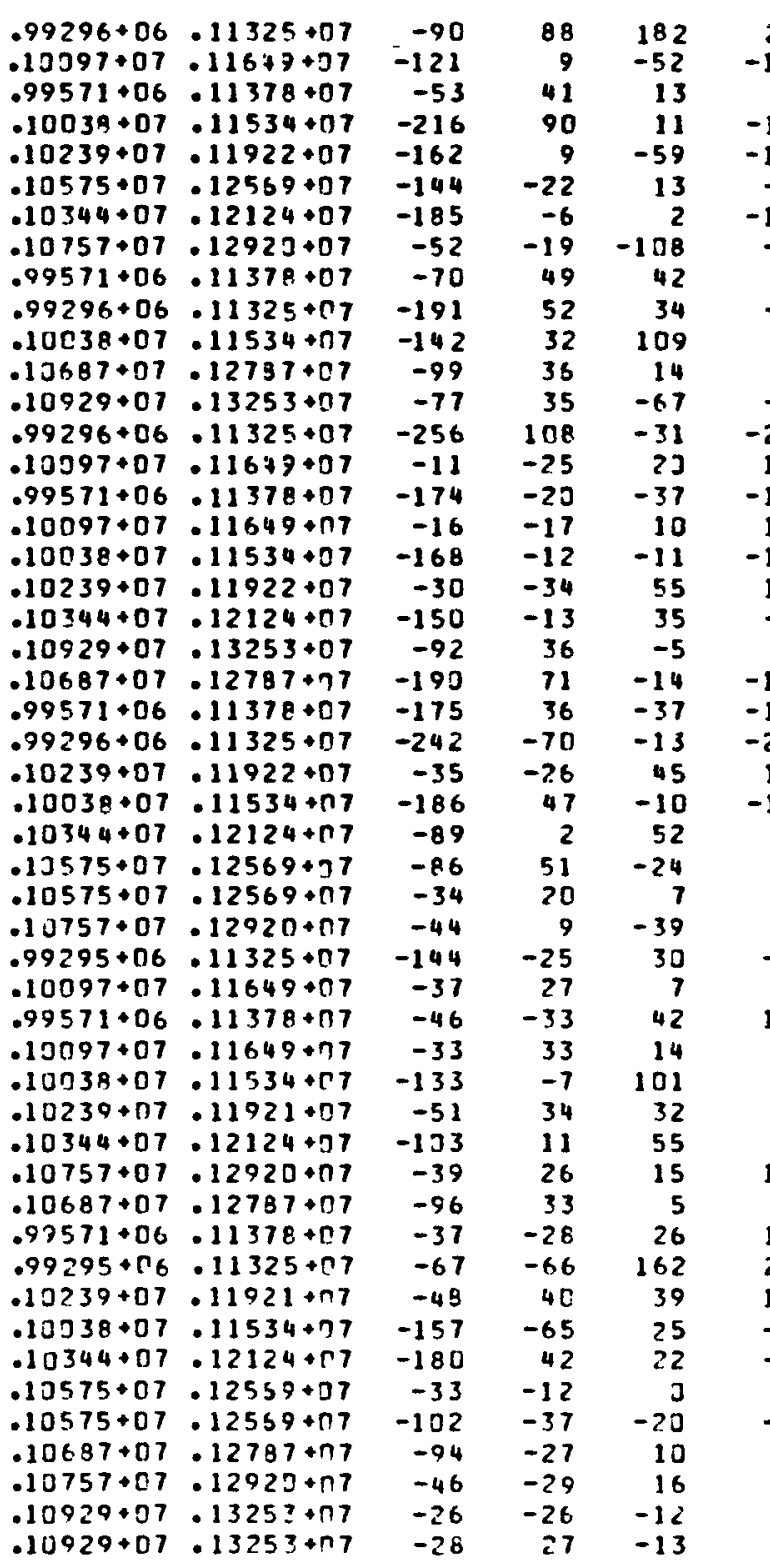

$.99296+06-11325+07--90$ $010039+07 \cdot 11534+07 \quad-216$ $0239+07 \cdot 11922+07-162$ $010929+07.13253+07-92$ $.10687+07 \cdot 12787+77-190$ $.99571+06 \cdot 11378+07-175$ -11325+07 -242 $38+07 \cdot 11534+77$ $.10929+07 \cdot 13253+n 7$
$X T R E S S$
$X$ COMPONENTS IN-PLANE PRINC STR \#STRESS RATIO\# CRA IND

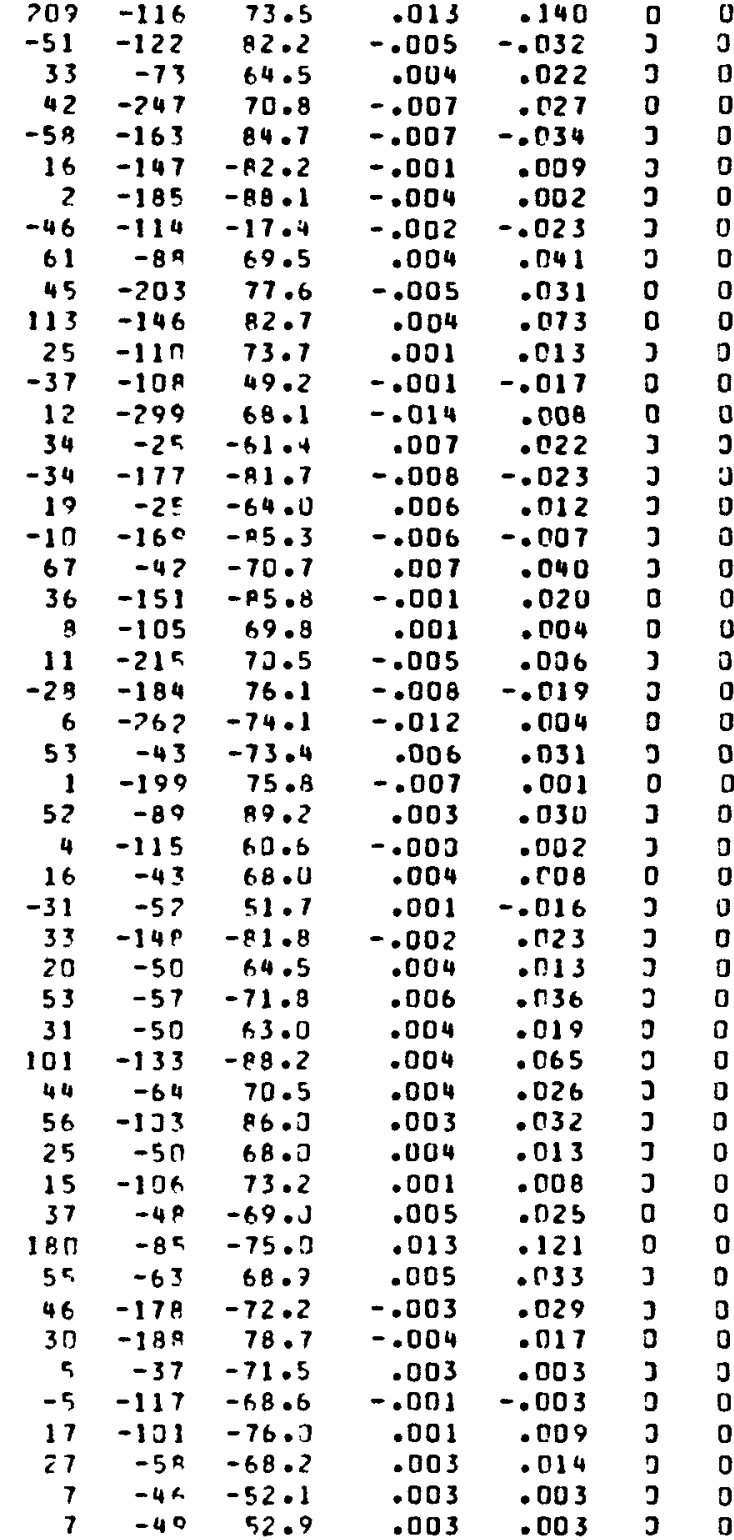




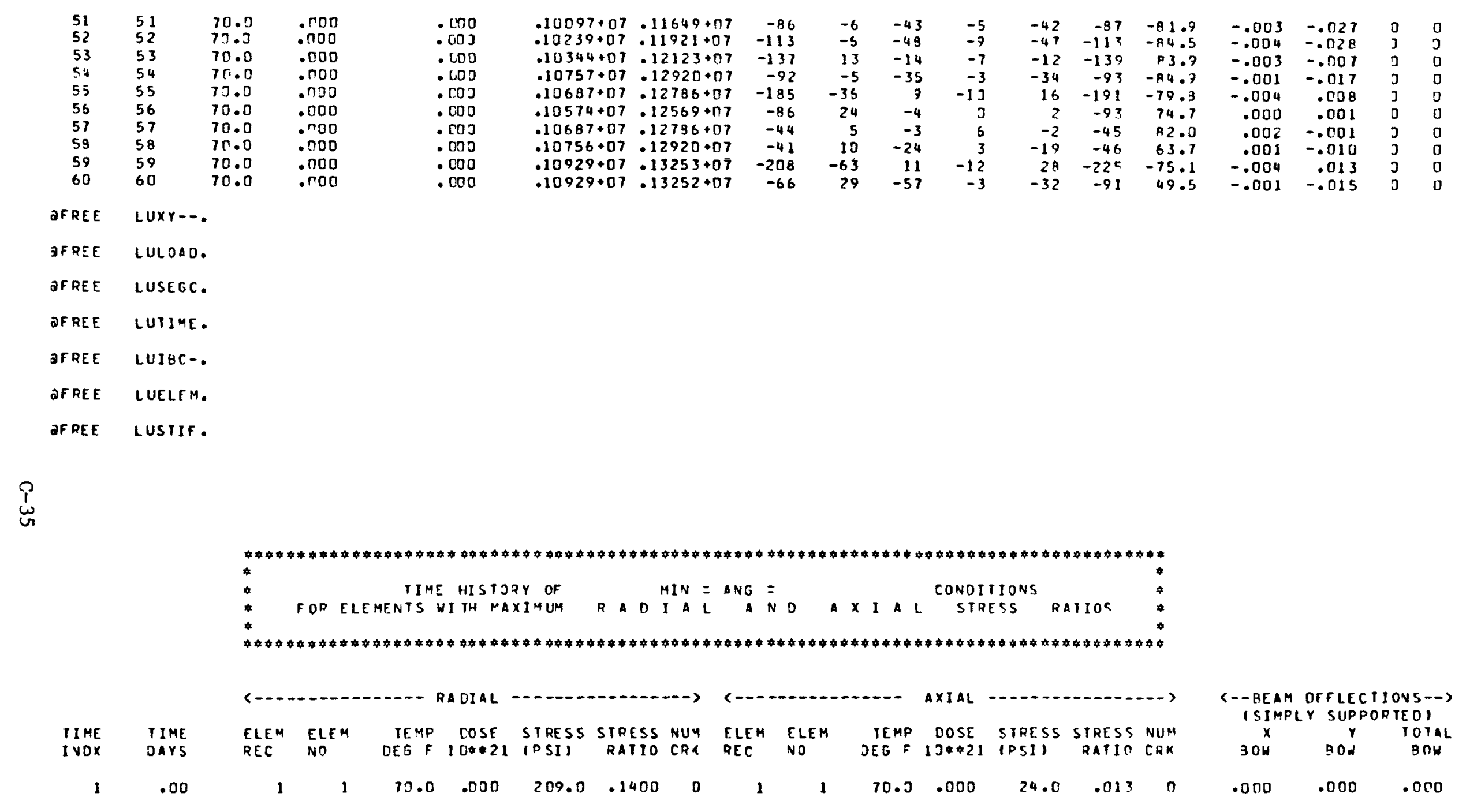

